\title{
Regional Differences in the Price-Elasticity of Demand for Energy
}

Subcontract Report NREL/SR-620-39512

February 2006

M.A Bernstein and J. Griffin RAND Corporation

Santa Monica, California

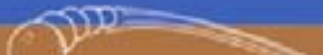




\section{Regional Differences in}

the Price-Elasticity of Demand for Energy

M.A Bernstein and J. Griffin

RAND Corporation

Santa Monica, California

NREL Technical Monitor: D. Arent

Prepared under Subcontract No. KACX-4-44454-01

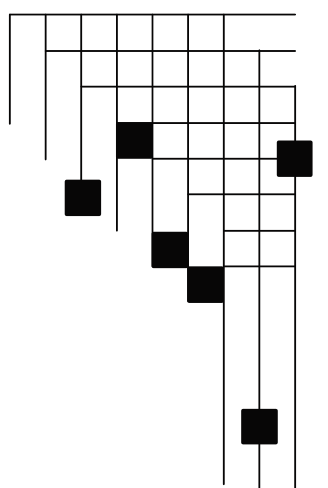


This publication was reproduced from the best available copy Submitted by the subcontractor and received no editorial review at NREL

\section{NOTICE}

This report was prepared as an account of work sponsored by an agency of the United States government. Neither the United States government nor any agency thereof, nor any of their employees, makes any warranty, express or implied, or assumes any legal liability or responsibility for the accuracy, completeness, or usefulness of any information, apparatus, product, or process disclosed, or represents that its use would not infringe privately owned rights. Reference herein to any specific commercial product, process, or service by trade name, trademark, manufacturer, or otherwise does not necessarily constitute or imply its endorsement, recommendation, or favoring by the United States government or any agency thereof. The views and opinions of authors expressed herein do not necessarily state or reflect those of the United States government or any agency thereof.

Available electronically at http://www.osti.gov/bridge

Available for a processing fee to U.S. Department of Energy and its contractors, in paper, from:

U.S. Department of Energy

Office of Scientific and Technical Information

P.O. Box 62

Oak Ridge, TN 37831-0062

phone: 865.576.8401

fax: 865.576 .5728

email: mailto:reports@adonis.osti.gov

Available for sale to the public, in paper, from:

U.S. Department of Commerce

National Technical Information Service

5285 Port Royal Road

Springfield, VA 22161

phone: 800.553 .6847

fax: 703.605.6900

email: orders@ntis.fedworld.gov

online ordering: http://www.ntis.gov/ordering.htm 


\section{Preface}

\section{About This Analysis}

Each year, the Department of Energy (DOE) requires its research programs to estimate the benefits from their research activities. These estimates are part of the programs' annual budget submissions to the DOE, and they are also required under the Government Performance and Review Act. Each program in the DOE's Office of Energy Efficiency and Renewable Energy (EERE) is responsible for providing its own assessment of the impact of its technology research and development (R\&D) programs. For the most part, the benefit estimates from each EERE program office are made at the national level, and the individual estimates are then integrated through the use of the National Energy Modeling System to generate an aggregate set of benefits from the EERE's various R\&D programs.

At the request of the National Renewable Energy Laboratory (NREL), the RAND Corporation examined the relationship between energy demand and energy prices with the focus on whether the relationships between demand and price differ if these are examined at different levels of data resolution. In this case we compare national, regional, state, and electric utility levels of data resolution. This study is intended as a first step in helping NREL understand the impact that spatial disaggregation of data can have on estimating the impacts of their programs.

This report should be useful to analysts in NREL and other national laboratories, as well as to policy nationals at the national level. It may help them understand the complex relationships between demand and price and how these might vary across different locations in the United States. 


\section{The RAND Environment, Energy, and Economic Development Program}

This research was conducted under the auspices of the Environment, Energy, and Economic Development Program (EEED) within RAND's Infrastructure, Safety and Environment Division. The mission of RAND's Infrastructure, Safety and Environment is to improve the development, operation, use, and protection of society's essential manmade and natural assets and to enhance the related social assets of safety and security of individuals in transit and in their workplaces and community. The EEED research portfolio addresses environmental quality and regulation, energy resources and systems, water resources and systems, climate, natural hazards and disasters, and economic development both domestically and internationally. EEED research is conducted for government, foundations, and the private sector.

Questions or comments about this report should be sent to the project leader, Mark Bernstein (mark bernstein@rand.org). Information about the Environment, Energy, and Economic Development Program is available online (www.rand.org/ise/environ).

Inquiries about EEED projects should be sent to the Program Director (ise_eeed@rand.org). 


\section{Table of Contents}

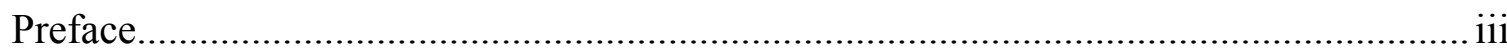

About This Analysis ................................................................................................ iii

The RAND Environment, Energy, and Economic Development Program .................. iv

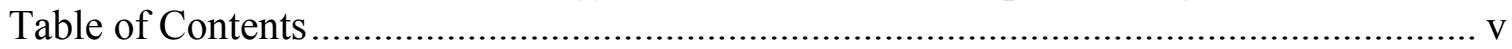

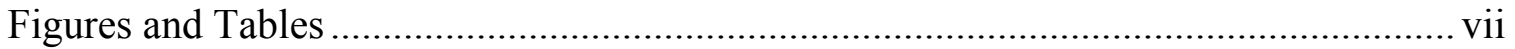

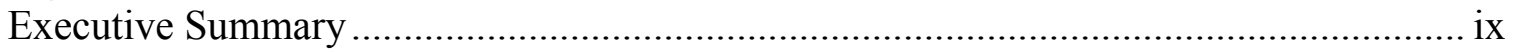

Are There Regional Differences in the Price-Demand Relationship? ..........................

Acknowledgements ......................................................................................... xiii

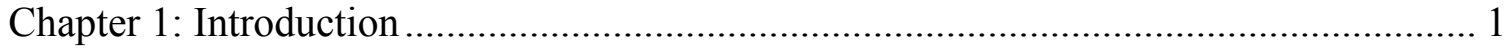

Relationship Between Energy Efficiency and Price Elasticity .................................. 6

Analytical Approach ........................................................................................ 7

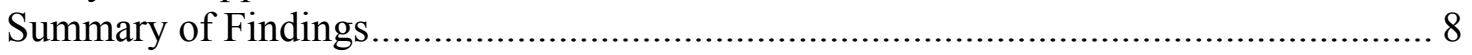

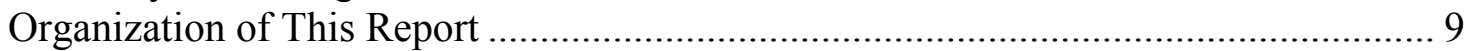

Chapter 2: Economic Theory, Literature, and Methodological Approach ...................... 10

Previous Literature on Energy Demand.................................................................... 10

Estimation Approach ........................................................................................... 12

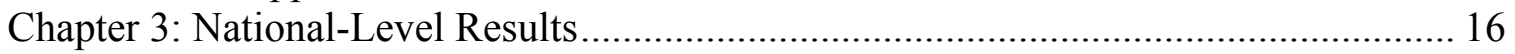

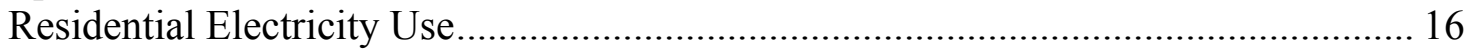

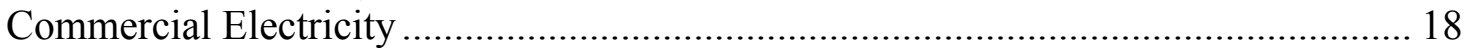

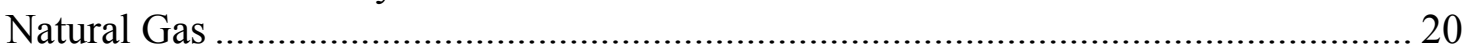

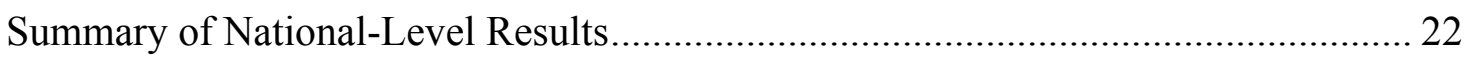

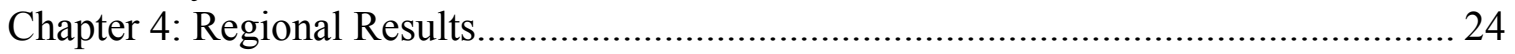

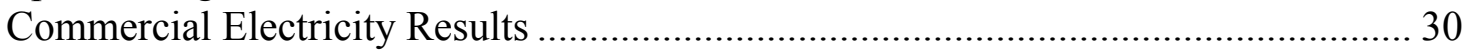

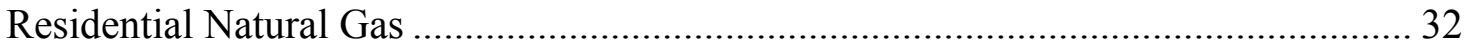

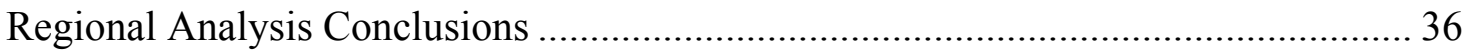

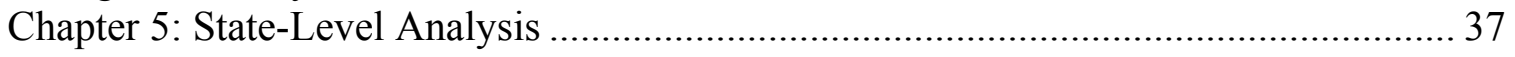

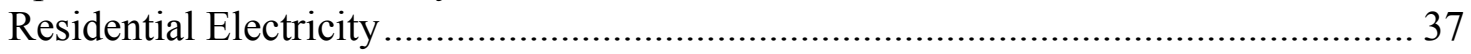

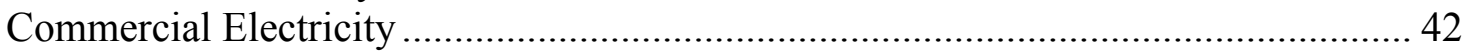

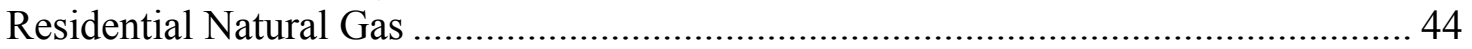

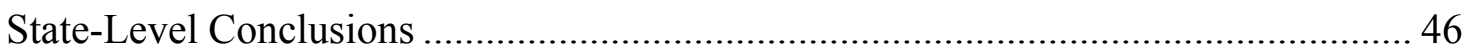

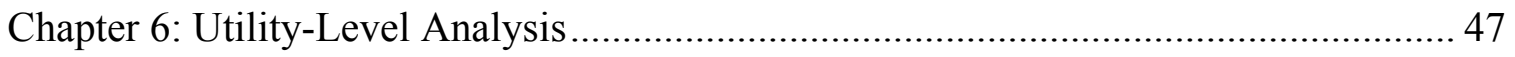

Chapter 7: Conclusions, Final Thoughts, and Implications of Analysis......................... 49

Should DOE Disaggregate Data for Estimating Energy-Efficiency Programs Benefits?

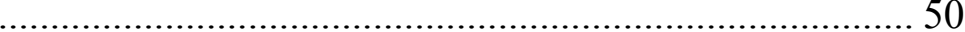

Price Elasticity of Demand ........................................................................... 51

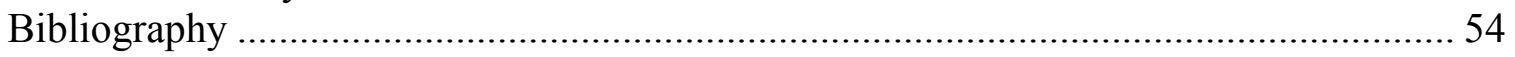

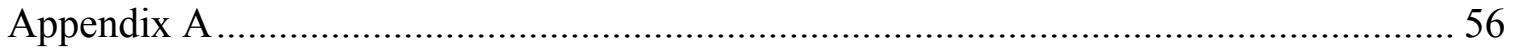

Details on the Methodology Used to Estimate Elasticities ....................................... 56

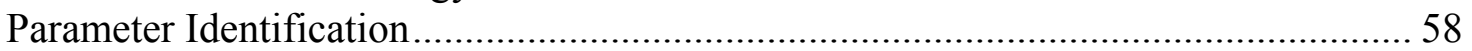

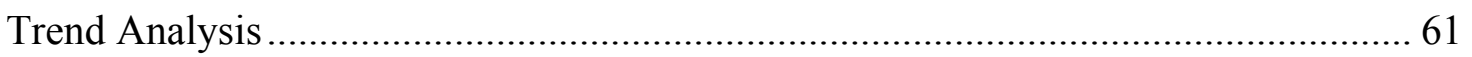

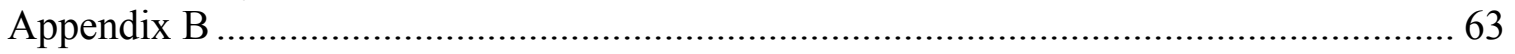

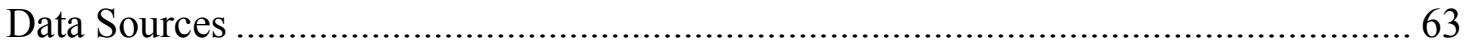

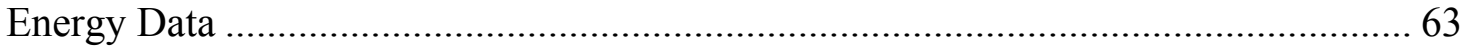

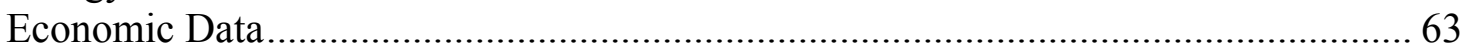




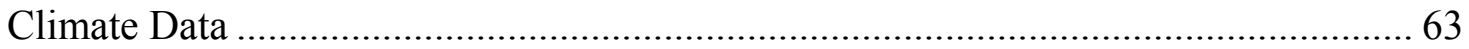

Appendix C: Variables and How They Were Constructed ................................................. 64

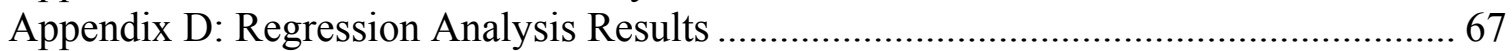

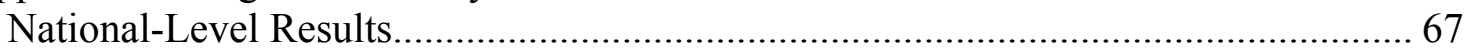

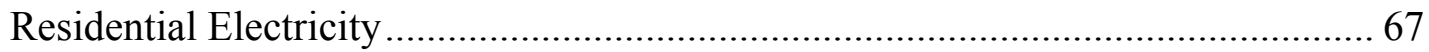

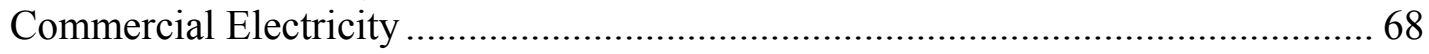

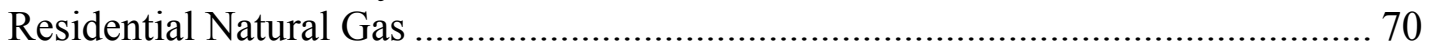

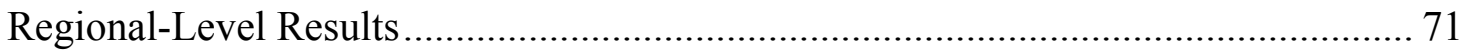

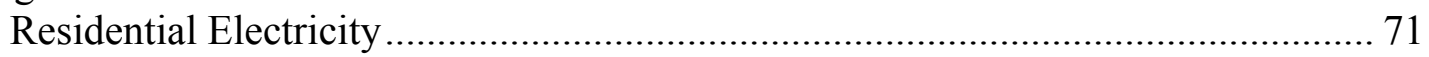

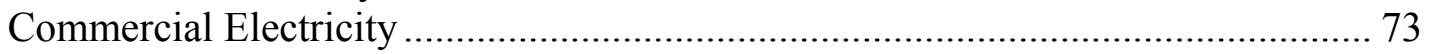

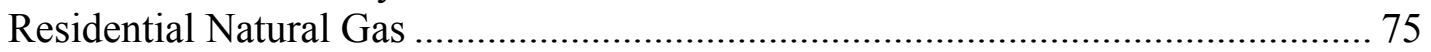

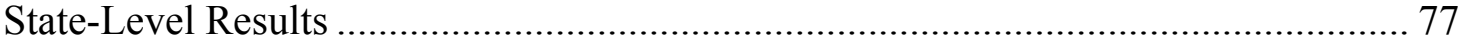

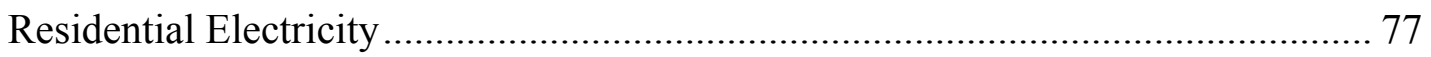

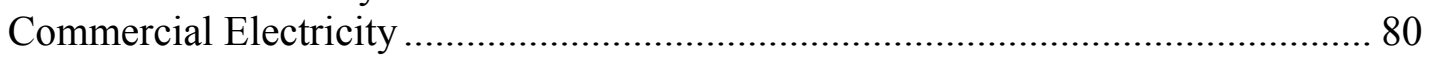

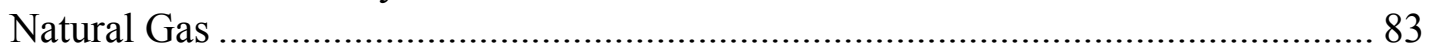

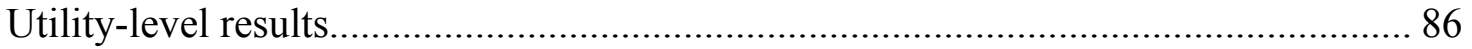

Results from Energy Use Trend Analysis............................................................. 90

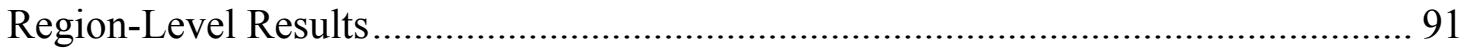

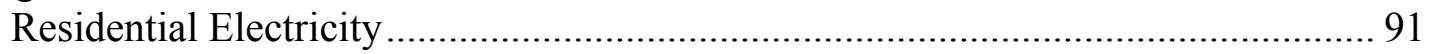

Commercial Electricity ……………………………................................... 92

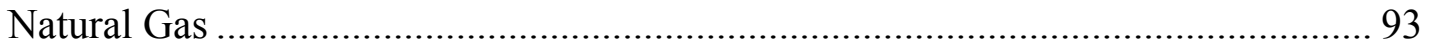

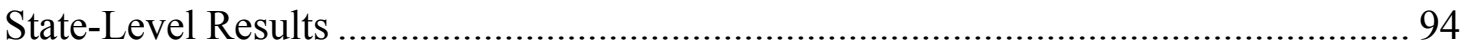

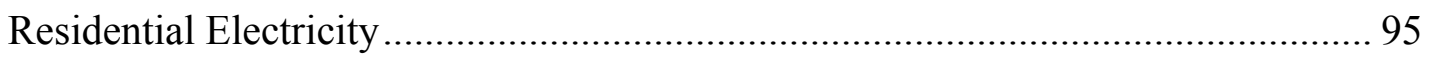

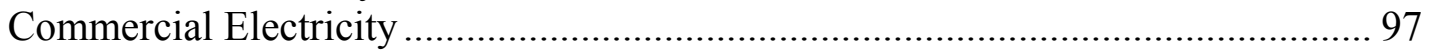

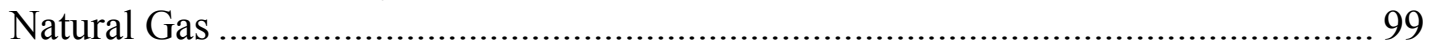


Figures and Tables

Figure 1.1: Relationship of supply and demand with two different demand curves.. 3 Figure 1.2: Impact of a shift in the supply curve ..................................................... 4

Figure 1.3: Impact of a shift in the demand curve.................................................5

Figure 3.1: Residential Electricity Prices, Demand, and Intensity, 1977-2003........ 16

Table 3.1: Results of Regression Analysis of Residential Electricity Demand, 19772004

Figure 3.2: Commercial Electricity Prices, Demand, and Intensity, 1977-1999....... 19

Table 3.2: Regression Analysis Results for Commercial Electricity Demand .......... 20

Figure 3.3: Residential Natural Gas Prices, Demand, and Intensity, 1977-2003 .... 21

Table 3.3: Regression Analysis Results for Residential Natural Gas Demand ......... 22

Table 3.4: Price Elasticities for Residential Electricity, Commercial Electricity, and

Residential Natural Gas at the National Level..................................................... 23

Figure 4.1: DOE Energy Information Agency Census Regions ................................ 24

Figure 4.2: Regional Trends in Per-Capita Residential Electricity-Intensity, 19772004

Figure 4.3: Regional Trends in Average Expenditures on Residential Electricity, 1977-2004

Figure 4.4: Regional Trends in Average Expenditures on Residential Electricity as a Share of Income, 1977-2004...................................................................... 28

Figure 4.5: Estimated Short-Run Residential-Electricity Price Elasticities by Region, 1977-2004.

Figure 4.6: Estimated Long-Run Residential-Electricity Price Elasticities by Region, 1977-2004. 29

Figure 4.7: Regional Trends in Commercial Electricity Use per Square Foot of Office Space, 1977-1999 31

Figure 4.8: Short-Run Commercial Electricity Price Elasticities by Region, 19771999.

Figure 4.9: Long-Run Commercial Electricity Price Elasticities by Region, 19771999

Figure 4.10: Natural-Gas Intensity Trends by Region, 1977-2004 ............................ 33

Figure 4.11: Natural-Gas Price Trends by Region, 1977-2004 ................................. 34

Figure 4.12: Short-Run Natural-Gas Price Elasticities by Region, 1977-2004........ 35

Figure 4.13: Long-Run Natural Gas Price Elasticities by Region, 1977-2004......... 35

Figure 5.1: State-Level Trends in Residential Electricity Intensity, 1977-2004 ....... 38

Figure 5.2: State-Level Trends in Residential Electricity Expenditures as a Share of

Income, 1977-2004 ........................................................................................................... 39

Figure 5.3: Estimates of Short-Run Residential Electricity Price Elasticities for Each

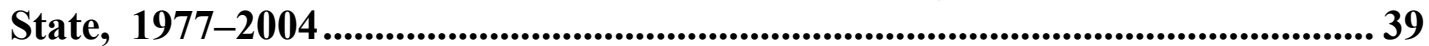

Figure 5.4: Estimated State-Level Short-Run Price Elasticities for Residential Electricity, 1977-2004..................................................................................... 41

Figure 5.5: Estimated State-Level Long-Run Price Elasticities for Residential Electricity, 1977-2004................................................................................................... 41

Figure 5.6: Estimated State-Level Trends in Electricity Intensity in the Commercial Sector, 1977-1999. 43 
Figure 5.7: Estimated Short Run Elasticities in Electricity Intensity in the

Commercial Sector at the State Level, 1977-1999.

Figure 5.8: Trends in Natural-Gas Intensity at the State Level, 1977-2004

Figure 5.9a: Estimated Short-Run Price Elasticities for Natural Gas at the State

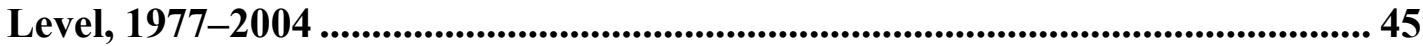

Figure 5.9b: Short-run Price Elasticities for Natural Gas ....................................... 46

Figure 6.1: Percentage of Utilities in the Sample within Each Region and Percentage

in Each Region with Significant Elasticities

Table C.1: Residential Electricity Regression Analysis Variables ............................. 64

Table C.2: Commercial Electricity Regression Analysis Variables ........................... 65

Table C.3: Residential Natural-Gas Regression Analysis Variables ........................ 66

Table D.1: Regression results from the residential electricity market ...................... 68

Table D.2: Regression results from the commercial electricity market ..................... 69

Table D.3: Results from natural gas market regression analysis............................. 70

Table D.4: Estimated short-run price elasticities for the residential electricity

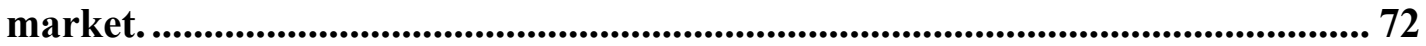

Table D.5: Estimated long-run price elasticities for the residential electricity

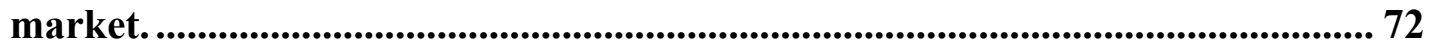

Table D.6: Short-run price elasticities for commercial electricity with and without

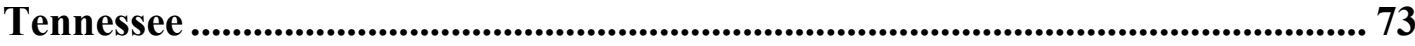

Table D.7: Long-run price elasticity estimates for commercial electricity................. 74

Table D.8: Short run price elasticity for natural gas.................................................... 75

Table D.9: Short run price elasticity for natural gas............................................... 76

Table D.10: State-level results for short-run price elasticity..................................... 77

Table D.11: Long Run Price Elasticity .................................................................. 79

Table D.12: Short-run elasticity estimates for commercial electricity........................ 80

Table D.13: Long Run Commercial Electricity Elasticity Estimates.......................... 81

Table D.14: Regression results for short run residential natural gas elasticity........ 83

Table D.15: Regression results for long-run price elasticities for residential natural

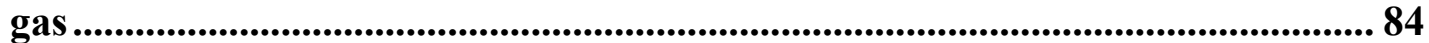

Table D.16: Short run elasticity estimates for residential electricity at the utility

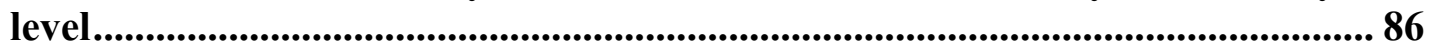

Table D.17: Regional trends in residential electricity energy intensity ..................... 91

Table D.18: Regional trends in residential electricity expenditures ........................... 91

Table D.19: Regional trends in residential electricity expenditures as a share of

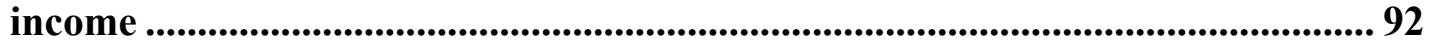

Table D.20: Regional trends in commercial energy intensity .................................... 92

Table D.21: Regional energy intensity trends for residential natural gas................. 93

Table D.22: Regional trends in natural gas energy expenditures .............................. 93

Table D.23: Annual trends for natural gas expenditures as a share of income ........ 94

Table D.24: Residential electricity energy intensity ................................................... 95

Table D.25: Trends in expenditures on residential electricity as a share of income 96

Table D.26: Estimates of the annual trend in commercial energy intensity.............. 97

Table D.27: Estimated trends for residential natural gas energy intensity............... 99 


\section{Executive Summary}

The Department of Energy (DoE) Office of Energy Efficiency and Renewable Energy (EERE) has a portfolio of energy efficiency research and development programs that is intended to spur development of energy-efficient technologies. The goal of these programs is to decrease costs and improve efficiency of emerging technologies and increase the potential for consumers and businesses to adopt them. EERE, under requirements of the Government Performance Results Act (GPRA), must estimate the benefits of their portfolio of energy efficiency programs. With these estimates of benefits, EERE can then assess the cost-effectiveness of its programs and use this information in allocating its budget.

Currently, EERE estimates the benefits of its programs by analyzing their effects using the DoE's National Energy Modeling System (NEMS), a complex model of the U.S. energy system. Because the projected benefits of their programs depend heavily on the NEMS model, EERE is interested to know if certain assumptions in the NEMS model might impact the projected benefits. Specifically, the NEMS model uses data and parameters aggregated to the regional and national levels. If, for instance, the data or parameters used in the analysis actually vary considerably within a region, then NEMS will project biased results and using more disaggregated data—possibly at the state or utility level - could improve accuracy of the results. In this study, we examine how trends in several measures of the energy market may vary at the state and regional levels and in particular how one important parameter used in the NEMS model, price elasticity of demand (a measure of how demand responds to price), varies at the national, regional, state, and utility levels. With this initial examination, we offer some recommendations on whether EERE can improve their benefit estimates by using more disaggregated data in analysis of their programs.

Economic theory says that as energy prices rise, the quantity of energy demanded will fall, holding all other factors constant. Price elasticities are typically in the negative range, which indicates that demand falls as prices increase or, conversely, that demand increases as prices fall. 
To determine if regional, state, or sub-state characteristics could affect the size of the impact from energy-efficiency technologies on energy prices, supply, and consumption, we looked at how individual factors - such as climate, supply constraints, energy costs, and demand for natural gas - might themselves affect the extent of the impact of energy efficiency.

\section{Are There Regional Differences in the Price-Demand Relationship?}

The object of this study is to determine whether the relationship between prices and demand differs at the regional, state, or sub-state level. In this study, we were interested solely in determining whether there are geographic differences in the price-demand relationship. We did not seek to understand how demand might impact prices and viceversa, although some of our findings provide some insights into these issues. Our focus was on finding out whether the state- and regional-level differences were significant enough to recommend to the DOE that it should explore disaggregating its data by state or region when estimating the potential benefits of energy efficiency.

We examined three energy-demand components-electricity use in the residential sector, natural gas use in the residential sector, and electricity use in the commercial sector - at three or four levels of disaggregation of the data, depending on the availability of data. For each sector, we looked at national, regional, and state-level results. We also examined residential electricity use at the electric-utility level.

Our analysis indicates that there are regional and state differences in the price-demand relationship for electricity and natural gas. We did find, though, that there tends to be some consistency in residential electricity use among states within a region and visible differences between regions in demand and price trends, particularly for residential electricity use and less so for commercial electricity use or residential natural gas use. What this implies, for estimating the impact of energy-efficiency technologies, is that the DOE may have reason to explore differentiating the impacts of energy efficiency by region, at least for residential electricity. There does not seem to be a need, at least in the 
short run, for further disaggregation by geographic area, although more research is needed to offer a more conclusive recommendation.

We also found that the relationship between demand and price is small. That is, demand is relatively inelastic to price. We also found that in the past 20 years, this relationship has not changed significantly; analyses performed in the $1980 \mathrm{~s}^{1}$ showed approximately the same results. These findings might imply that there are few options available to the consumer in response to changes in the price of energy, and that price does not respond much to changes in demand. On the other hand, because prices were declining in real terms over most of the period we studied, the inelasticity of demand may be more of an artifact of the lack of price increases.

However, we now may be witnessing some changes in this area. The past few years have seen some increases in energy prices, with some states facing increasing electricity prices and all states facing increasing natural gas prices. While it is difficult statistically to uncover specific changes in trends, there are signs that demand growth has slowed, possibly due to a combination of increasing or flat prices and the economic slowdown of the past few years. Although we cannot say specifically that the relationship between price and demand might shift in an increasing-price environment, more analysis of recent trends may be warranted.

\footnotetext{
${ }^{1}$ Bohi, Douglas R., and Mary Beth Zimmerman, "An Update on Econometric Studies of Energy Demand Behavior," Annual Review of Energy, Vol. 9, 1984, pp. 105-154; Dahl, Carol A., "Do Gasoline Demand Elasticities Vary?" Land Economics, Vol. 58, No. 3, August 1982, pp. 373-382; and Dahl, Carol A. and Thomas Sterner, “Analyzing Gasoline Demand Elasticities: A Survey,” Energy Economics, July 1991, pp. 203-210.
} 



\section{Acknowledgements}

We would like to thank Doug Arent of the National Renewable Energy Laboratory for his efforts to fund this study and help guide the development of the analysis. Special thanks to Brian Unruh from the Department of Energy and David Loughran of RAND for their insightful reviews of the analysis and helping us focus the paper. We also appreciate conversations we had with Dan Relles on understanding some of the data issues. We appreciate assistance provided to us by staff at the Energy Information Administration, and finally thanks to Nancy DelFavero for assistance in editing. 



\section{Chapter 1: Introduction}

The Department of Energy (DoE) Office of Energy Efficiency and Renewable Energy (EERE) has a portfolio of energy efficiency research and development programs that are intended to spur development of energy-efficient technologies. The goal of these programs is to decrease costs and improve efficiency of emerging technologies and increase the potential for consumers and business to adopt them. EERE, under requirements of the Government Performance Results Act (GPRA), must estimate the benefits of their portfolio of energy efficiency programs. With these estimates of benefits, EERE can then assess the cost-effectiveness of its programs and use this information in allocating its budget.

Currently, EERE estimates the benefits of its programs by analyzing their effects using the DoE's National Energy Modeling System (NEMS), a complex model of the U.S. energy system. To make the estimates, DoE runs the NEMS model with traditional assumptions about the energy system and uses the results to establish baseline estimates of energy use and prices. DoE then introduces into the model the changes to the energy system attributable to EERE's R\&D programs and estimates a new set of energy demands and prices. EERE uses the differences in the two projections as estimates of the impacts of its programs.

Because the projected benefits of their programs depend heavily on the NEMS model, EERE is interested to know if certain assumptions in the NEMS model might impact the projected benefits. Specifically, the NEMS model uses data and parameters aggregated to the regional and national levels. If, for instance, the data or parameters used in the analysis actually vary considerably within a region, then NEMS estimates of the impacts of energy efficiency might be misstated. Using more disaggregated data-possibly at the state or utility level - could then improve accuracy of the results. In this study, we examine how trends in several measures of the energy market may vary at the state and regional levels and in particular how one important parameter used in the NEMS model, price elasticity of demand (a measure of how demand responds to price), varies at the national, regional, state, and utility levels. With this initial examination, we offer some 
recommendations on whether EERE can improve their benefit estimates by using more disaggregated data in analysis of their programs.

Geographic Variability in Energy Markets Could Affect DOE Benefit Estimates Geographical variation in price-demand relationship and price elasticity has important implications for the benefit estimates of EERE's programs. The NEMS model represents energy demand and supply at the regional level and uses one price elasticity for all regions. If energy markets vary substantially at the sub-regional level or if price elasticities vary across the country, then estimates of the impacts of energy efficiency technologies will vary by region and this will not be reflected I the NEMS runs.

Economic theory says that as energy prices rise, the quantity of energy demanded will fall, holding all other factors constant. Economic theory also suggests that consumers' demand for energy is less sensitive to price changes than the demand for many other commodities. Economists define consumers' sensitivity to price changes as a measure of price elasticity. Price elasticity is calculated as follows:

$$
\text { Price Elasticity }=\frac{\% \Delta \text { QuantityDemanded }}{\% \Delta \operatorname{Pr} i c e}
$$

In this equation, the numerator and denominator are expressed as a percentage of change. Because price elasticity is a ratio of two percentages, it is not expressed as a specific unit of measure and can be compared across different commodities.

Price elasticities are typically in the negative range, which indicates that demand falls as prices increase or, conversely, that demand increases as prices fall. Demand elasticities are of two types, inelastic and elastic, and the range of each type differs. The range of inelastic demand is within absolute values of 0 to 1 , and the elastic range begins with values greater than 1 . These terms can be interpreted intuitively. A commodity with inelastic demand has a less than proportional change in demand for a given change in the price for the commodity. For instance, if prices increase by 10 percent on a good with a price elasticity of -0.20 , then demand for the good drops by only 2 percent. In the elastic 
range, consumer demand responds with a greater-than-proportional change for a given price change. For instance, a good with an elasticity of -1.5 would have a 15 percent drop in demand with a 10 percent increase in price. This relationship is pictured in Figure 1.1.

The figure shows a conventional supply curve $\left(\mathrm{S}_{1}\right)$ and two demand curves with different elasticities $\left(\mathrm{D}_{1}\right.$ and $\left.\mathrm{D}^{\prime}{ }_{1}\right)$. $\mathrm{D}_{1}$ is less elastic (i.e. steeper) than $\mathrm{D}^{\prime}{ }_{1}$. At equilibrium, both demand curves intersect the supply curve at the same point, with price at P1 and quantity at $\mathrm{Q}_{1}$.

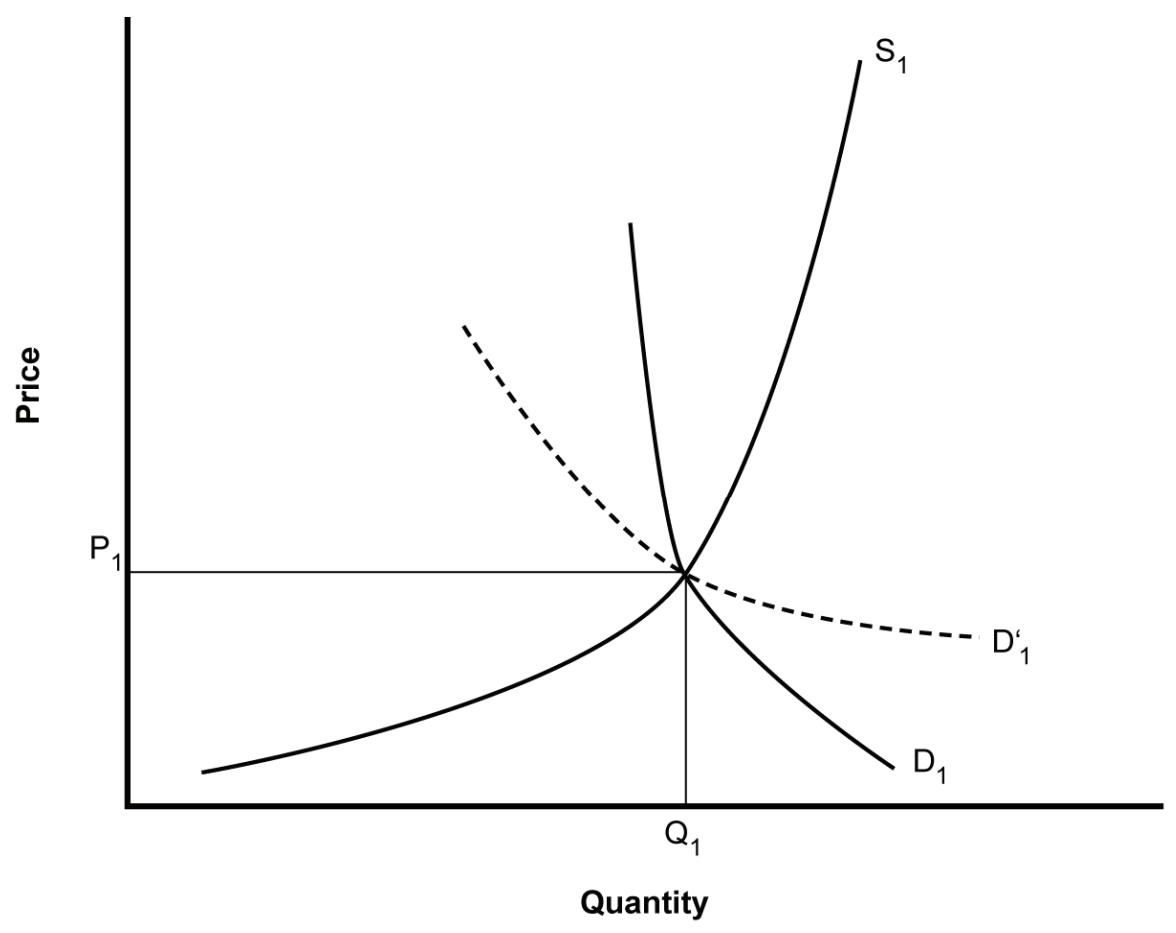

RAND TR292-1.1

Figure 1.1: Relationship of supply and demand with two different demand curves

If the supply curve shifts inward, which could represent an increase in the price of a fuel used to produce electricity such as natural gas, the new equilibrium point would depend on which demand curve is used as demonstrated in Figure 1.2. If the demand curve is relatively inelastic $\left(D_{1}\right)$ then prices would rise and there would be only a small reduction in demand $\left(\mathrm{P}_{2}, \mathrm{Q} 2\right)$. With the more elastic demand curve $\left(\mathrm{D}^{\prime}{ }_{1}\right)$, both the equilibrium 
price and the quantity are lower than the more inelastic curve $\left(\mathrm{P}_{2}{ }_{2}, \mathrm{Q}_{2}{ }_{2}\right)$. In the end, the difference in the equilibriums would depend on the magnitude in the variation between the elasticities.

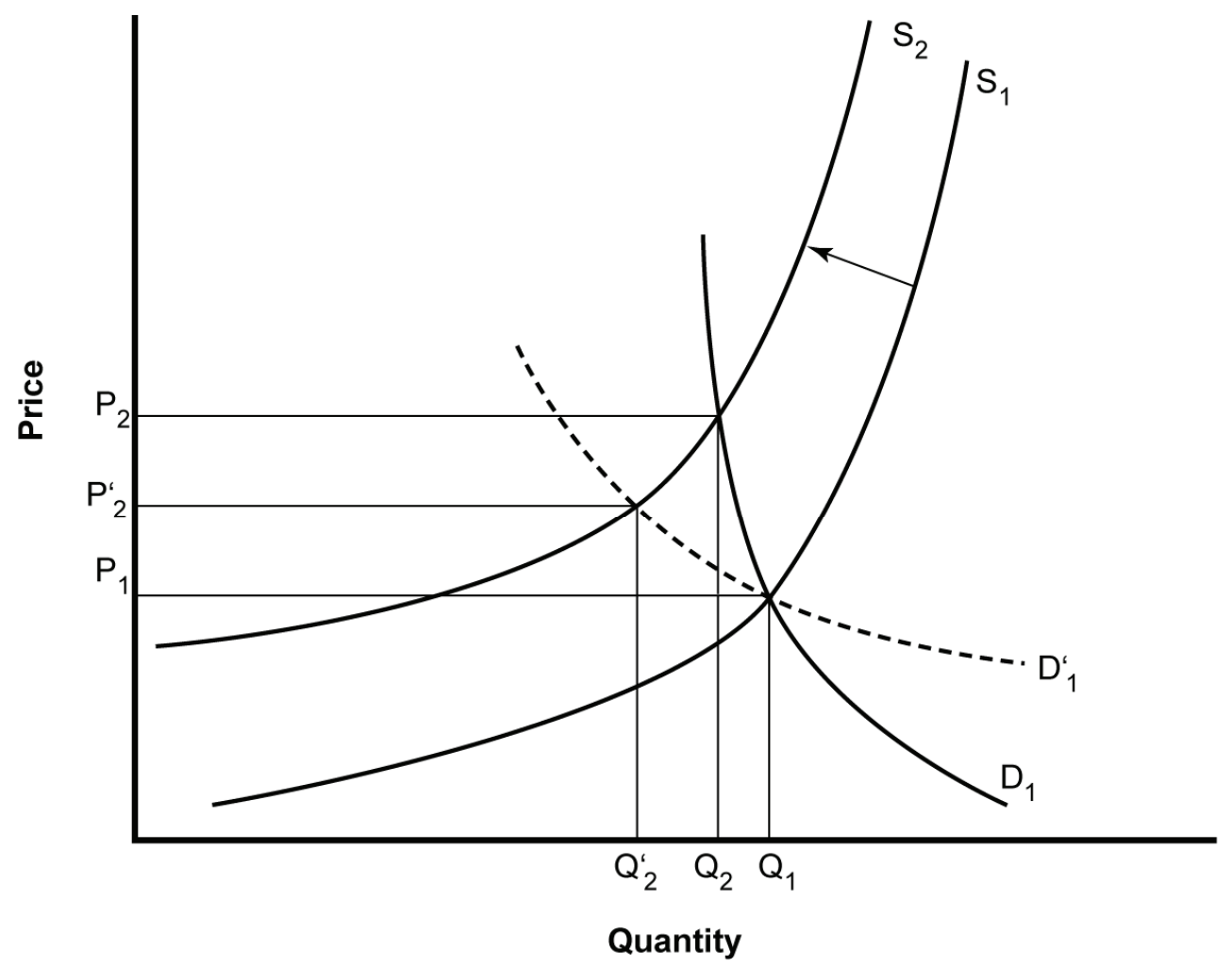

RAND TR292-1.2

Figure 1.2: Impact of a shift in the supply curve

The price elasticity will also impact results if changes in demand are expected. In figure 1.3 we show the impact on price and quantity of a shift in the demand curve. In this case let's say demand increases - so the curve shifts outward from $\mathrm{D}_{1}$ to $\mathrm{D}_{2}$. If the supply does not change, with a less elastic demand curve the prices and quantity would be higher $\left(\mathrm{P}_{2}, \mathrm{Q}_{2}\right)$ than if the demand curve was elastic $\left(\mathrm{P}_{2}{ }_{2}, \mathrm{Q}_{2}{ }_{2}\right)$. Since energy efficiency impacts demand first, this picture is very relevant for EERE analysis. The impacts on price and quantity of changes in demand will certainly be different with different elasticities. 


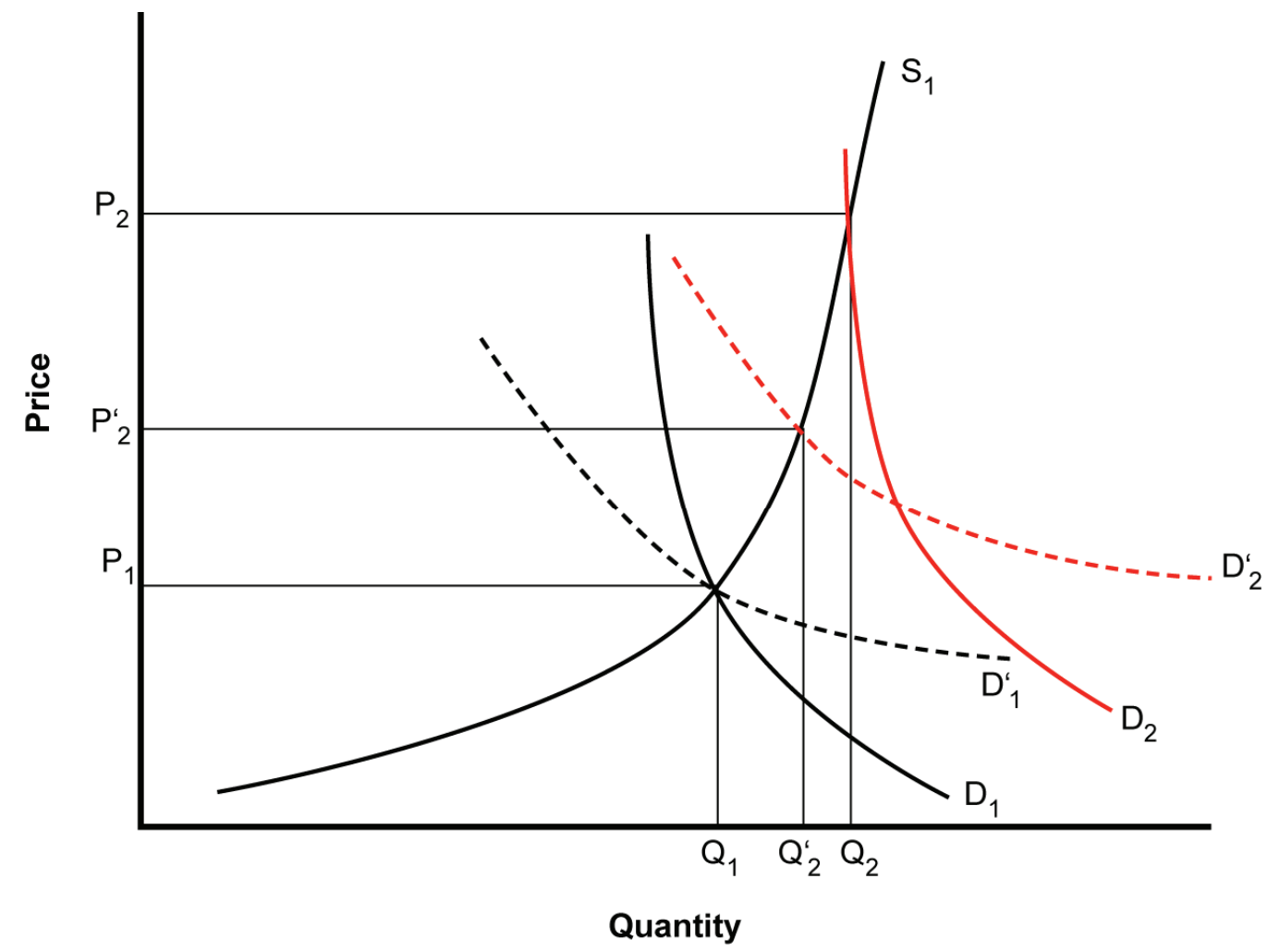

RAND TR292-1.3

Figure 1.3: Impact of a shift in the demand curve

Price elasticities can be used to interpret how consumer demand responds to price changes. They also indicate how readily consumers can purchase substitutes for a product that has gone up in price and how much consumers value a particular good. Price elasticities can be used in this way because of the underlying theory of consumer response to price changes. A consumer with a fixed budget in the short term has three possible responses to a price change: (1) The consumer can buy another good as a substitute; (2) the consumer can buy less of the good with no corresponding purchase of a substitute; or (3) the consumer can continue to purchase the same amount of the good and reduce expenditures on other goods in his or her consumer bundle.

In the case of electricity and natural gas (the focus of this study), these commodities have a limited degree of substitutability, especially in the short term. For end uses such as home heating and cooking, consumers can switch between energy-using systems that use electricity or natural gas. However, the consumer may want to purchase a new appliance 
that uses the less-expensive energy source. In other uses, such as a power supply for a computer, electricity has no substitutes. Nevertheless, the consumer still has the option to purchase a more efficient computer and enjoy the same level of service using less electricity. Typically, purchasing a more efficient appliance or one that uses a different type of fuel requires replacing a relatively expensive item, like a computer or refrigerator, and is considered a long-run adjustment by the consumer to high energy prices.

Based on this analysis, consumer demand for electricity and natural gas should be relatively unresponsive to price changes in the short term and more responsive to price changes in the long term but could differ substantially by region. Demand for these goods is generally inelastic in the short term, because a consumer's main options when energy prices change are to vary how he or she uses energy-consuming appliances (e.g., adjust a thermostat or turn on fewer lights) or reduce expenditures on other goods. Over the longer term, consumers can buy appliances that use a different energy source and/or purchase more-efficient appliances. Therefore, price elasticities tend more toward the elastic range than the inelastic range in the long term.

One of the important benefit measures for the EERE programs is the projected energy savings from the energy efficiency programs. The diagrams above show that estimating the impacts on demand depends on the price elasticities used in the analysis. Therefore, if elasticities differ between regions, the model needs to include geographical variation in price elasticities to make accurate estimates. The following sections will discuss possible reasons for geographic variation in price elasticities and the relationship between energy efficient technologies and price elasticity.

\section{Relationship Between Energy Efficiency and Price Elasticity}

Energy-efficient technologies provide a substitute for energy consumption when energy prices increase, which has important implications for the price elasticity of demand in energy markets. The price-elasticity of demand measures the percentage change in the amount demanded given a percentage change in the price of a good. Overall, this measure reflects the value of a good to consumers and the availability of substitutes. 
For the goods considered in this study, electricity and natural gas, the availability and cost of substitutes vary throughout the country. Constraints in infrastructure cause some of the differences in availability. For instance, the states of Maine and Florida have limited capacity for natural gas. Therefore, natural gas is a more costly substitute for electricity in these states relative to most others. In some cases, policy can drive differences in the cost of substitutes. Many states have programs to subsidize adoption of energy-efficient technologies, which also creates geographic differences in the cost of a substitute to electricity and natural gas. Both cases may cause price elasticities to vary across the country.

The preceding discussion provided reasons why the price elasticity of demand may vary and it suggests the direction that price elasticities could change. In areas where the costs of substitutes are competitive, price elasticities may increase in absolute magnitude (become more elastic) because consumers could more easily switch to substitutes as prices increase. Locations where particular energy uses are very valuable, such as air conditioning in southern states or winter heating in northern states, could have price elasticities smaller in absolute magnitude (more inelastic) because air conditioning and heating are so valuable during periods of extreme climate that consumers are unwilling to change their use when prices change. Again, both of these driving factors, the cost of substitutes and value of energy uses, vary geographically, which suggests price elasticity may differ across the country.

\section{Analytical Approach}

In this study, we analyzed energy demand for three markets - residential electricity, commercial electricity, and residential natural gas - and geographical variation in energy markets by region, state, and utility (for residential electricity). We assessed how trends in energy intensity, per capita energy expenditures, and expenditures as a share of income varied across the country. And, since the NEMS model currently uses one national value for price elasticity and the preceding discussion suggested some reasons why price elasticity might differ geographically, a primary focus of the study was to analyze if price elasticities vary at the regional, state, and utility levels. These analyses will help EERE 
evaluate whether they need to use more disaggregated analysis in estimating the benefits of their programs.

\section{Summary of Findings}

Our analysis indicates that there are significant regional and state differences in the pricedemand relationship for residential electricity and less so for commercial electricity and for residential natural gas. We did find, though, that there tends to be some consistency among states within a region and visible differences between regions in consumption and price trends. This tendency seems to be particularly strong for residential electricity use. It is possible that this relationship is more significant for residential electricity because some electricity uses in the home may be more discretionary than commercial or natural gas uses. Some electric using appliances can be used less, lights can be switched off and more efficient bulbs used. Most commercial business has limited availability to alter electricity sue in the short run, and residential natural gas use which is primarily for water heating, cooking and heating has less potential for modifications.

The results imply that the DOE may have reason to explore differentiating the impacts of energy efficiency by region, at least for residential electricity. There does not seem to be a need, at least in the short run, for further disaggregation by geographic area in the two other energy markets, although more research is needed to offer a more conclusive recommendation.

We also found that the relationship between consumption and price is small. That is, demand is relatively inelastic to price. We also found that in the past 20 years, this relationship has not changed significantly; analyses performed in the $1980 \mathrm{~s}^{2}$ showed approximately the same results. These findings might imply that there are few options available to the consumer in response to changes in the price of energy, and that price does not respond much to changes in demand. On the other hand, because prices were

\footnotetext{
${ }^{2}$ Bohi, Douglas R., and Mary Beth Zimmerman, "An Update on Econometric Studies of Energy Demand Behavior," Annual Review of Energy, Vol. 9, 1984, pp. 105-154; Dahl, Carol A., "Do Gasoline Demand Elasticities Vary?" Land Economics, Vol. 58, No. 3, August 1982, pp. 373-382; and Dahl, Carol A. and Thomas Sterner, “Analyzing Gasoline Demand Elasticities: A Survey,” Energy Economics, July 1991, pp. 203-210.
} 
declining in real terms over most of the period we studied, the inelasticity of demand may be more of an artifact of the lack of price increases.

However, we now may be witnessing some changes in this area. In the past few years, energy prices have increased with some states facing increasing electricity prices and all states facing increasing natural gas prices. While it is difficult statistically to uncover specific changes in trends, there are signs that demand growth has slowed, possibly due to a combination of increasing or flat prices and the economic slowdown of the past few years. Although we cannot say specifically that the relationship between price and demand might shift in an increasing-price environment, more analysis on recent trends may be warranted.

\section{Organization of This Report}

In Chapter Two, we provide a brief overview of 30 years of literature on the energy price-demand relationship and past attempts to estimate price elasticity. We then follow with an explanation of the methodology we used in this study. Chapters Three through Six present the study results in order by increasing levels of disaggregation of datanational-level analysis in Chapter Three, regional-level analysis in Chapter Four, statelevel analysis in Chapter Five, and utility-level analysis for the residential electricity sector in Chapter Six, Chapter Seven presents the conclusions derived from the results of the study, implications for the DOE and for federal energy-efficiency policy, and thoughts for next steps on research topics. The appendixes present methodological details and our data sources. 


\section{Chapter 2: Economic Theory, Literature, and Methodological Approach}

In this chapter, we present information that we used in producing our findings on energy price-demand relationships and the comparative impacts from energy efficiency at the national, regional, state, and utility levels. We first provide an overview of some of the literature on energy demand, and then describe the model we used to estimate energy demand.

\section{Previous Literature on Energy Demand}

Previous studies have found that energy demand is inelastic in the short run but more elastic in the long run. Several studies also found that price elasticities varied across locations, but the same general pattern remained (inelastic demand in the short run and more-elastic demand in the long run). The energy-demand literature consists of several dozen papers and is too voluminous to describe here in detail. Therefore, this section focuses on a representative handful of survey articles on this subject.

Taylor (1975) completed one of the first literature surveys on electricity demand. He reviewed the existing studies on residential, commercial, and industrial electricity demand. For residential electricity, he reported that short-run price elasticities varied from -0.90 to -0.13 . Long-run price elasticities ranged from -2.00 to near zero. The only study of commercial price elasticities that differentiated between long-run and shortrun elasticities observed a short-run price elasticity of -0.17 and a long run elasticity of -1.36 .

Bohi and Zimmerman (1984) conducted another comprehensive review of studies on energy demand. They surveyed the existing research on demand in the residential, commercial, and industrial sectors for electricity, natural gas, and fuel oil. They also reviewed studies on gasoline demand. Bohi and Zimmerman found that the consensus estimates for residential electricity price elasticities was -0.2 in the short run and -0.7 in the long run. They reported that the range of estimates in commercial electricity was too variable to make conclusions about consensus values. For residential natural gas 
consumption, they reported consensus values of -0.2 in the short run and -0.3 in the long run.

Bohi and Zimmerman also concluded that the energy price shocks of the 1970s did not change the structural characteristics of consumer demand. The studies they reviewed include studies from before and after the energy-price shocks in 1974 and 1979. They compared studies from the pre- and post-price-shock periods and also reported findings from studies that had divided study samples across the various periods to determine if any structural changes occurred in energy demand. One hypothesis they tested is that demand may become more elastic at higher price levels. Another hypothesis they tested is that rapid price changes sensitize consumers to energy demand, causing consumers to change their habits to conserve more energy.

Bohi and Zimmerman did not find much evidence to support their hypotheses. The estimated price elasticities from studies before and after the price shocks of the 1970s do not differ substantially. However, the authors could not use statistical tests of significance to evaluate the differences between price elasticities. In addition, several studies reviewed by Bohi and Zimmerman tested whether the price shocks changed the structural characteristics of the energy demand equation used to estimate elasticities. They found that energy demand decreased significantly after the price shocks. But, their analyses did not reveal any change to the structural characteristics of the energy demand equation.

Dahl and Sterner (1991) conducted a comprehensive review of the literature on gasoline demand (gasoline demand was not included in our study due to lack of available data). However, their review found consensus estimates on price elasticities. Dahl and Sterner concluded that the average short-run price elasticity was -0.24 , and the average long-run price elasticity was -0.80 .

Several previous studies also examined whether energy-price elasticity varied across locations. Houthakker et al. (1974) estimated price elasticities for residential electricity 
and gasoline and found that elasticities varied across states. They also found some correlation between price elasticity and degree of urbanization. Elasticities generally became more elastic as the degree of urbanism decreases, except for the most-rural states, which had a positive elasticity for both gasoline and residential electricity demand. Houthakker et al. did not offer an explanation for this pattern, especially the positive elasticity for the most-rural states.

Maddala et al. (1997) estimated price elasticities in 49 U.S. states (excluding Hawaii) and found variation across states. The mean of the estimates was -0.16 . The minimum was -0.28 , and the maximum was -0.06 . In the long run, the mean was -0.24 , with a minimum of -0.87 and a maximum of 0.24 .

Garcia-Cerrutti (2000) estimated price elasticities for residential electricity and natural gas demand at the county level in California. For residential electricity, the estimate of the mean was -0.17 , with a minimum of -0.79 and a maximum of 0.01 .

In summary, previous studies show that price elasticities are generally inelastic in the short run and more elastic in the long run. Further, elasticities vary at the state and county levels; however, the same general pattern of inelastic demand in the short run and more elastic demand in the long run still holds.

\section{Estimation Approach}

For this study, we used a dynamic demand model developed by Houthakker et al. (1974). This model estimates long-run and short-run energy demand by using lagged values of the dependent variable along with current and lagged values of energy prices, population, economic growth/per capita income, and climate variation. The model estimates shortrun demand using energy prices and quantity demanded in the current period, and it estimates long-run demand through changes in the stock of energy-consuming appliances reflected by the lagged dependent variable. The technical details of the model and the process for making adjustments to reflect long-term demand are described in Appendix A. 
We used state-level panel data on residential and commercial electricity consumption and residential natural gas consumption in the 48 contiguous U.S. states. The residential electricity and natural-gas data span 1977 through 2004. The commercial electricity data include only the years 1977 through 1999 because of limitations in economic data available from the Bureau of Economic Analysis. We also used a dataset on residential electricity consumption at the utility level from 1989 through 1999. The state energy data are from the DOE Energy Information Administration's (EIA) Electric Power Annual (see Appendix B for details). This publication contains data on electricity consumption and prices by energy-using sector. The natural gas data are from a "U.S. Gas Prices" table on the EIA's Natural Gas Navigator Web site. ${ }^{3}$ Finally, the utility data set comes from data reported to the DOE on form EIA-861. Submission of this form is a mandatory reporting requirement for utilities in the United States. The data on demographic and economic variables are from the Bureau of Economic Analysis in the Department of Commerce (again, see Appendix B for details).

The analysis uses a fixed-effects model, which controls for time effects, and a set of covariates. The location-specific price elasticity estimates come from interaction terms in the model between a location-indicator variable (region, state, or utility) and the variable of interest (price or lagged quantity). The estimates on the interaction terms indicate any differences between locations in the sample. The final elasticity estimates for each state are the sum of the estimate of the main effect and the interaction term for the location. The analysis uses hypothesis tests to determine if individual estimates are significantly different from zero and if a location is significantly different from the other locations.

We estimate this model using the following fixed-effect specification:

$$
Q_{i, t}^{D}=Q_{i, t-1}^{D} \gamma+X_{i, t} \beta+X_{i, t-1} \alpha+s_{i}+y_{t}+\varepsilon_{i, t}
$$

\footnotetext{
${ }^{3}$ Current data on the Web site can be found at table can be found at $\mathrm{http}$ //tonto.eia.doe.gov/dnav/ng/ng_pri_sum_dcu_nus_m.htm.
} 
where $\mathrm{Q}_{\mathrm{i}, \mathrm{t}}^{\mathrm{D}}$ is $\log$ energy demand in state $i$ and year $t, \mathrm{Q}_{\mathrm{i}, \mathrm{t}}^{\mathrm{D}}$ is the lag value of log energy demand, $\mathrm{X}_{\mathrm{i}, \mathrm{t}}$ is a set of measured covariates (e.g., energy prices, population, income, or climate) that affect energy demand, and $\mathrm{X}_{\mathrm{i}, \mathrm{t}-1}$ is the lag values of the covariates. The residual has three components:

- $s_{i}$ is an indicator variable that captures time-invariant differences in energy demand across states ("state fixed effects").

- $y_{t}$ is an indicator variable that captures time effects common to all states ("year fixed effects").

- $\varepsilon_{i, t}$ is a random error term.

We estimate any spatial differences in the energy demand relationship by adding interaction terms between the region or state indicator variables and the regressors of interest (price, quantity, and income). These interaction terms allow the estimated parameters to vary for each region or state, and we can then determine whether price elasticities differ across geographical units.

The fixed-effects model controls for state-specific time-invariant factors that could bias the parameter estimates. The year effects in the model control for any time effects common to all states in a particular year, which could bias the parameter estimates. These effects control for many potential sources of bias. However, the fixed and year effects do not control for state-specific factors that vary through time. If any of these factors are correlated with explanatory variables and also affect energy demand, then the regression will have biased estimates.

The fixed-effects model controls for effects specific to each state or utility that do not vary through time. An example of such a fixed effect is abundant energy supplies in certain states, such as hydroelectric power in the Pacific Northwest states or coal in West Virginia. This is a fixed effect because the states have those resources due to geographical factors that cannot change in the sample period. These states also tend to have much lower energy prices than other states. The fixed-effects model controls for 
this particular state-specific effect that does not vary through time and all other fixed effects that may or may not be measurable. Without controlling for these effects, the effects would bias the results. Appendix A explains the fixed-effects model in more detail.

The model also controls for time trends that affect all the states uniformly. An example of a time trend would be the enactment of a new energy-related law or a change in the majority political party in Congress. These factors have a constant, national effect, for which the model can control using indicator variables for each year.

The next four chapters present an overview of the results of our analysis of how energy prices and demand interact for residential electricity and natural gas and for commercial electricity. Details of all the results are presented in Appendix D. Because the purpose of this study is to see whether the price-demand relationship differs at the regional or state level, we present the results in descending order of dissaggregation - national, then regional, then state, and finally utility-level results. Within the chapters, we first discuss residential electricity, then commercial electricity, and then residential natural gas. 


\section{Chapter 3: National-Level Results}

\section{Residential Electricity Use}

Real electricity prices peaked in the early 1980s in the United States and steadily declined until 2000-2001 (see Figure 3.1). In 2001, average electricity prices increased in many states, and the figure shows a slight price rise over the past two years in the period studied. The figure also shows that residential electricity demand rose steadily during this period, although it appears that demand growth may have slowed after 2002. The long-term trend is an average annual increase in demand of approximately 2.6 percent.

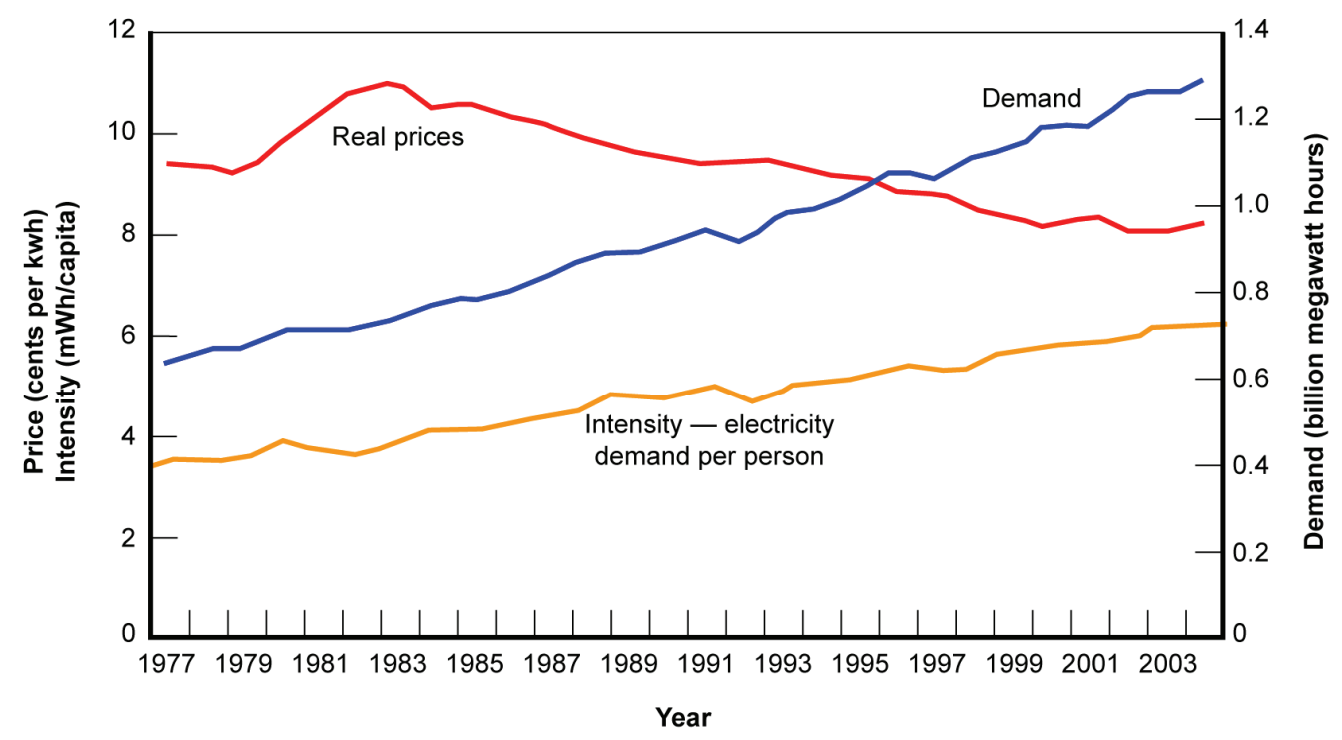

RAND TR292-3.1

Figure 3.1: Residential Electricity Prices, Demand, and Intensity, 1977-2003

There also was a steady increase in intensity (i.e., per-capita residential electricity use) until 2002. The long-term trend in the time series is an average annual increase of 1.5 percent. Per-capita residential electricity seems to have leveled out over the past few years of the period, perhaps due to the flattening of prices and the post-9/11 recession.

To generate values of the price-demand relationship that we could compare across regions and states, we use the functional form described in Chapter Two for estimating the price elasticity for residential electricity. Table 3.1 displays the results of our 
regression analysis for the residential electricity sector. It presents the coefficients from the regression analysis and notes whether the variable is significant. The dependent variable is residential electricity demand. The data points represent each state for each year in the sample. The independent variables are electricity demand in the previous year; average real electricity price in the current and previous years; residential disposable income in the current and previous years; population in the current and previous year; natural gas price in the current and previous years; and climate measured as heating and cooling degree days (see Appendix A for a definition of degree days). Definitions of the variables are presented in more detail in Appendix C. Details of the regressions are in Appendix D.

These estimates reflect national-level values.

Table 3.1: Results of Regression Analysis of Residential Electricity Demand, 1977-2004

\begin{tabular}{|l|c|c|}
\hline Variable & Coefficient & $\begin{array}{c}\text { Statistically } \\
\text { Significant }\end{array}$ \\
\hline Electricity demand in previous year & .232 & Yes \\
\hline Electricity price in current year & -.243 & Yes \\
\hline Electricity price in previous year & -.129 & Yes \\
\hline Income in current year & .003 & No \\
\hline Income in previous year & .384 & Yes \\
\hline Population in current year & -.225 & No \\
\hline Population in previous year & .827 & Yes \\
\hline Natural gas price in current year & -.005 & No \\
\hline Natural gas price in previous year & .111 & Yes \\
\hline Climate - heating and cooling degree-days & .246 & Yes \\
\hline
\end{tabular}

The table shows that the estimated short-run price elasticity is -0.2 , which is statistically significant. The estimated long-run price elasticity is -0.32 , and this value is also statistically significant. These estimates are consistent with results from the studies of residential electricity elasticity, cited in Chapter Two, which were conducted with data from earlier years. The survey literature concluded that the residential short-run elasticity was near 0.2 . 
The results also generally show that, except for price, the current-year variables are not significant, but the lagged or previous-year variables are statistically significant, suggesting that demand for electricity responds after changes occur in factors that influence the demand. For example, a consumer's level of income does not seem to impact demand in the same year, but income from one year seems to impact demand in the following year. This essentially means that change in income over time impacts electricity use, and growing incomes lead to increasing electricity use. Population growth has a similar effect. Natural gas prices have an expected result-increasing natural gas prices one year lead to increasing electricity demand in the following year. This pattern would reflect cases in which people switch from natural gas to electricity for some energy-consuming applications, such as heating or cooking. Finally, the more heating and cooling degree days there are, the higher the demand for electricity.

None of these results are unexpected, although what might be somewhat surprising is that the basic magnitude of these results has not changed in the past 20 to 30 years. Previous analyses done in the late 1980s and early 1990s showed just about the same results.

\section{Commercial Electricity}

We next examine the price-demand relationship for use of electricity by the commercial sector. Some commercial-sector electricity data exhibit trends similar those seen in the residential-sector data (see Figure 3.2). Real prices of electricity peaked in the early 1980s and steadily decreased through the period studied. Demand consistently increased throughout the study period. The average annual growth in demand during the period was 3.4 percent. Because the data we have for the commercial sector go only to the year 2000, we do not display recent price increases and do not know how they might have impacted demand.

In Figure 3.2, we show two pictures of commercial electricity intensity. One is electricity demand in $\mathrm{mWh}$ per dollar of commercial gross state product (GSP) - i.e., the size of the commercial electricity sector in economic terms. By this measure, electricity use has declined as a ratio of electricity demand to economic output from the commercial sector. 


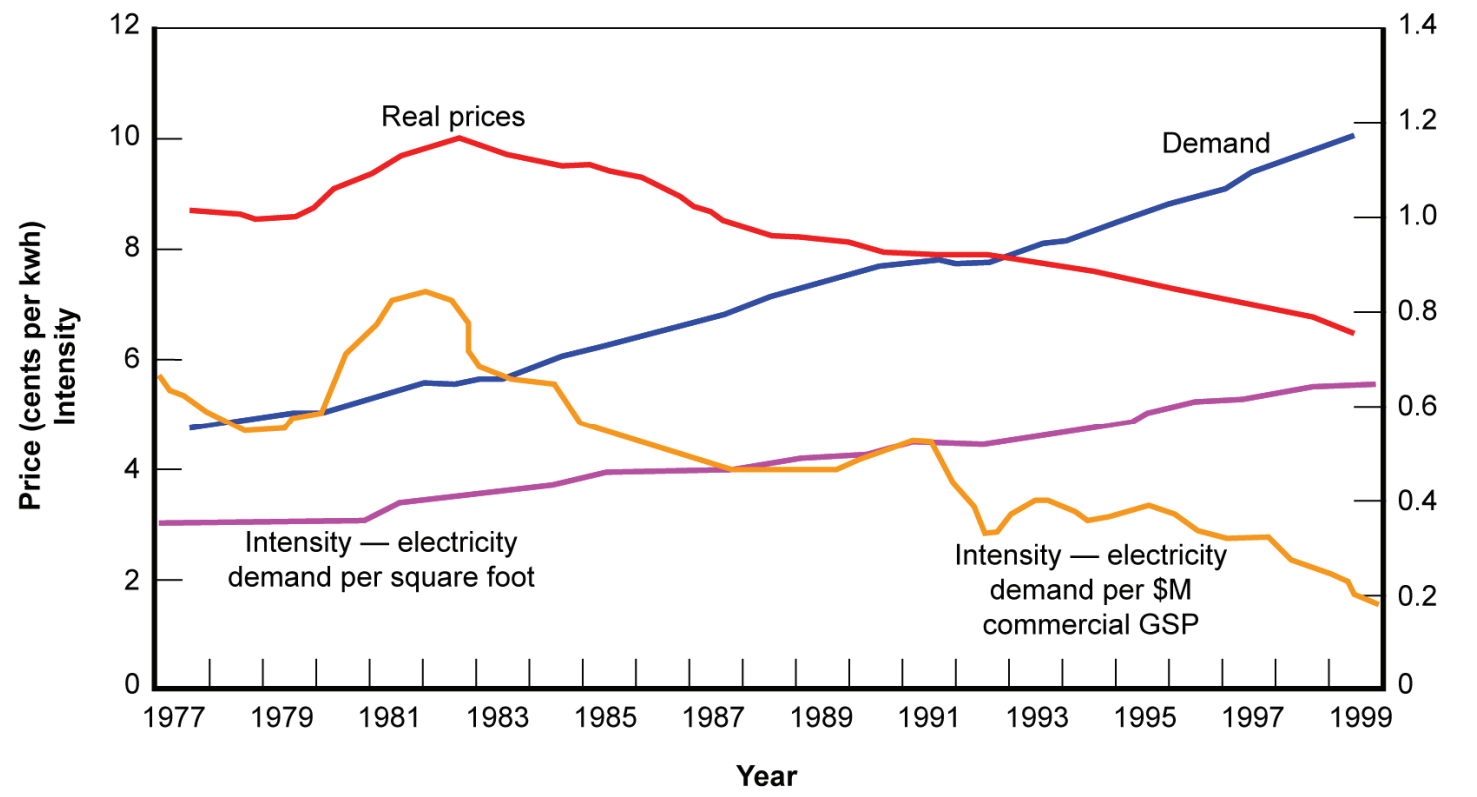

RAND TR292-3.2

Figure 3.2: Commercial Electricity Prices, Demand, and Intensity, 1977-1999

The other measure of intensity is electricity use per available square feet of space in the commercial sector. By this measure, electric intensity has increased over the period, reflecting the rapid growth in demand. This trend implies that the commercial sector, while getting more productivity out of electricity on a per-dollar basis, is continuing to add electricity loads to buildings, despite the fact that significant amounts of new, and ostensibly more-efficient, commercial space was added over the last few years of the period illustrated in the figure.

The relationship among demand, price, and other factors in the commercial sector has some similarities to the relationship among demand, price, and other factors in the residential sector and also some significant differences. Table 3.2 displays the regression analysis results for a regression with the dependent variable being commercial electricity demand. The independent variables have a similar construct as the residential modeldemand in the previous year; prices in the current and previous year; GSP for the commercial sector (i.e., income) in the current and previous year; office-space measures in square feet in the current and previous year; natural gas prices; and climate. 
The commercial electricity regression estimates are also consistent with estimates cited in Chapter Two. The short-run price elasticity is -0.21 , and the long-run price elasticity estimate is -0.97 . Previous studies found short-run elasticities somewhere around -0.2 . Long-run elasticities were more variable, and the survey literature did not report consensus values for long-run elasticities. Our long-run estimate of -0.97 is within the consensus range for residential electricity and natural-gas demand, however.

Table 3.2: Regression Analysis Results for Commercial Electricity Demand

\begin{tabular}{|l|c|c|}
\hline Variable & Coefficient & $\begin{array}{c}\text { Statistically } \\
\text { Significant }\end{array}$ \\
\hline Electricity demand in previous year & .785 & Yes \\
\hline Electricity price in current year & -.209 & Yes \\
\hline Electricity price in previous year & -.148 & Yes \\
\hline Commercial GSP in current year & .155 & No \\
\hline Commercial GSP in previous year & -.039 & No \\
\hline New floor space in current year & .504 & No \\
\hline New floor space in previous year & -.421 & No \\
\hline Natural gas price in current year & -.023 & No \\
\hline Natural gas price in previous year & .049 & Yes \\
\hline Climate - heating and cooling degree-days & .246 & Yes \\
\hline
\end{tabular}

Interestingly, of the many of the factors that we thought should impact electricity demand in the commercial sector, commercial economic output (i.e., GSP) and floor space turned out to be not significant.

\section{Natural Gas}

The patterns for residential natural-gas demand differ from those in the electricity markets (see Figure 3.3). Prices peaked in the early 1980s and then again after 2001. Demand for natural gas in the short term is more variable than demand for electricity in the short term, and there is no real growth in demand over the period that was studied, and a recent downward trend perhaps reflects increased prices. 


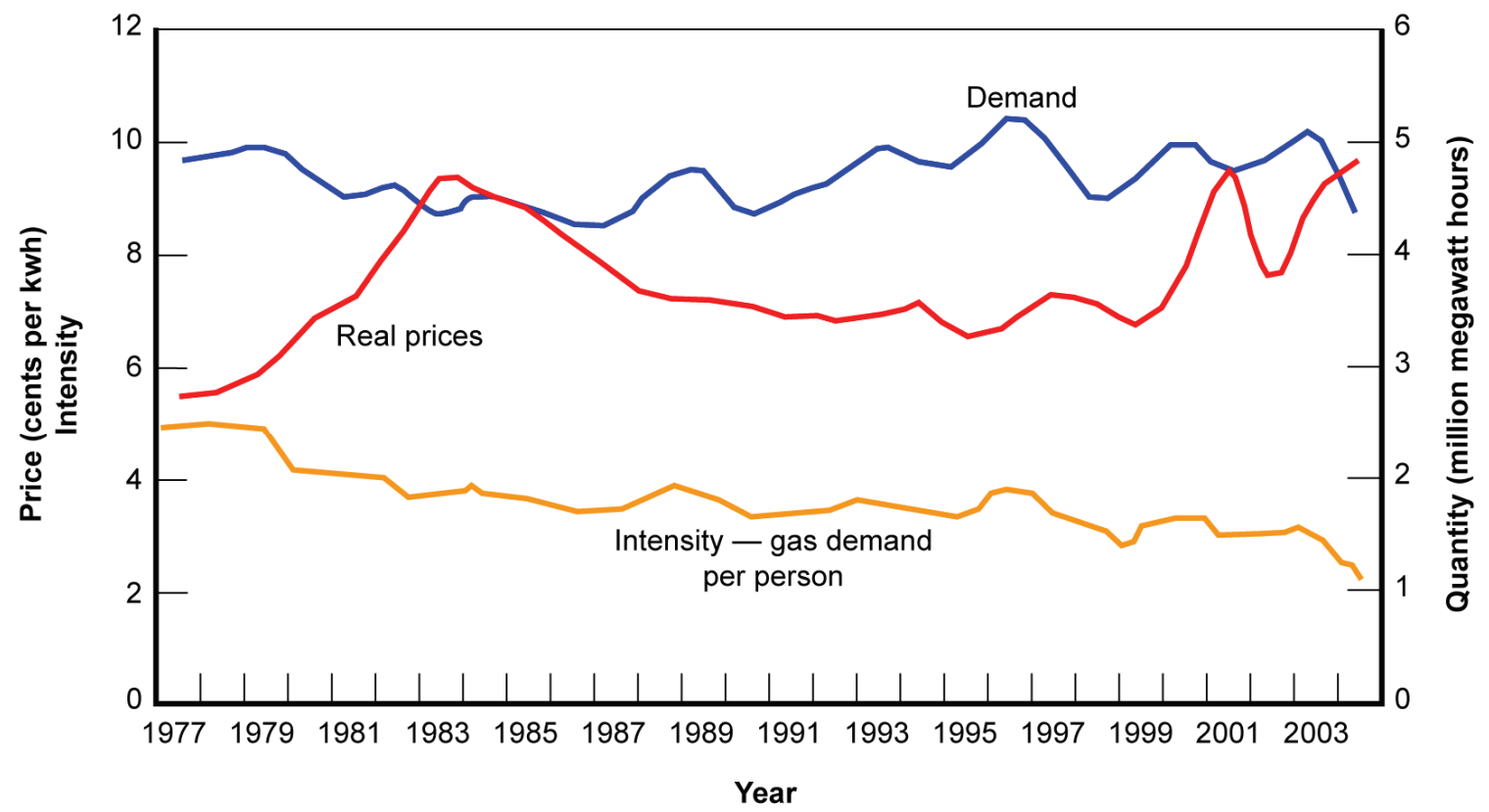

RAND TR292-3.3

Figure 3.3: Residential Natural Gas Prices, Demand, and Intensity, 1977-2003

In contrast to residential electricity intensity, natural gas intensity declined during this period. The long-term trend during this period was a 0.9 percent decline in intensity (defined for this sector as demand per capita for natural gas), reflecting some improved energy efficiency and some substitutions away from natural gas.

The regression estimates also differ from those for the electricity market (see Table 3.2). Table 3.3 shows regression results, with the dependent variable being residential natural gas prices and the same variables as were used for the residential electricity regression. The short-term price elasticity is -0.12 , and long-term price elasticity is -0.36 . Bohi and Zimmerman (1984) reported consensus values of -0.2 in the short term and -0.3 in the long term. These values may reflect the fact that there are fewer opportunities for consumers to reduce their demand for natural gas in response to price, possibly because the use of natural gas in the home (i.e., for air and water heating and cooking) is a necessity, whereas turning off some lights or using fewer electric appliances is optional. 
Table 3.3: Regression Analysis Results for Residential Natural Gas Demand

\begin{tabular}{|l|c|c|}
\hline Variable & Coefficient & $\begin{array}{c}\text { Statistically } \\
\text { Significant }\end{array}$ \\
\hline Natural gas demand in previous year & .67 & Yes \\
\hline Natural gas price in current year & -.12 & Yes \\
\hline Natural gas price in previous year & -.08 & Yes \\
\hline Electricity price in current year & .03 & No \\
\hline Electricity price in previous year & .11 & Yes \\
\hline Income in current year & .24 & Yes \\
\hline Income in previous year & .07 & No \\
\hline Population in current year & 1.18 & Yes \\
\hline Population in previous year & -.86 & Yes \\
\hline Climate - heating and cooling degree-days & .27 & Yes \\
\hline
\end{tabular}

The natural gas results differ from those for electricity. Income in the current year is a significant factor in demand for natural gas, whereas income in the previous year is not. The reason that previous-year income is significant for electricity could be because increased income might lead to consumers buying new appliances that add to the electrical load in the following year. In the case of natural gas, by comparison, there a that increased income might lead to consumers turning up the thermostat in the winter, adding to their current-year natural-gas consumption. The impact of electricity price on natural gas demand in the previous year is consistent with what we saw with the impact of natural gas price on electricity demand.

\section{Summary of National-Level Results}

As we have seen in this chapter, there are similarities and differences between the patterns of demand and price when comparing residential electricity, residential natural gas, and commercial electricity. Residential electricity use and intensity increased over the period we studied, although recent electricity price increases have slowed the growth of demand. Natural gas use has been flat, and intensity has declined, and we might see a greater decline due to recent natural-gas price increases. Commercial electricity use grew rapidly over the period studied, and while electricity as a share of output in the commercial sector has declined, electricity use per square foot of office space has 
continued to increase. A comparison of estimated price elasticities for the three sectors is presented in the Table 3.4.

Table 3.4: Price Elasticities for Residential Electricity, Commercial Electricity, and Residential Natural Gas at the National Level

\begin{tabular}{|l|c|c|c|}
\hline & $\begin{array}{c}\text { Residential } \\
\text { Electricity }\end{array}$ & $\begin{array}{c}\text { Commercial } \\
\text { Electricity }\end{array}$ & $\begin{array}{c}\text { Residential Natural } \\
\text { Gas }\end{array}$ \\
\hline Short-run elasticity & -.24 & -.21 & -.12 \\
\hline Long-run elasticity & -.32 & -.97 & -.36 \\
\hline
\end{tabular}

Short-run price elasticities for electricity are similar for residential and commercial demand, although it appears that changes in commercial electricity price can have a bigger impact in the long term than in the short term. In the short run, natural gas demand is less elastic than demand for electricity but is about the same in the long run.

We used the national-level information presented in this chapter as a starting point for determining whether elasticities differ significantly among regions and states. The next chapter describes the regional-level results. 


\section{Chapter 4: Regional Results}

This chapter describes the results from our analysis of trends in the three energy markets (residential electricity, commercial electricity, and residential natural gas) at the regional level. The analysis uses the nine census divisions that the DOE Energy Information Agency uses in energy modeling and forecasting: New England, Mid-Atlantic, South Atlantic, East North Central, East South Central, West North Central, West South Central, Mountain, and Pacific (see Figure 4.1). ${ }^{4}$

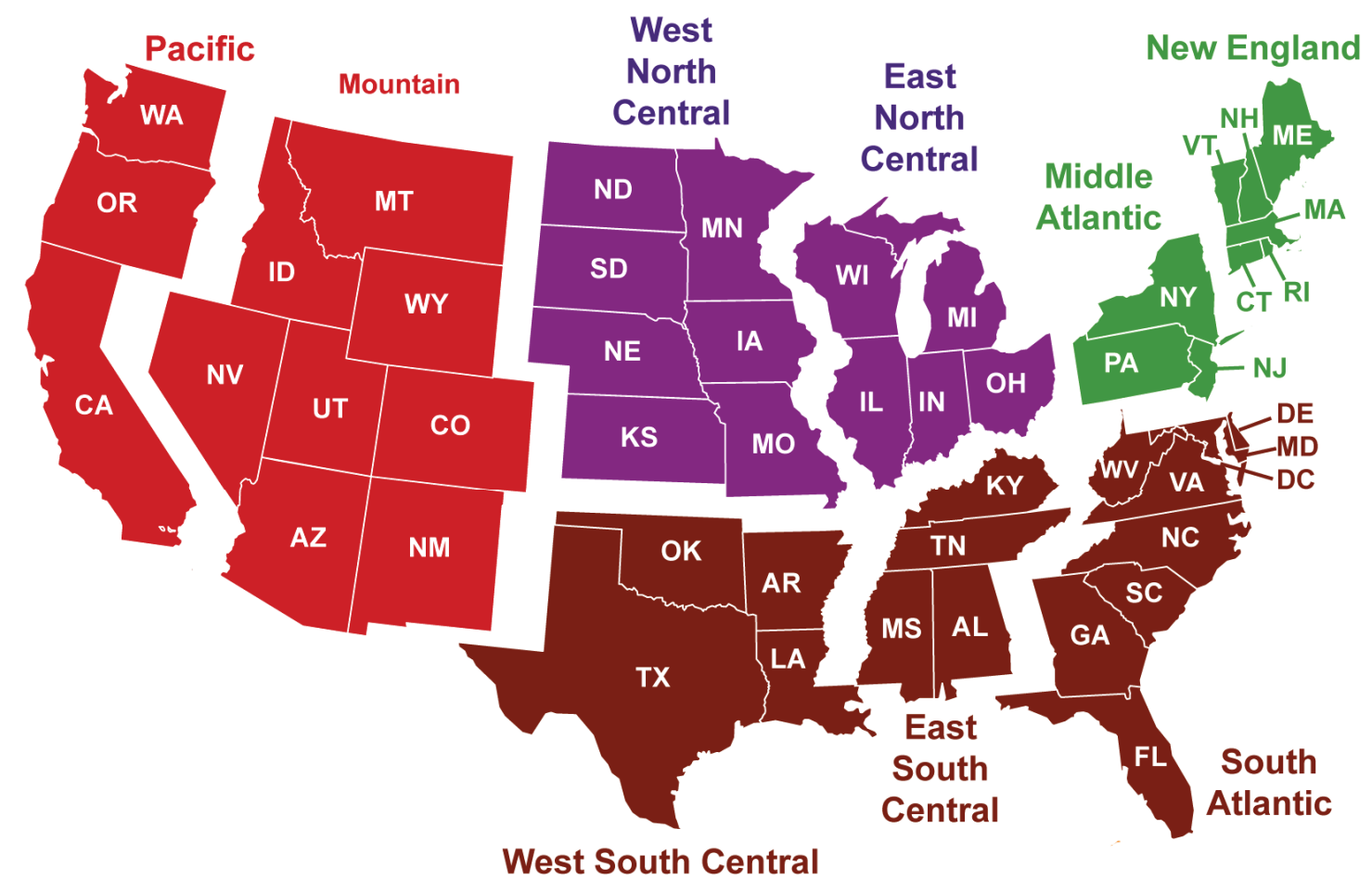

RAND TR292-4.1

Figure 4.1: DOE Energy Information Agency Census Regions

In this analysis, we look at regional trends in energy intensity, energy expenditures, and expenditures as a share of income to determine if they differ among regions. We then

\footnotetext{
${ }^{4}$ We excluded Alaska and Hawaii from our analysis because they are unique in their energy uses and climate.
} 
reproduce the regressions shown in the national-level analysis in Chapter Three to determine if there are significant differences in the price elasticities among regions.

\section{Residential Electricity}

Of the three markets that we examined in this study, residential electricity shows the most regional differentiation. Figures 4.2, 4.3, and 4.4 display trends in residential electricity use, expenditures, and expenditures as a share of total income, respectively, for the nine DOE census regions. The Figure 4.2 shows regional trends in per-capita residential electricity intensity.

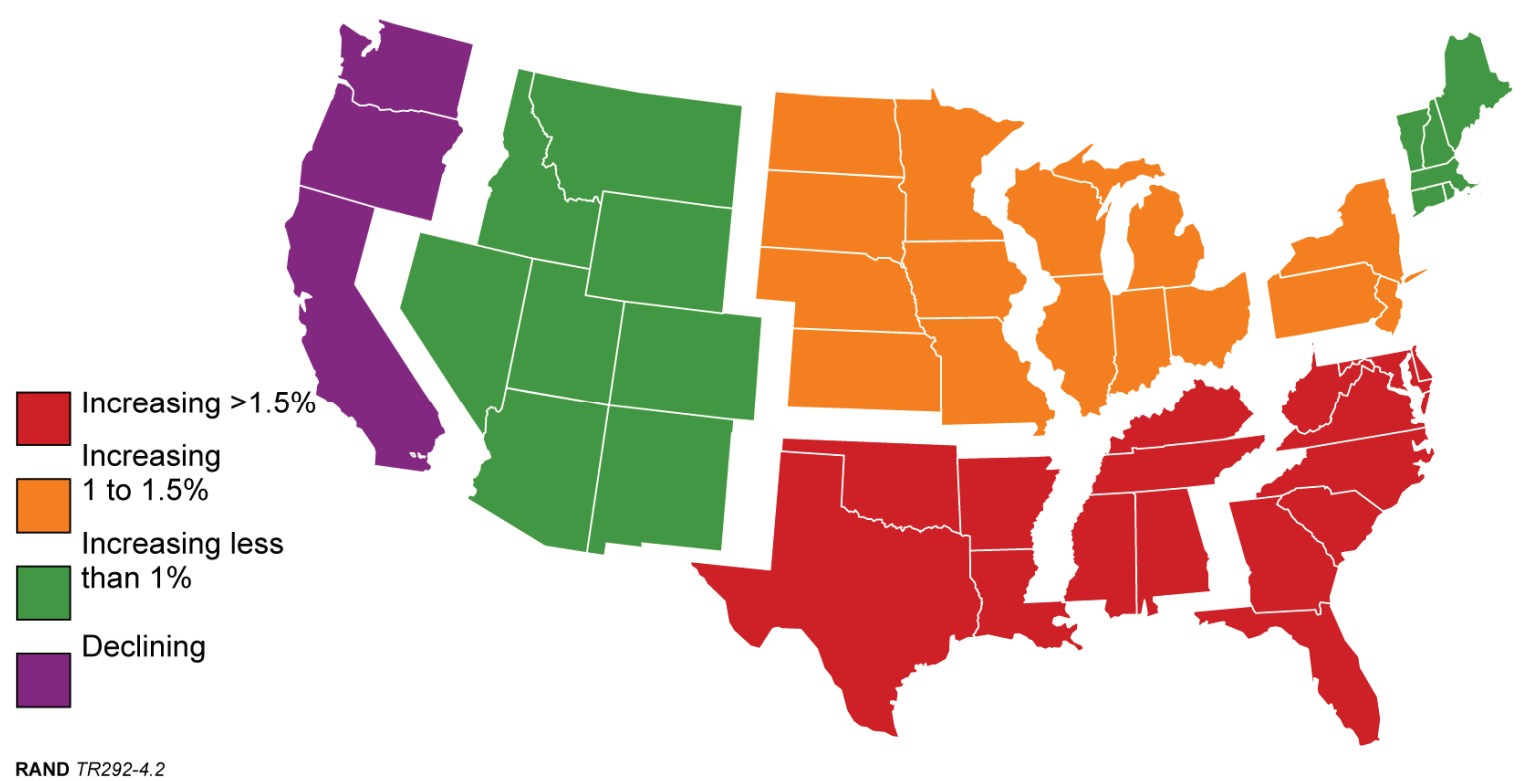

Figure 4.2: Regional Trends in Per-Capita Residential Electricity-Intensity, 1977-2004

Figure 4.2 shows four categories of trends in intensity-increasing over the period more than 1.5 percent on average, increasing between 1 percent and 1.5 percent per year on average, increasing less than 1 percent, or declining. Only one region had declining electricity intensity--the Pacific. Residential electricity intensity is growing fastest in the South Atlantic and East South Central regions. The Middle Atlantic, East North Central, and West North Central regions have the next-fastest growth rates. New England and the Mountain states have growth rates of less than 1 percent. 
It is interesting to note that some commonality exists across contiguous regions. The East South Central, West South Central, and South Atlantic regions have experienced the most-rapid growth in electricity intensity, perhaps driven by air-conditioning loads and rapidly growing populations. The Middle Atlantic and West North Central regions also have had increasing air-conditioning loads at levels that did not exist until the late 1980s, and they have seen relatively rapid growth in electricity intensity over this period.

The Pacific Coast, which is dominated by California in its magnitude of electricity use, has had declining electricity intensity, possibly due to energy-related building codes that are the strictest in the nation and have been in place longer than any others.

All of these findings might imply that the impact of energy efficiency would be greater in areas such as the South in which the intensity of electricity use has been growing more rapidly than in other regions and might have less of an impact in the Pacific Coast where intensity has been declining.

Figure 4.3 shows growth trends for average expenditures on residential electricity. The figure shows that average expenditures on residential electricity are growing in all regions but provides a different picture than residential electricity intensity. Expenditures are growing most rapidly in the South Atlantic, East South Central, New England, and Pacific Coast regions. The Middle Atlantic and West South Central regions have the next-fastest growth rate, while the Mountain, East North Central, and West North Central regions have the slowest growth rates.

In a demand-price relationship, one might expect to see a picture similar to the one for electricity intensity--those areas with the most rapid increases in expenditures would have declining or slower growth in electricity intensity. While this is true for the Pacific states and Northeast, the opposite is true for the South Atlantic and East South Central regions. This is the first indication that the regional differences in the demand-price relationship might matter when estimating the impact of energy efficiency on other demand changes. 


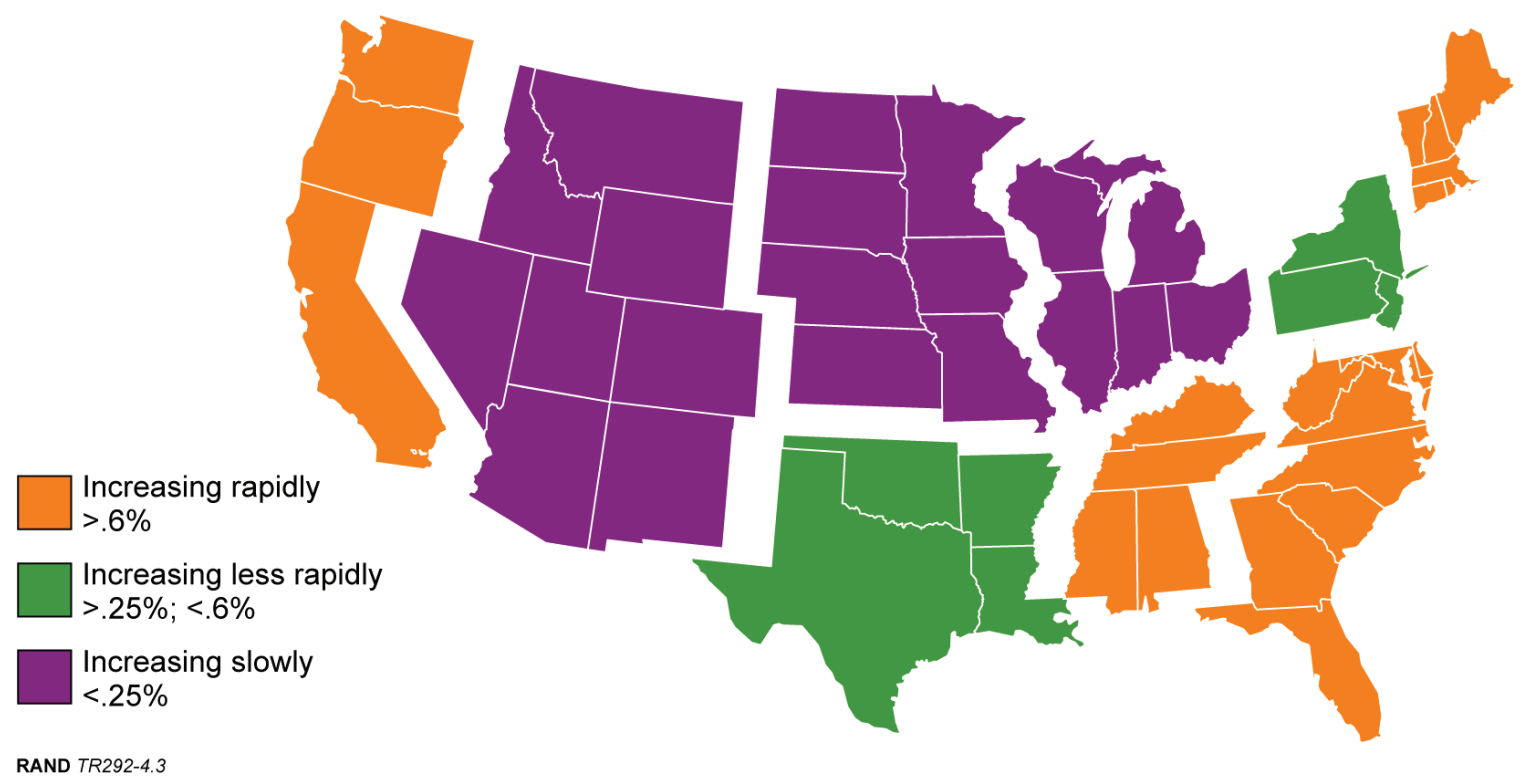

Figure 4.3: Regional Trends in Average Expenditures on Residential Electricity, 1977-2004

We now look at average expenditures on residential electricity as a share of personal income (see Figure 4.4). Although the spread of the numbers is small, there are a few interesting findings to note. First, even though expenditures on electricity have been rising, the share of electricity as a percentage of income has been declining, meaning that incomes are growing faster than electricity use. In the Mountain and Northeast regions, the relationship is what we would expect-where expenditures per dollar of income are declining rapidly, electricity intensity is growing quickly. We would expect that where the expenditures per dollar of income are declining more slowly than in other regions, electricity intensity growth would be slower or declining (as is the case in the Pacific Coast). But in the South Atlantic and East South Central regions, we find that even though the expenditure per dollar of income is not declining as fast as that in other regions, electricity intensity is growing more rapidly than in the other regions. This finding might be an indication that electricity use in the South Atlantic and East South Central regions is relatively insensitive to the cost of using electricity. At the very least, it is another indication of regional diversity. We also see some commonality among neighboring regions--for example, energy intensity in all the Southern regions is declining more slowly than in other regions, while in the mid-Northern regions it is declining more rapidly. 


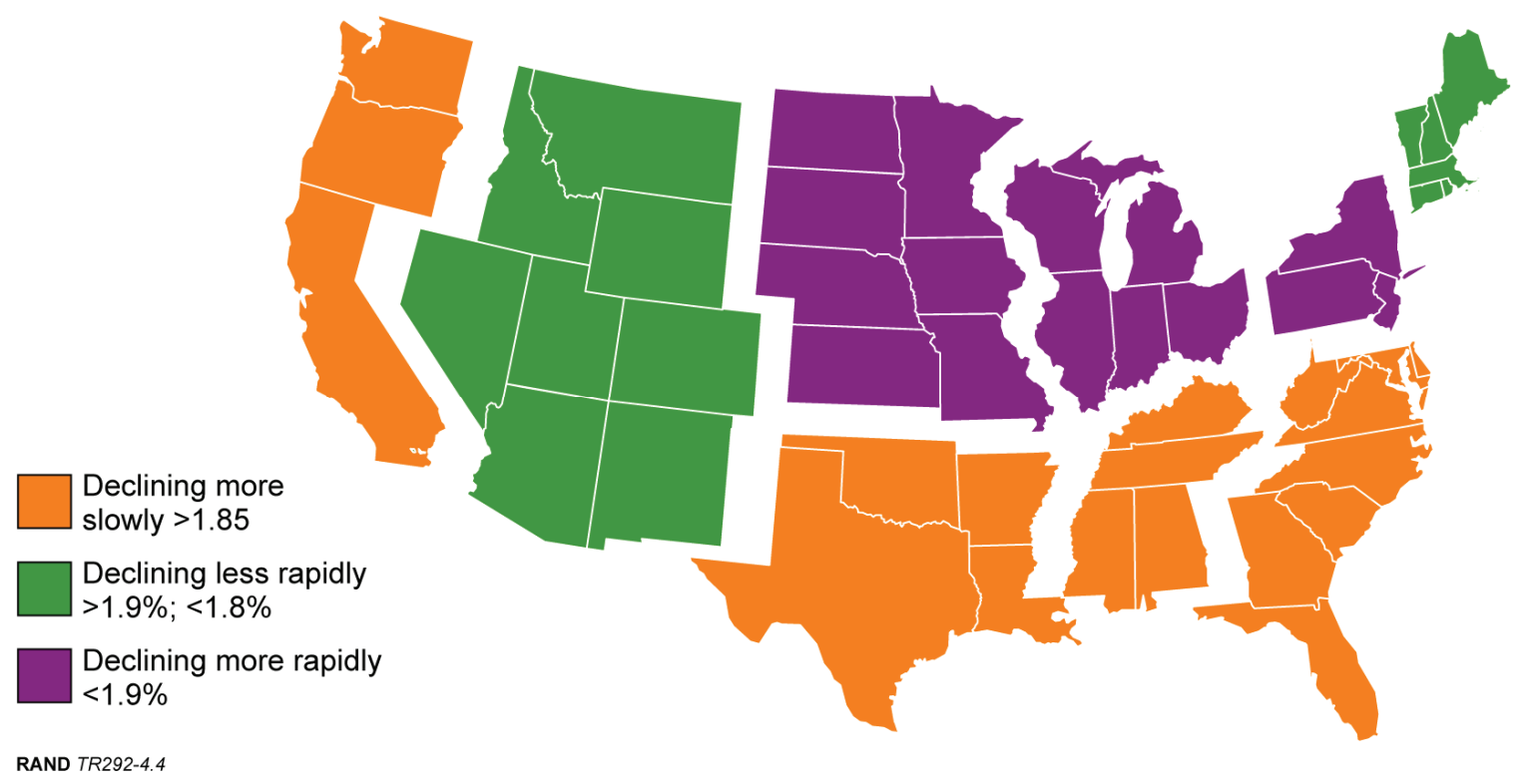

Figure 4.4: Regional Trends in Average Expenditures on Residential Electricity as a Share of Income, 1977-2004

One might conclude from Figures 4.2 through 4.4 that there are regional differences in the relationship between electricity demand and price and regional differences in the trends in electricity usage and expenditures. Using the method described in Chapter Two, we estimated the short-run and long-run price elasticities by region, which are presented in Figures 4.5 and 4.6. We find that the regional estimates of short-run elasticities range from -.04 in the East North Central region to .31 in the South Atlantic region. We also present the 95 percent confidence interval for each of the regional estimates. Where the confidence intervals do not overlap, we can say the regions are significantly different from each other. Where they do overlap, there may be differences, but, statistically, it is difficult for us to determine if they are actually distinct. In this case, all the confidence intervals overlap to some extent, except for those for the South Atlantic and East North Central estimates. Those two regions are the only ones that have significant differences in elasticities.

Long-run demand (see Figure 4.6) is more elastic than short-run demand in each region, and while the long-run pattern is relatively similar to the short-run pattern, the East South Central region in this case is the most elastic, and the differences between the East South 
Central and South Atlantic regions and the East North Central region are statistically significant. The other regions differ from one another less for long-run elasticities than they do for short-run elasticities.

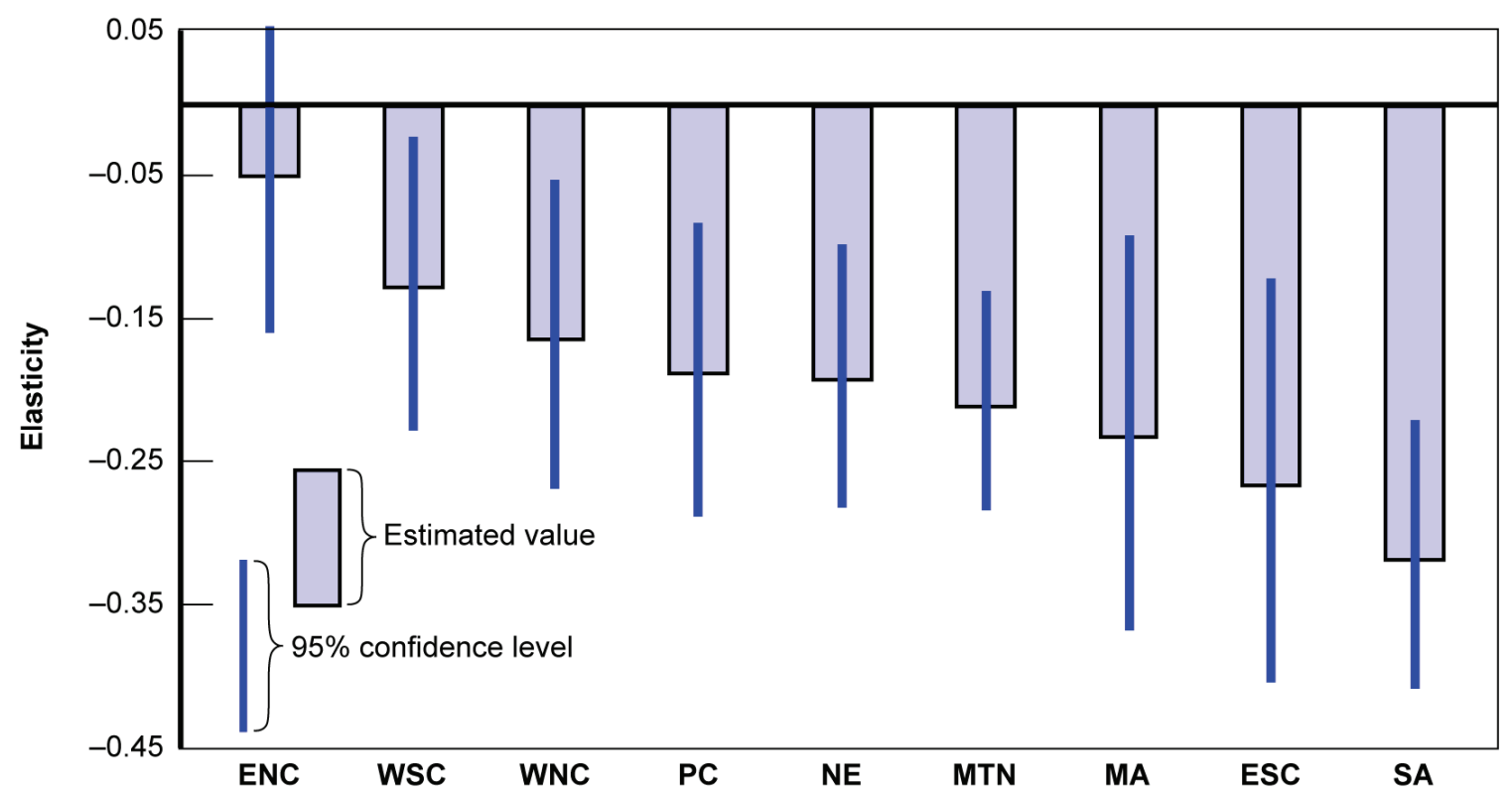

RAND TR292-4.5

Figure 4.5: Estimated Short-Run Residential-Electricity Price Elasticities by Region, 1977-2004

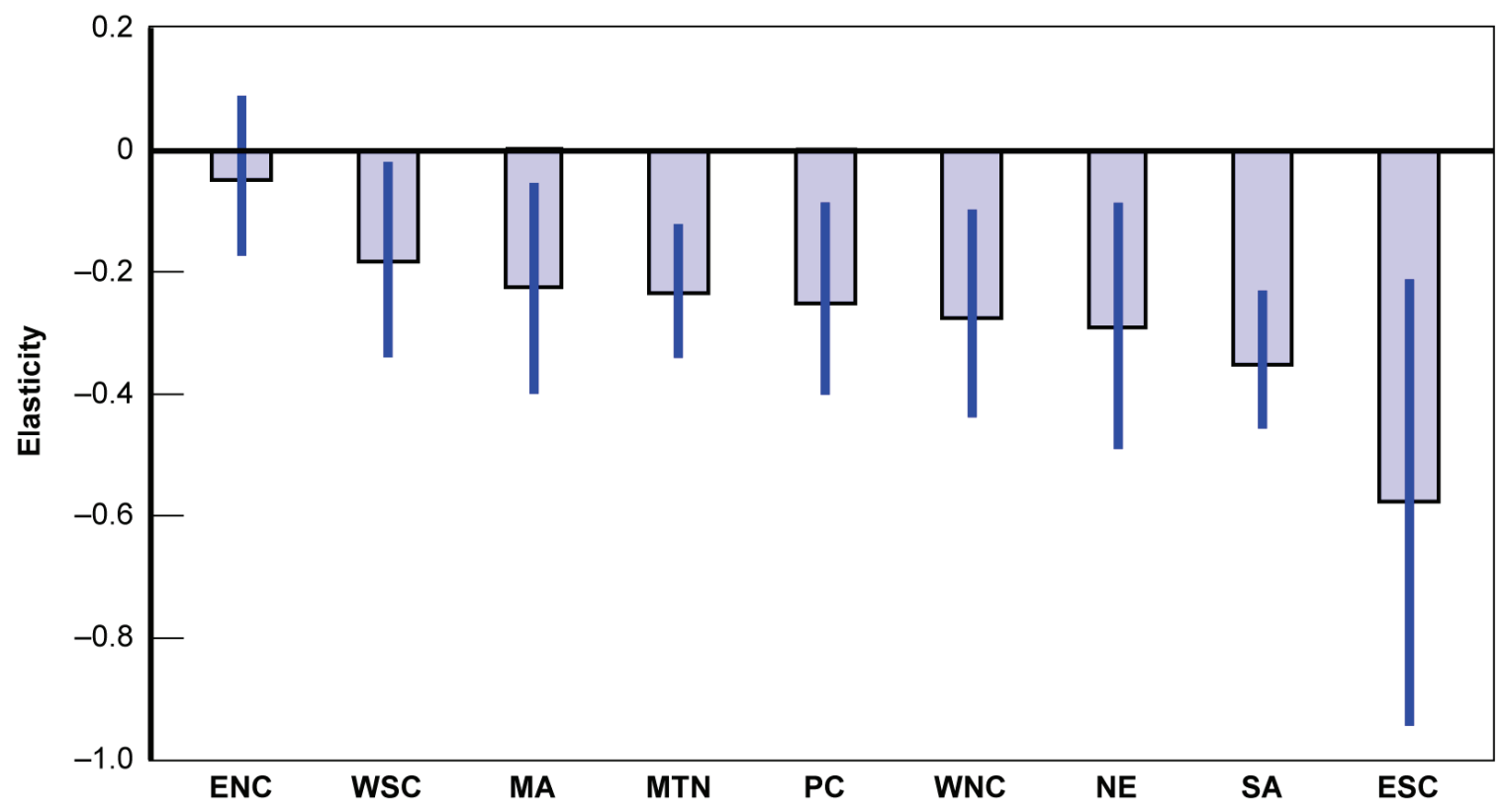

RAND TR292-4.6

Figure 4.6: Estimated Long-Run Residential-Electricity Price Elasticities by Region, 1977-2004 
When the various pieces of this analysis are brought together, they indicate that the relationship between demand and price vary enough by region that estimates of future residential electricity use or estimates of the impacts of energy-efficiency programs should reflect some of the regional variation.

\section{Commercial Electricity Results}

While the analysis of the residential electricity sector showed significant regional differences, the commercial electricity sector is somewhat less diverse. Our analysis of commercial energy intensity found some differences across regions, but the elasticities did not differ. The trend in electricity intensity per square foot of office space has been moving toward increased intensity, with slower increasing rates in the Pacific Coast and East South Central regions (see Figure 4.7). We cannot say that the Pacific Coast region is statistically different from zero in terms of commercial electricity intensity, and the West Southern Central and East Southern Central regions are significantly lower than most of the other regions. This finding indicates that new newly constructed buildings may be more energy efficient in some regions than in other regions. It may also indicate that the impacts of future improvements in commercial electricity efficiency may be larger regions with high growth in energy use, such as New England, the West North Central, and the South Atlantic, and might have little additional impact on the Pacific Coast region.

The short-run price elasticities for commercial electricity range from just under -. 3 to -.15 (see Figure 4.8). Figure 4.8 indicates that some differences exist in short-run price elasticity estimates across regions, but they are smaller than the differences in such estimates across regions in the residential electricity sector. In addition, the commercial electricity estimates have considerably greater variance (larger confidence intervals) than the residential sector estimates. Given this large variance, there are no significant differences among regions. Although we cannot say the regions are statistically different from each other, it does appear that the Pacific Coast and East South Central regions are 
somewhat more elastic in terms of commercial electricity than the other regions, and one might look at these two regions somewhat differently than the others.

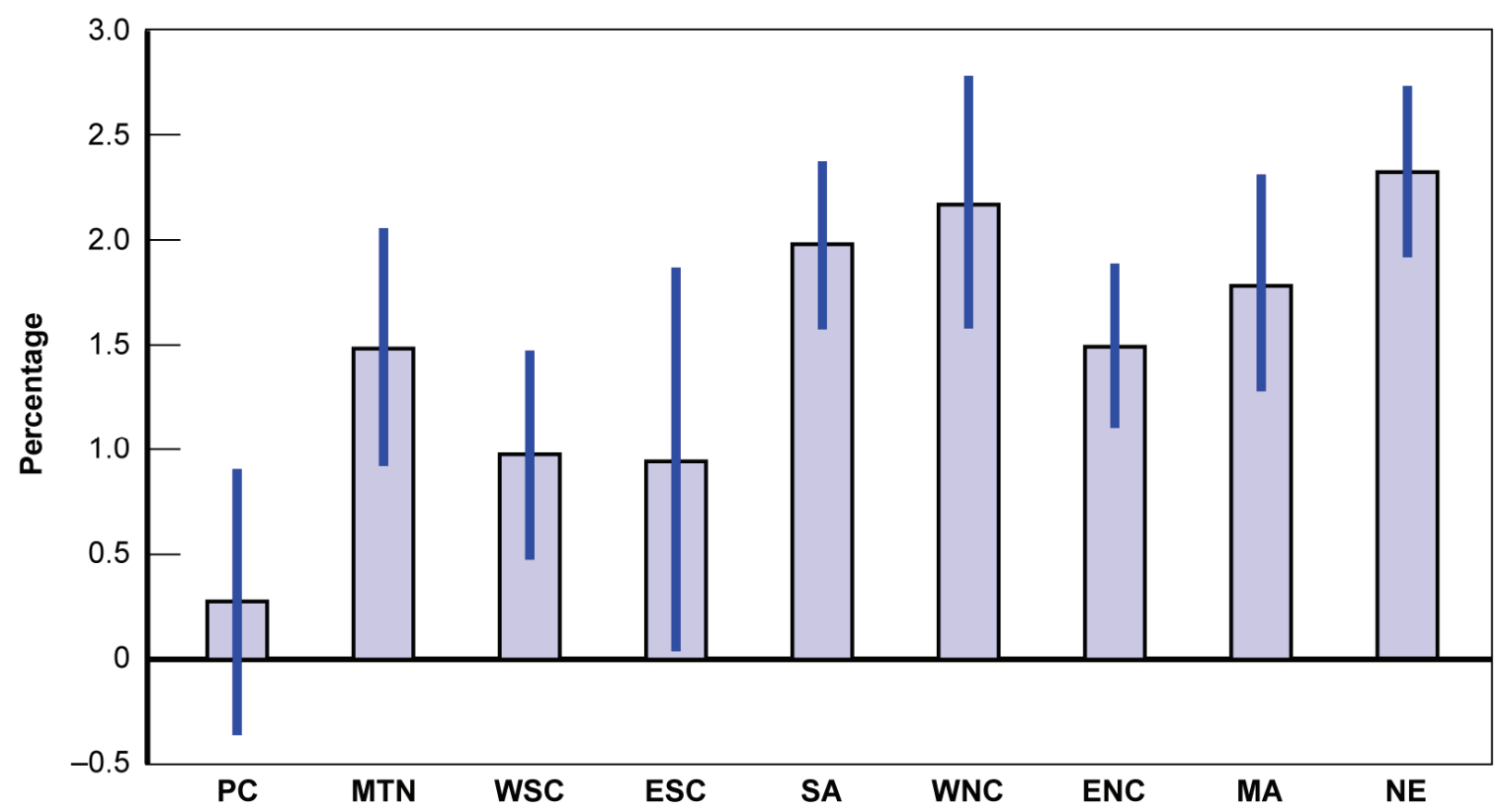
RAND TR292-4.7

Figure 4.7: Regional Trends in Commercial Electricity Use per Square Foot of Office Space, 1977-1999

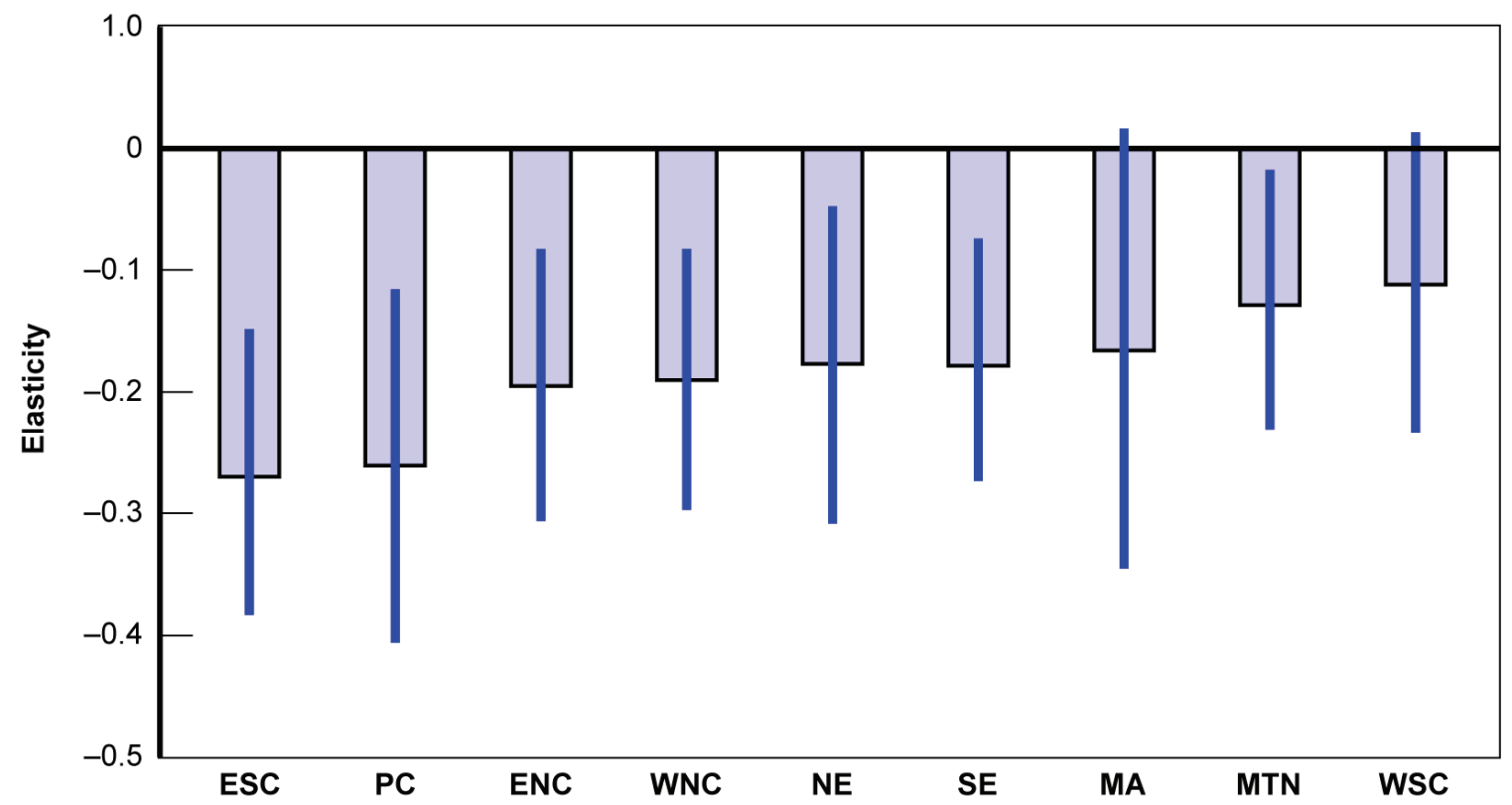

RAND TR292-4.8

Figure 4.8: Short-Run Commercial Electricity Price Elasticities by Region, 1977-1999 
Figure 4.9 shows that demand is more elastic in the long run than in the short run for the commercial electricity sector, but there is even less variation among the regions. The estimates shown in Figure 4.9 have large variances, and discerning differences in elasticities among the regions is not possible.

What we can conclude from the above discussion is that there are not many regional differences in commercial electricity use. Therefore, estimates of future electricity use at the regional level will not be greatly impacted by dissaggregation to the regional level, except perhaps for the Pacific Coast and East South Central estimates. Differences in elasticities among states are still possible, and those differences are assessed in Chapter Five.

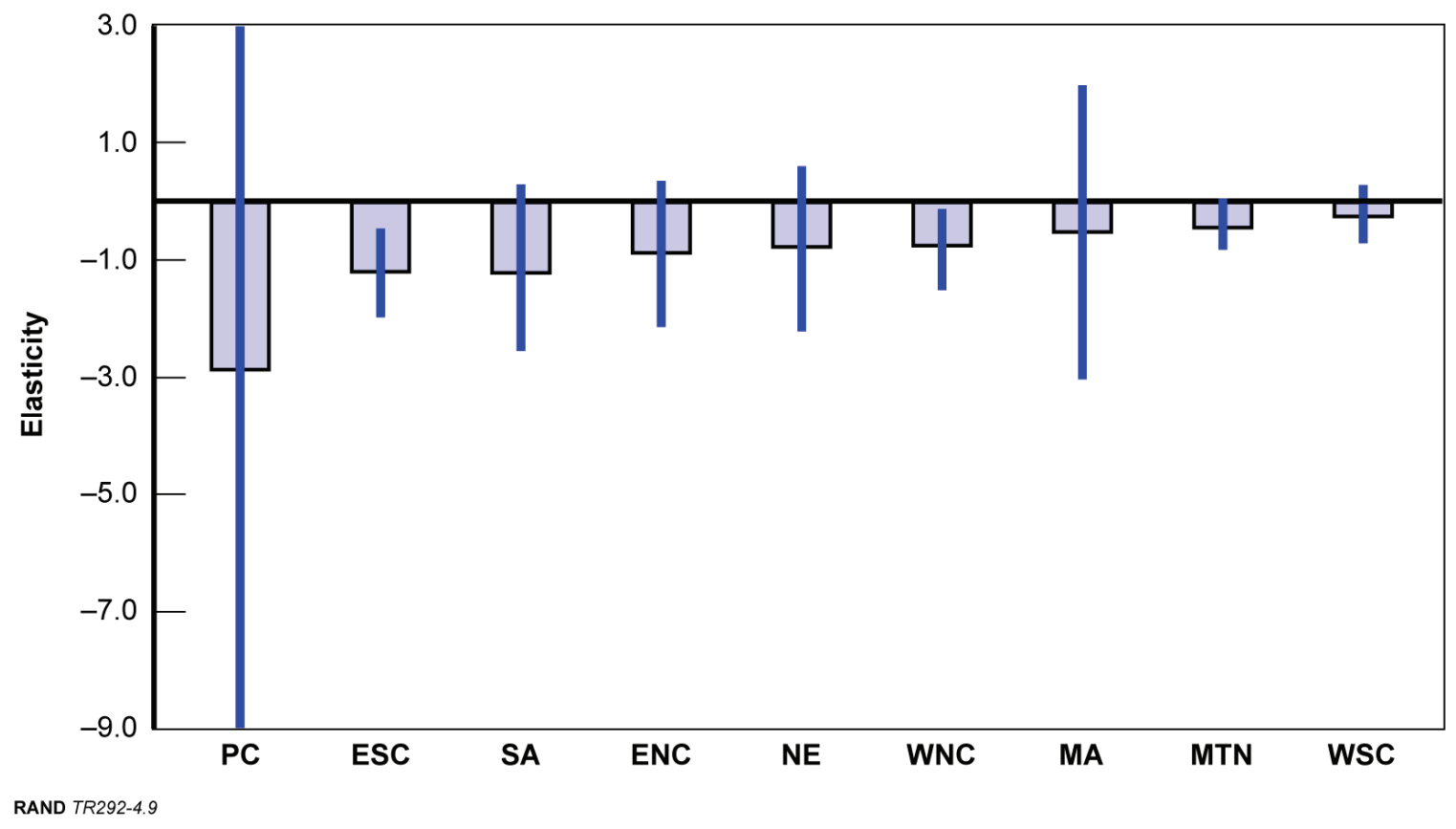

Figure 4.9: Long-Run Commercial Electricity Price Elasticities by Region, 1977-1999

\section{Residential Natural Gas}

Our analysis of residential natural-gas energy intensity and expenditures on natural gas as a share of income shows that there are differences in long-term trends among regions, although the trends themselves are small in magnitude. Figures 4.10 and 4.11 show 
intensity and price trends by region for natural gas. The largest increase in intensity is in the Pacific Coast, driven by Washington and Oregon, and the greatest decline in intensity is in the West South Central region, driven by Texas. There are large variations in the estimates; therefore, for the most part, we cannot distinguish among trends in intensity in the regions. Clearly, though, the Pacific Coast and Mid-Atlantic trends are positive, and the rest are negative (with the New England trend being indistinguishable from zero). This finding does suggest, however, that improvements in the efficiency of natural-gasusing appliances might have a bigger impact in the Pacific Coast and Middle Atlantic regions than they would in most other regions, and that additional improvements in the energy efficiency of natural-gas-using appliances in the West South Central region may have little impact.

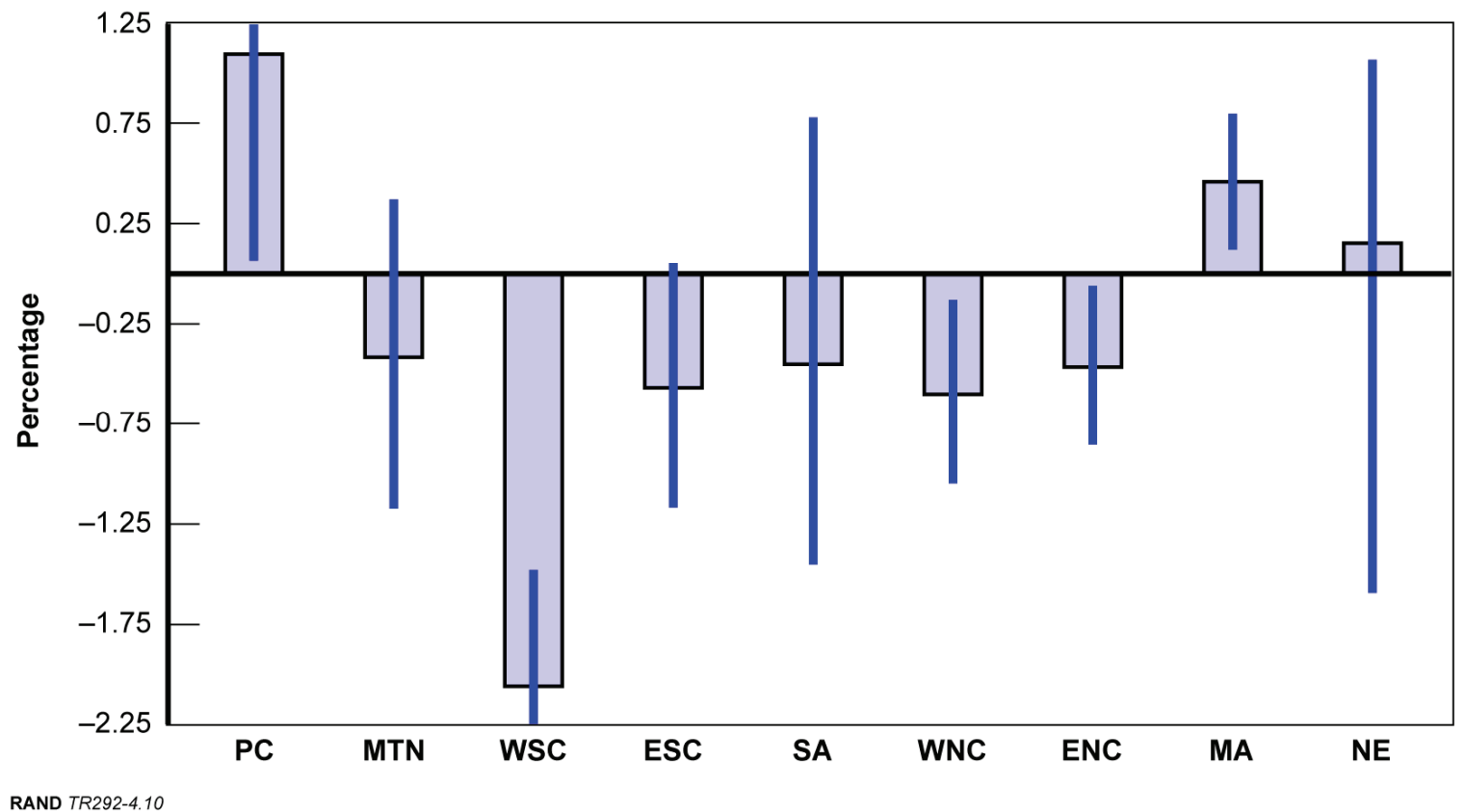

Figure 4.10: Natural-Gas Intensity Trends by Region, 1977-2004

The price trends for natural gas provide an interesting picture of the demand-price relationships one would expect. Increasing-price trends occurred in the regions with declining natural-gas intensity; the Pacific Coast and New England regions, which had increases in intensity, had an overall trend of prices not increasing (prices fluctuated across the sample for all the regions, but in the Pacific Coast and New England regions, the overall average trend was indistinguishable from zero). The sole exception to these 
trends is the Middle Atlantic region, which had small increasing price trends and increasing intensities. In Washington and Oregon, which were the primary drivers on the Pacific Coast for the increasing intensity, there has been some substitution of natural gas for electricity for heating purposes, some of which may have been driven by building codes that encouraged shifts from electricity for water heating. These results certainly indicate that some interesting results should be expected from the elasticity estimates.

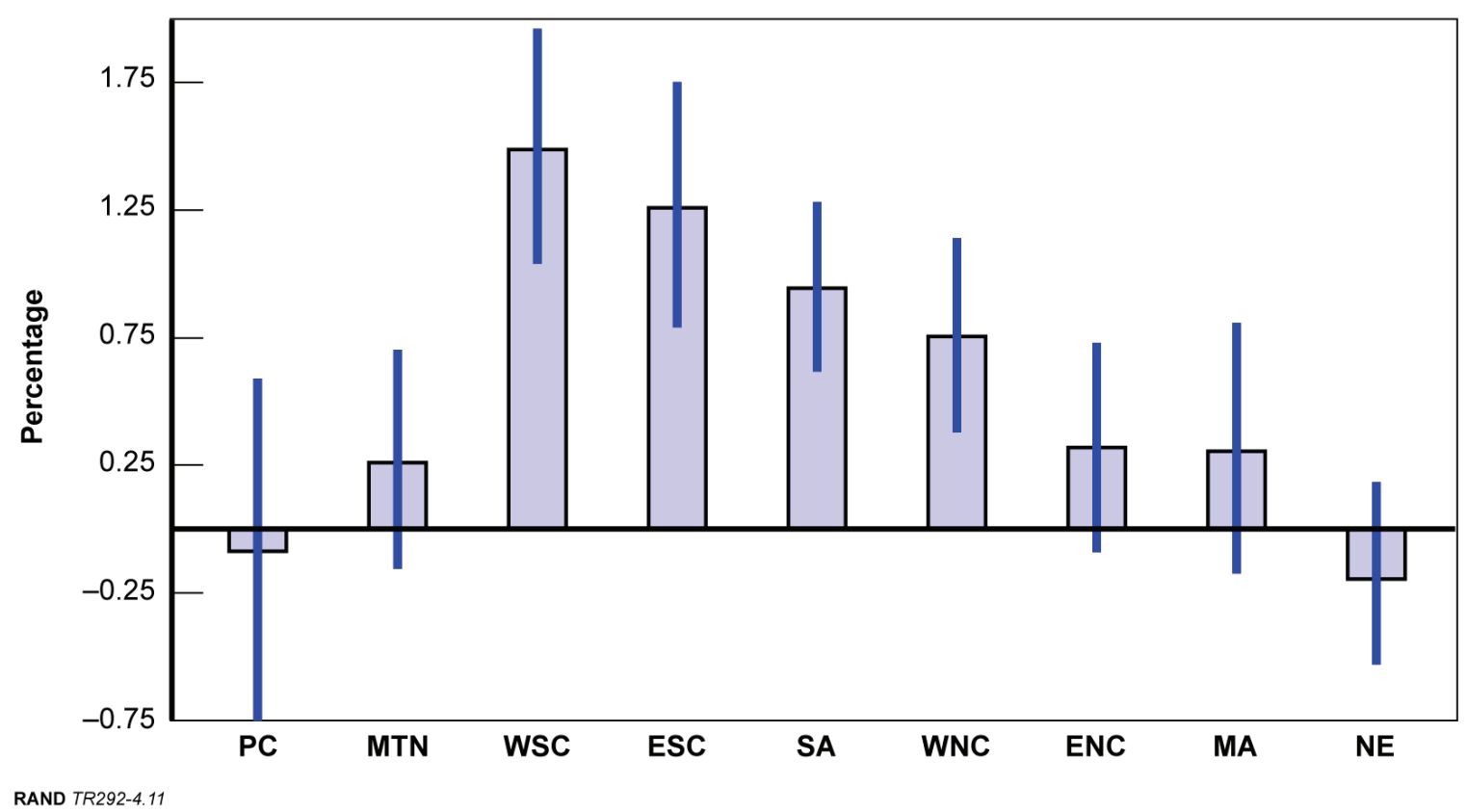

Figure 4.11: Natural-Gas Price Trends by Region, 1977-2004

Short-run price elasticity for residential natural gas varies from -0.03 for the West South Central region to -0.18 for the Pacific Coast (see Figure 4.12). The variance in the estimates, as in the commercial sector, is large. The Pacific Coast, again, has the greatest elasticity, and its neighboring Mountain region runs a close second. While we cannot say that the elasticity in these two regions is significantly different from that of the other regions, it may be worth further exploring benefits estimates for these two regions. Of the contiguous regions, the southern-state regions are the least elastic, and the northern-state regions are in the middle.

The long-run price-elasticity estimates (see Figure 4.13) are more elastic than the shortterm estimates, with the most inelastic region still the West South Central and the most 
elastic still the Pacific Coast. While the variances are large in the long run, too, the Pacific Coast and Mountain regions are close to being significantly different from the West South Central, and there is a group in the middle with similar elasticities.

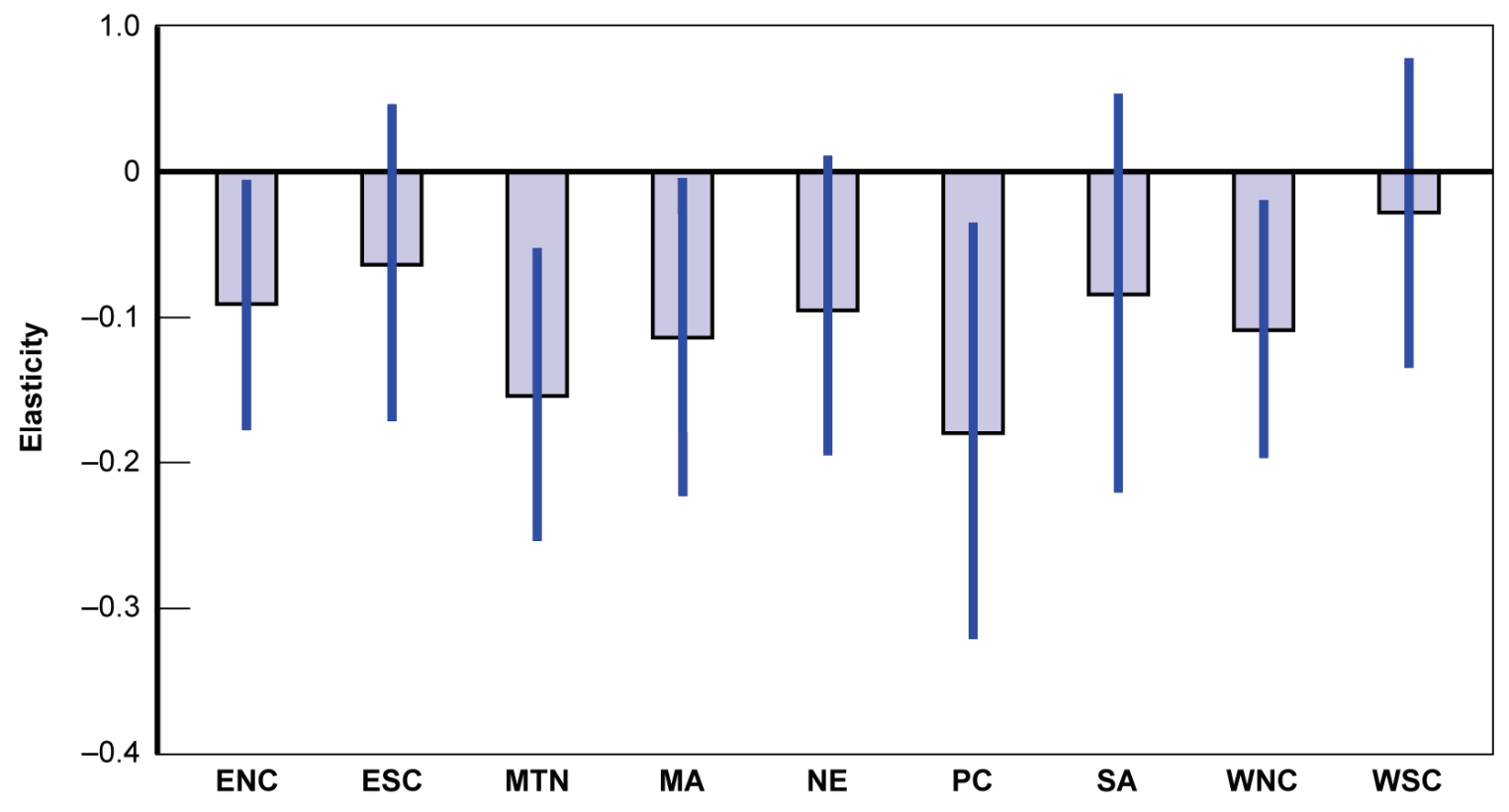

RAND TR292-4.12

Figure 4.12: Short-Run Natural-Gas Price Elasticities by Region, 1977-2004

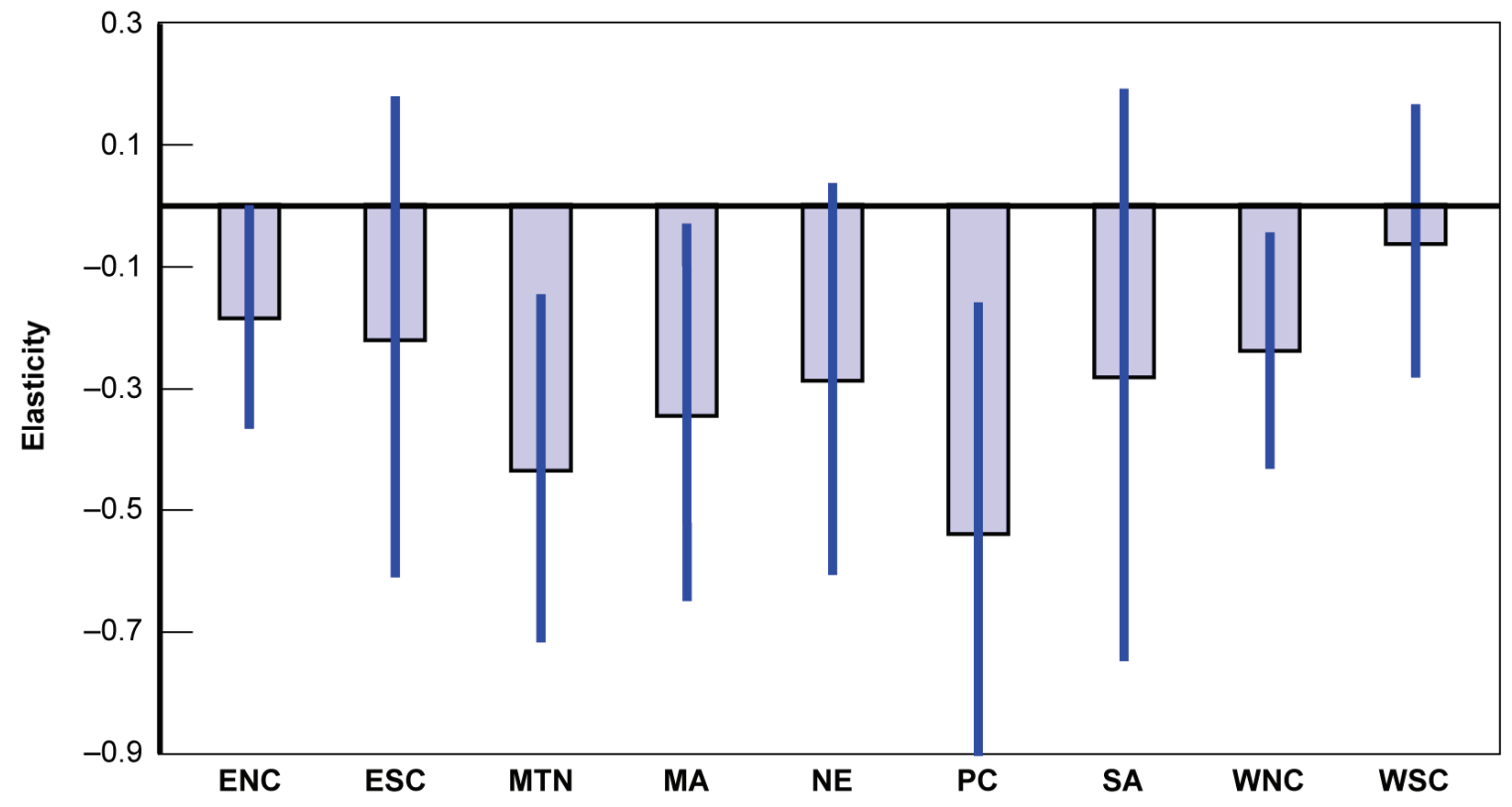

RAND TR292-4.13

Figure 4.13: Long-Run Natural Gas Price Elasticities by Region, 1977-2004 
The results for residential natural gas fall somewhere in between those for residential electricity and those for commercial electricity in terms of regional differences. As was the case with commercial electricity, there are few discernable differences in trends among the regions, but there are more differences in the elasticities than in commercial electricity, although still not at the level of significance that was seen in residential electricity. It might make a difference in forecasts and estimates if the Pacific Coast and Mountain regions are differentiated from the other regions.

\section{Regional Analysis Conclusions}

The analysis of regional-level differences in the price-demand relationship provides different answers for different markets. It seems clear that there are regional differences in the residential electricity market, and that estimates of the impact of energy efficiency and forecasts of electricity demand could differ significantly if the regional differences are taken into account. Clearly, commercial electricity does not appear to differ significantly by region; therefore, national-level estimates of commercial electricity price-demand relationships are likely to be sufficient for analyzing the impact of energy efficiency in the commercial sector. The picture for residential natural gas is somewhat different. There is not a lot of variability in energy-use trends over time, which is probably why there is not much difference by region in the price-demand relationship. It appears that demand responds more to price in two of the regions than in the others, and this finding could have some implications for estimates of the benefits of energy efficiency, but national level results in this case are probably also sufficient for analyzing the impact of energy efficiency in the commercial sector 


\section{Chapter 5: State-Level Analysis}

In this chapter, we use a methodology similar to the one that was used for the analysis in the previous chapter, but in this case, we differentiate state-level elasticities and trends. The state-level analysis consists of an examination of trends and an estimation of shortrun and long-run price elasticities for each state.

\section{Residential Electricity}

Beginning again with residential electricity, we look at the key trends in energy intensity and expenditures as a share of income. In terms of electricity use per capita (see Figure 5.1), there are only a few states, which are concentrated in the West and New England, with trends of small or declining energy intensity over the period studied. As we found in the regional-level analysis, the high-growth areas in terms of residential electricity usage are concentrated in the South. The significance of Figure 5.1 is in the consistency it shows within regions. While the energy intensity trends do vary within each region, they do not vary significantly. There are no regions with some states with declining intensity and some states with rapidly increasing intensity. This is a first indication that the regional-scale analysis might be sufficient for analyzing the impacts of energy efficiency.

We do observe some inter-regional variation in electricity expenditures as a share of income (see Figure 5.2). There is some diversity within each of the regions, although in most cases, the differences among states in a region are small except for a single state. Because the demand is consistent within regions, but the expenditures and prices are not, the elasticities in states in each region might vary.

Next, we take a look at the differences in estimated residential electricity price elasticities, which are illustrated in Figure 5.3. Each square-shaped plot point in the figure represents a U.S. state, and the vertical lines represent the 95 percent confidence interval. Sixteen states have an estimated elasticity that is positive over the period studied, although the variance is large enough in most cases that it is difficult to 
distinguish it from zero. There are a few possible explanations for this observation. In the early years that were studied, when prices were rising, these states saw consistent increases in demand, and in the later time period, when prices were declining in real terms, these states did not have rapid growth in demand. Therefore, overall, it would appear that the demand-price relationship reacts differently in these states than in other states. We caution, however, that it is possible that in the future, increases in prices in these states would not lead to increases in demand, but that the demand in these states would indeed slow or decrease in a manner similar to that in other states (although the elasticity might still be substantially less than that in other states).

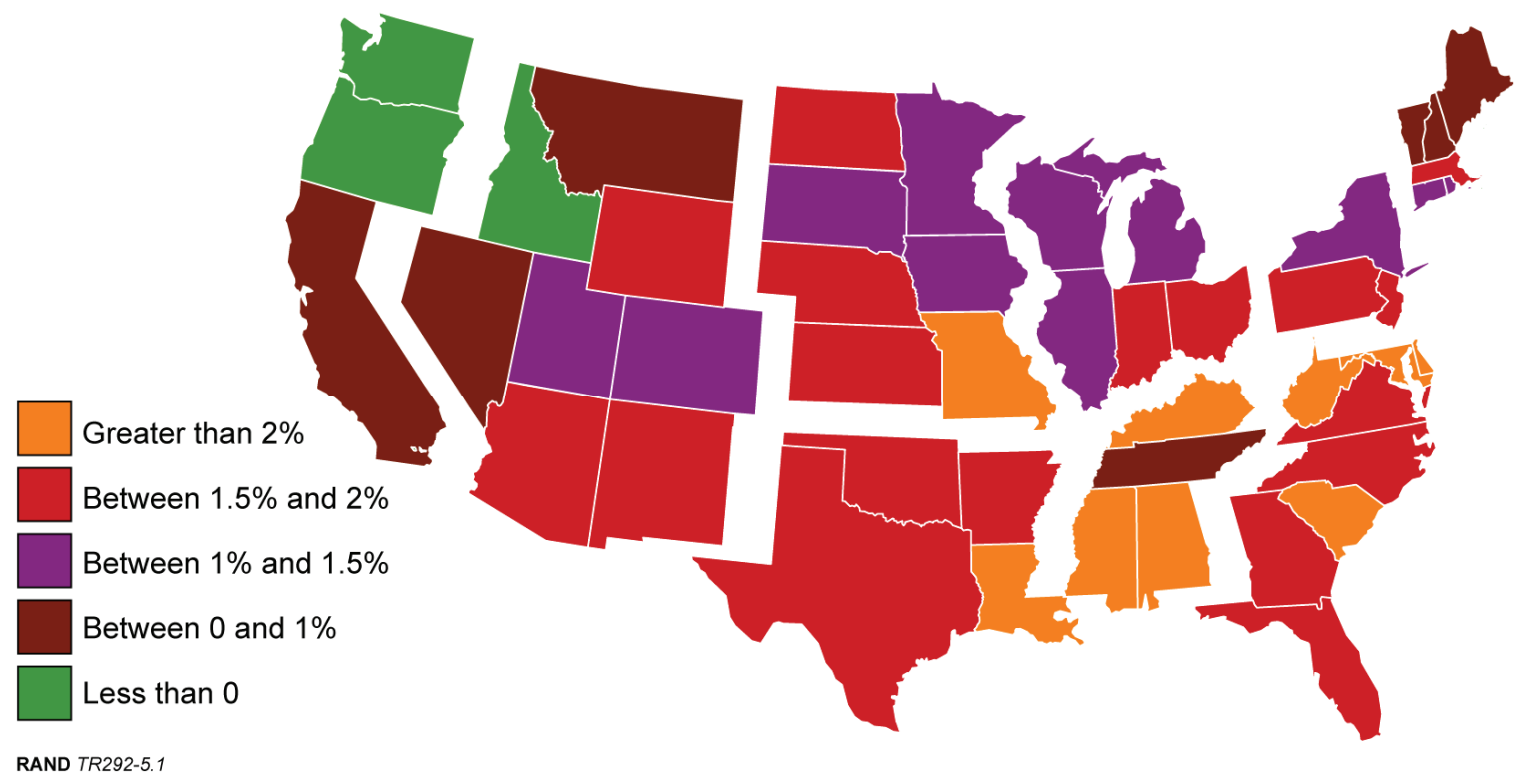

Figure 5.1: State-Level Trends in Residential Electricity Intensity, 1977-2004 


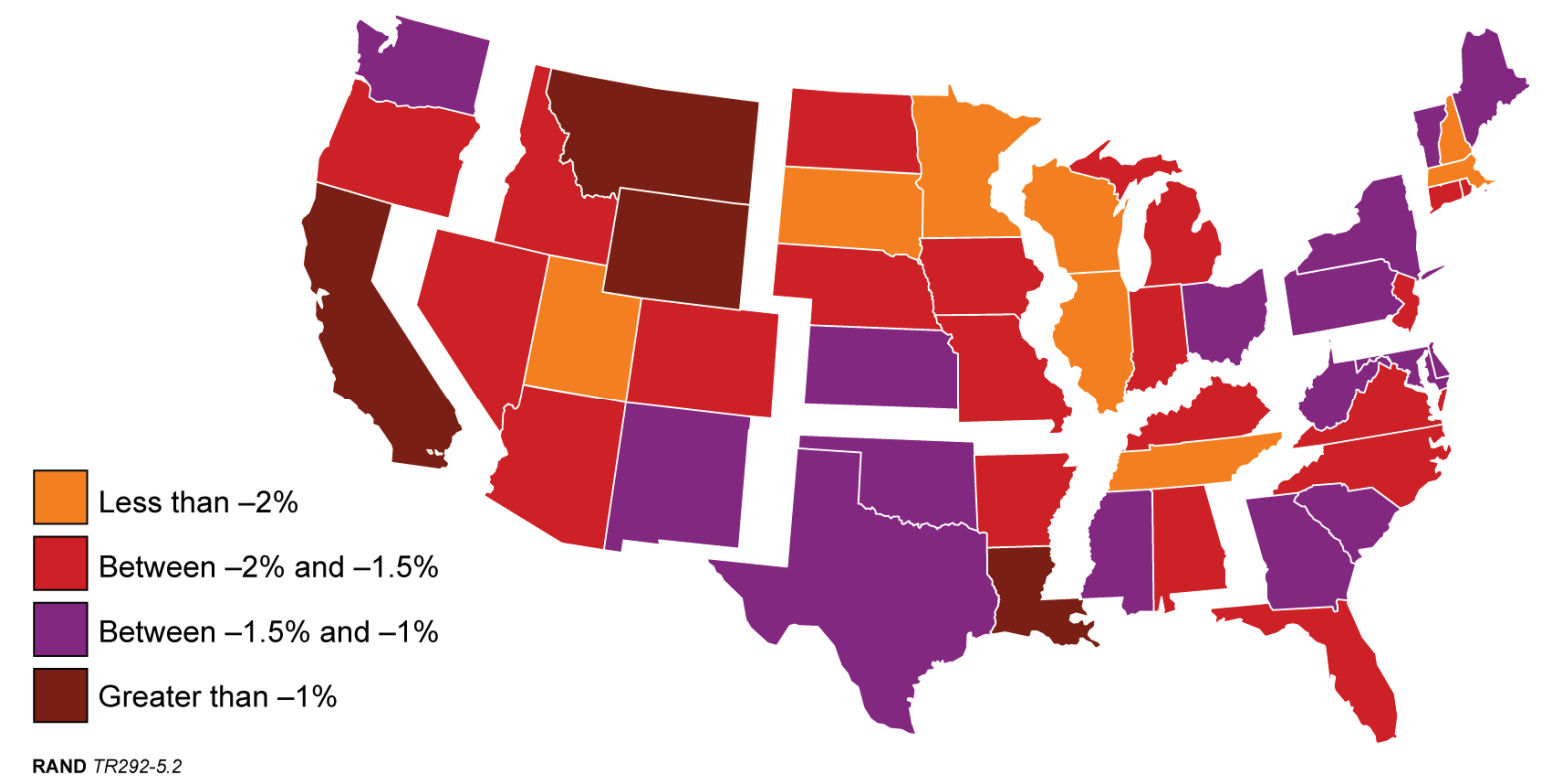

Figure 5.2: State-Level Trends in Residential Electricity Expenditures as a Share of Income, 1977-2004

One other finding of note, illustrated in Figure 5.3, is that there are ten states (represented by the squares on the right-hand side of the figure with positive elasticities) that are significantly different than 11 states represented by the squares on the left-hand side of the figure (all of which have elasticities less than -.2). Given the size of the variances, it is difficult to distinguish differences in price elasticities among the other states.

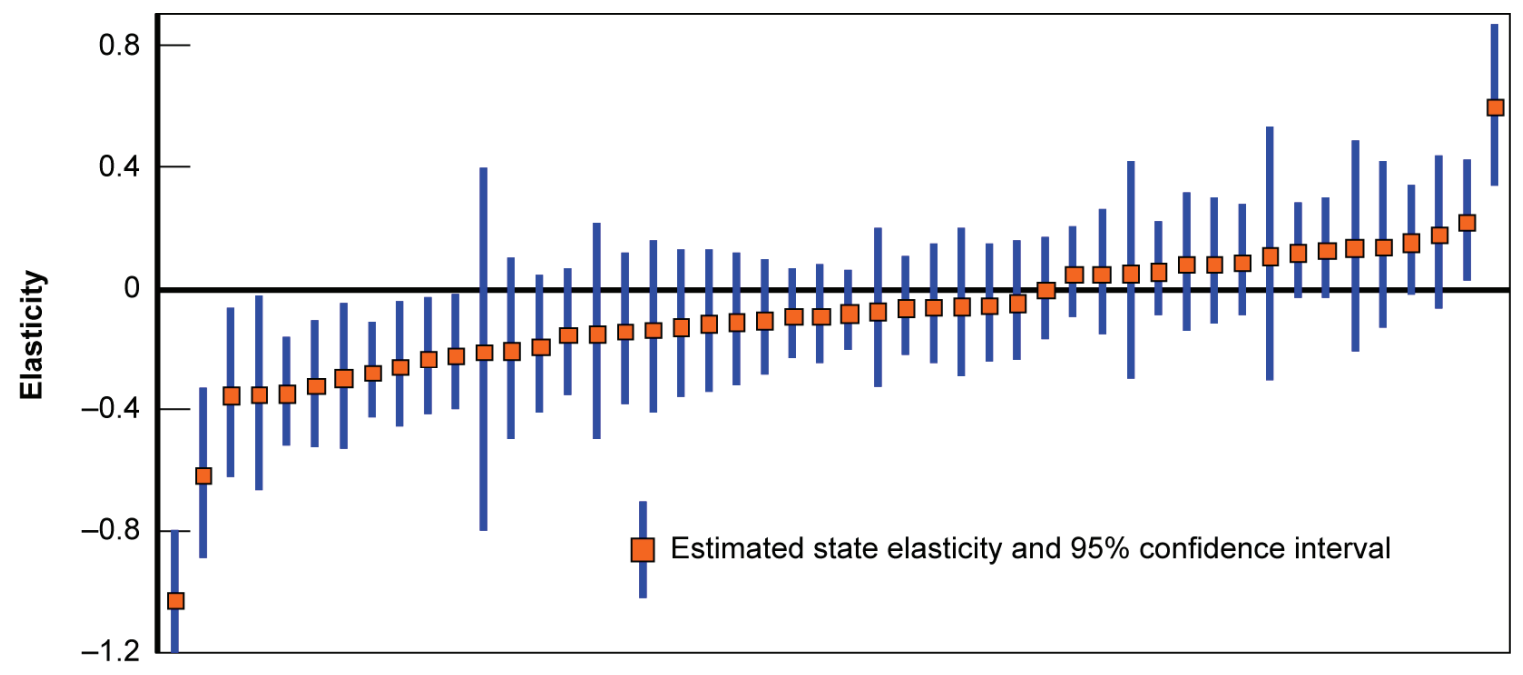

RAND TR292-5.3

Figure 5.3: Estimates of Short-Run Residential Electricity Price Elasticities for Each State, 1977-2004 
In Chapter Four, we illustrated significant differences in elasticities among regions. When we look at the individual state elasticities, some consistencies within the regions emerge. Figure 5.4 shows that several Mountain, West South Central, and West North Central states appear to have similar lower-positive or higher-positive price elasticities for residential electricity. Nevada, Idaho, Utah, Wyoming, Colorado, New Mexico, Oklahoma, Kansas, and Nebraska form a block of states with very inelastic demand (or estimated positive elasticities); the price-demand relationship in these states appears to be somewhat similar. Another broad region with notable results falls in the middle of the country and the Southeast. The group of states from Missouri to Florida has larger-thanaverage price elasticities, with the East South Central and South Atlantic regions showing some inter-regional inconsistencies. States within the Middle Atlantic region are consistent in terms of elasticities, as are the states in the East North Central region (with the exception of Wisconsin). This finding implies that even though there are considerable differences among the states in price elasticities, there are some regional consistencies. Therefore, disaggregation of data by region might still be sufficient for energy-efficiency impact analyses.

As one might expect, the geographic patterns in long-run price elasticity estimates (see Figure 5.5) are similar to those in the short-run price elasticity estimates. The Mountain states have inelastic demand, whereas states in the South Atlantic and East South Central, Pacific Coast, and New England region have more-elastic demand in the long run. The variance in the long-run elasticity estimates is larger than in the short-run estimates, and more states exhibit positive long-run price elasticities than positive short-run price elasticities. Overall, these findings seem to indicate that over the time period studied, electricity demand continued to rise in many of these states, regardless of price. Given the prices and demand that were observed over this time period, it is not clear whether any conclusions can be made about how long-run demand would react to price increases. We can say, again, that there appear to be regional differences, but consistencies among states within the regions, in the long-run price-demand relationship. 


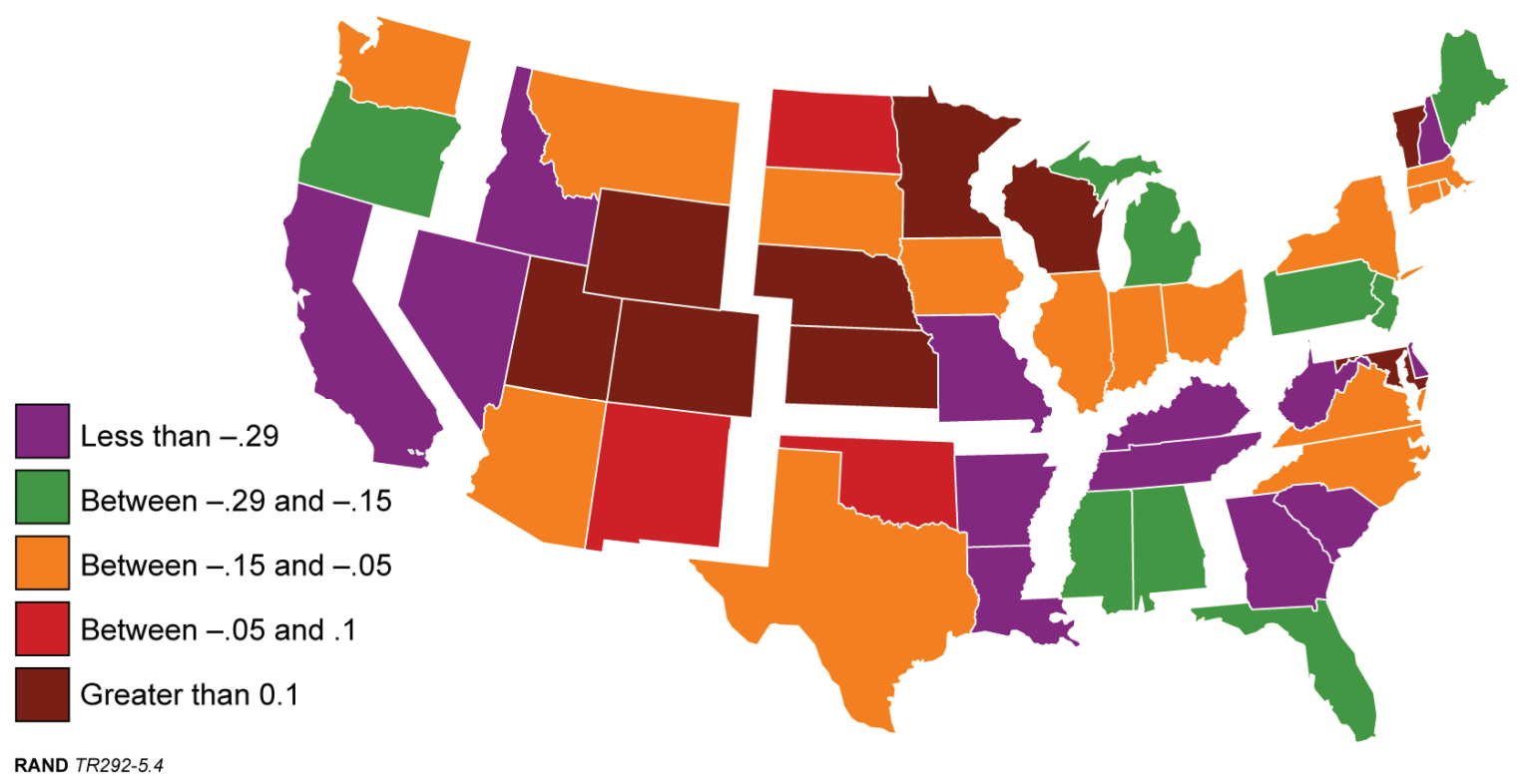

Figure 5.4: Estimated State-Level Short-Run Price Elasticities for Residential Electricity, 1977-2004

Overall, the findings presented in this section imply that while regional disaggregation will be important for estimating future impacts of energy-efficiency technology and forecasting demand for residential electricity, state-level disaggregation may not be necessary for that purpose.

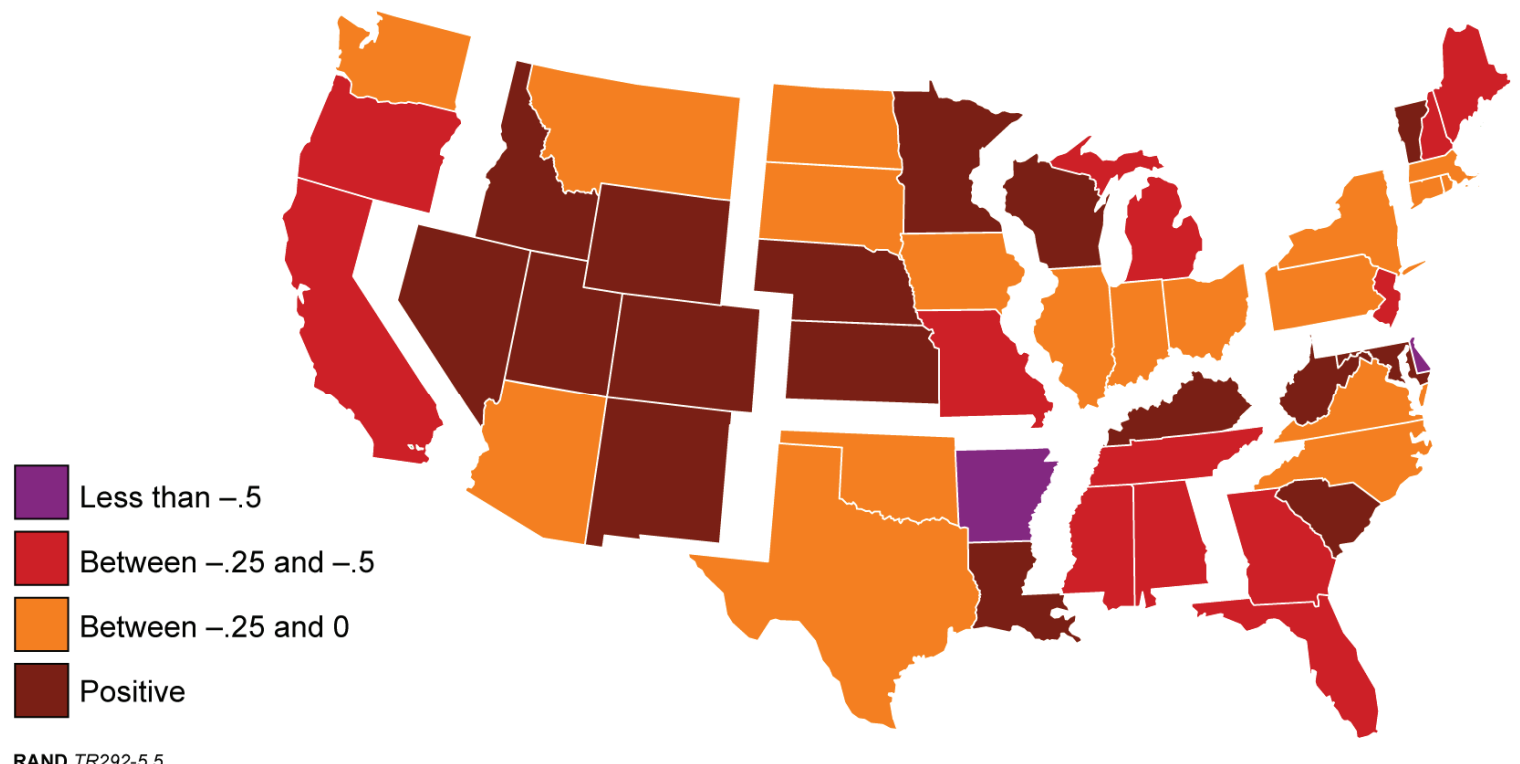

Figure 5.5: Estimated State-Level Long-Run Price Elasticities for Residential Electricity, 1977-2004 


\section{Commercial Electricity}

The state-level analysis of the commercial electricity sector reveals a pattern of electricity usage similar to that at the regional level - there seems to be some state-level variation in electricity use patterns, but few differences in the price-demand relationship. Figure 5.6 shows trends in commercial electricity use per square foot of office space (i.e., the trends in intensity). We see the slowest growth in electricity use in states in the West, although a few of those states show a slow growth in intensity. There is some consistency in intensity among states within regions. For the most part, states within a region fall into one of two consecutive categories of growth. Again, this finding seems to indicate that the regional analysis would be sufficient to capture any differences that might exist in electricity intensity in the commercial sector.

The estimated elasticities in commercial-sector intensity are what we might expect from the previous sets of analysis. Figure 5.7 shows the estimated state-level short-run elasticities. There is not much variation across the states in intensity, except for a few that are represented at the left side of the figure. For the most part, the estimated elasticities range between -.5 and zero, with a few states with positive elasticity (that is not significantly different from zero), and a few states that seem to have more-elastic demand. It is interesting to note that for a large number of states, the variance is small, which means that the elasticities are well estimated. This is in contrast to the residential sector, in which the variance is large for a number of states. There is also more variation among the states in the residential-sector analysis in comparison with the commercialsector analysis, which shows little variation among the states. We observed the same sort of patterns for the long-run elasticities.

Clearly, there does not seem to be a reason to disaggregate the analysis for commercial electricity to the state level. 


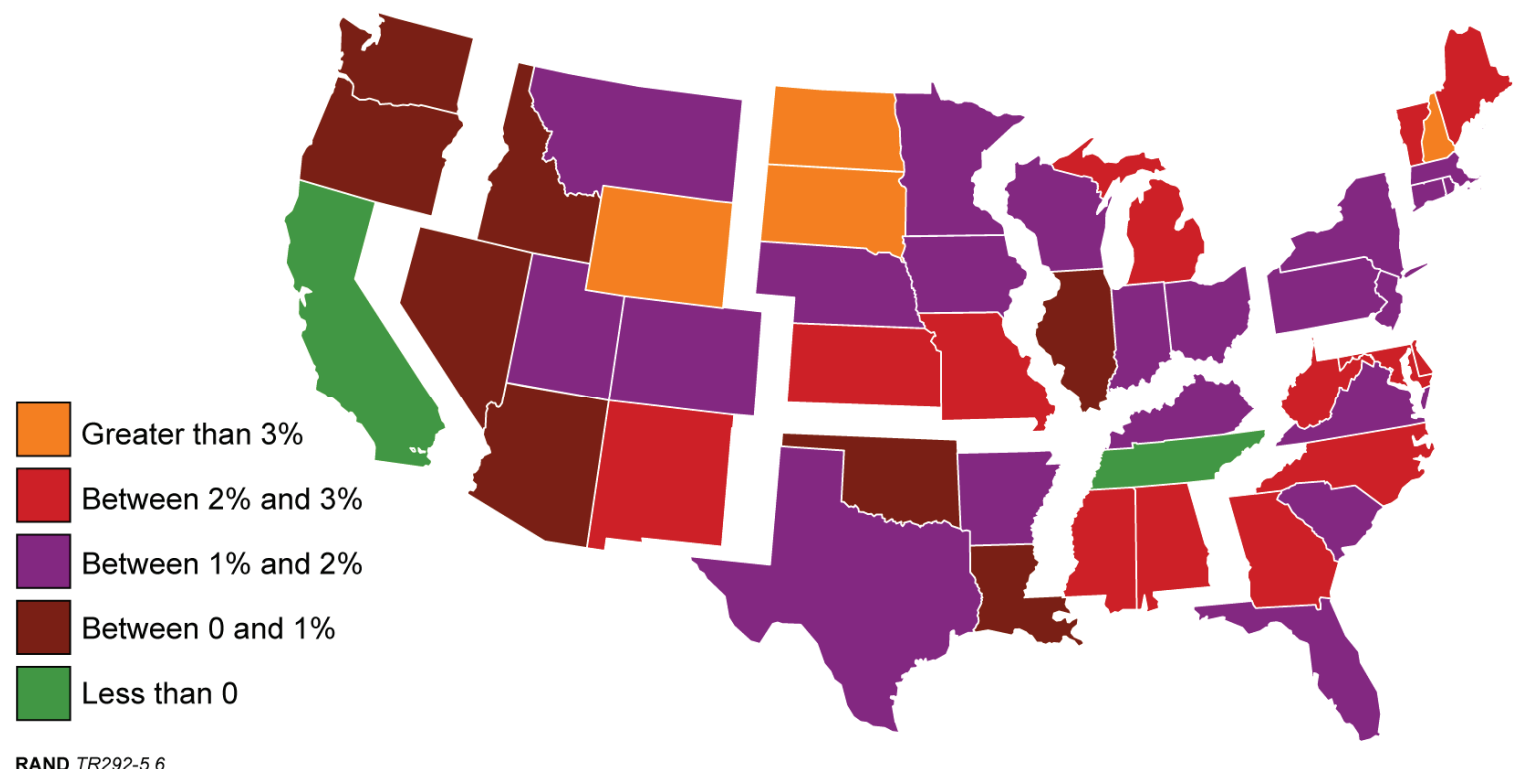

RAND TR292-5.6

Figure 5.6: Estimated State-Level Trends in Electricity Intensity in the Commercial Sector, 1977-1999

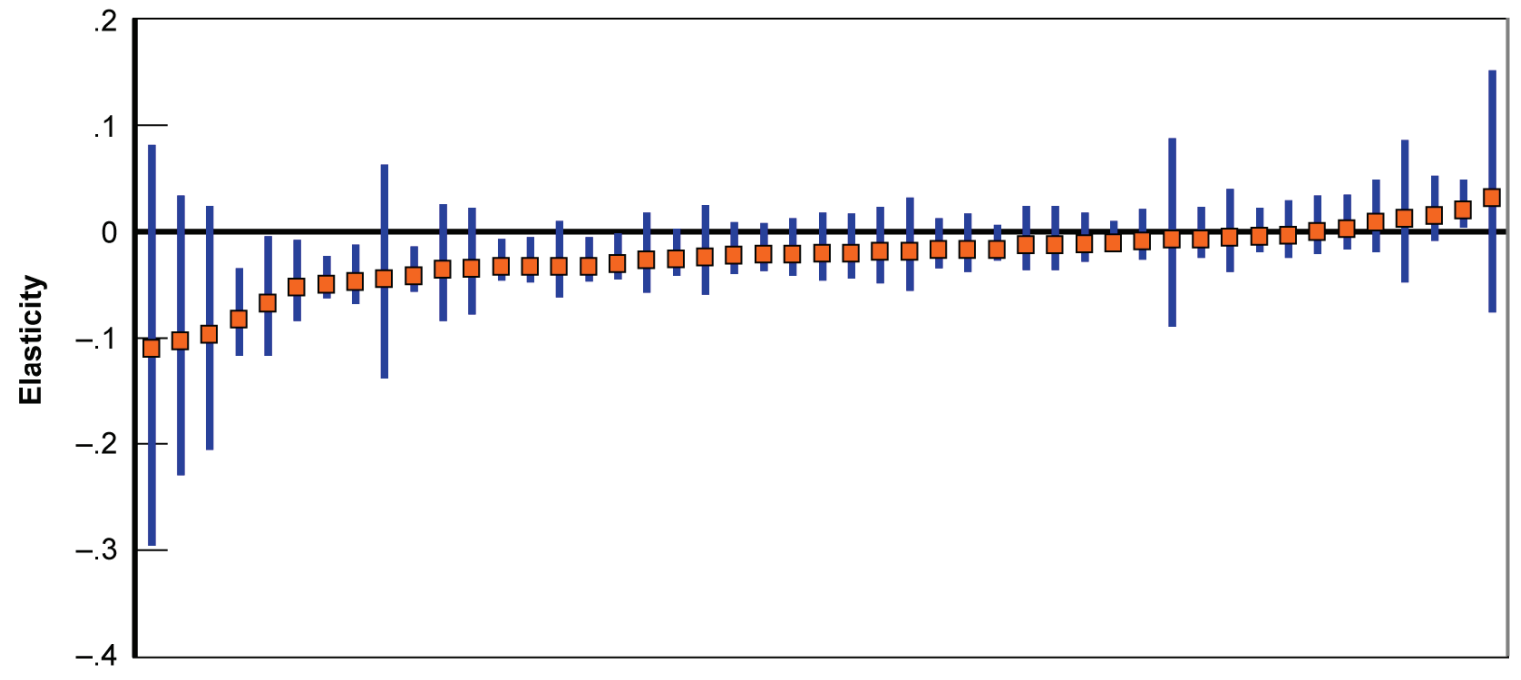
RAND TR292-5.7

Figure 5.7: Estimated Short Run Elasticities in Electricity Intensity in the Commercial Sector at the State Level, 1977-1999 


\section{Residential Natural Gas}

Because the regional-level results for residential natural gas showed little regional diversity and a lot of variance in the estimates, it is not surprising that we find basically the same results at the state level. There are differences among states, which become evident when looking at natural-gas intensity at the state level (see Figure 5.8). What is also evident is that there is significant variation among states within regions, with the notable exception of the East North Central and the West South Central, where the trends in natural gas use per capita are fairly consistent. Otherwise, there is not much in the way of observed patterns to note. There are more states in the North that have growing natural-gas intensities, but a group of states in the South Atlantic (and Tennessee) also have growing intensities.

Given these findings, it is not surprising that we also find some large differences among the states in estimated short-run price elasticities for natural gas (see Figures 5.9a and $5.9 \mathrm{~b})$ along with very large variances among the states. The price elasticities range from -.3 to .1 , which is quite a broad range, but the variances are so large that we cannot even say that states at the extreme low end of the range are statistically different from other states. Reflecting what we observed at the regional level, there is not much in the way of consistency among states within the regions in terms of price elasticity. There is a group of contiguous states ranging from the middle of the country to the East Coast that have some similarities in elasticities. But again, because the variances are so large, there is not much we can interpret from these results, and there does not seem to be much of a reason to assess natural-gas demand and the benefits of energy-efficiency technologies at the state level. 


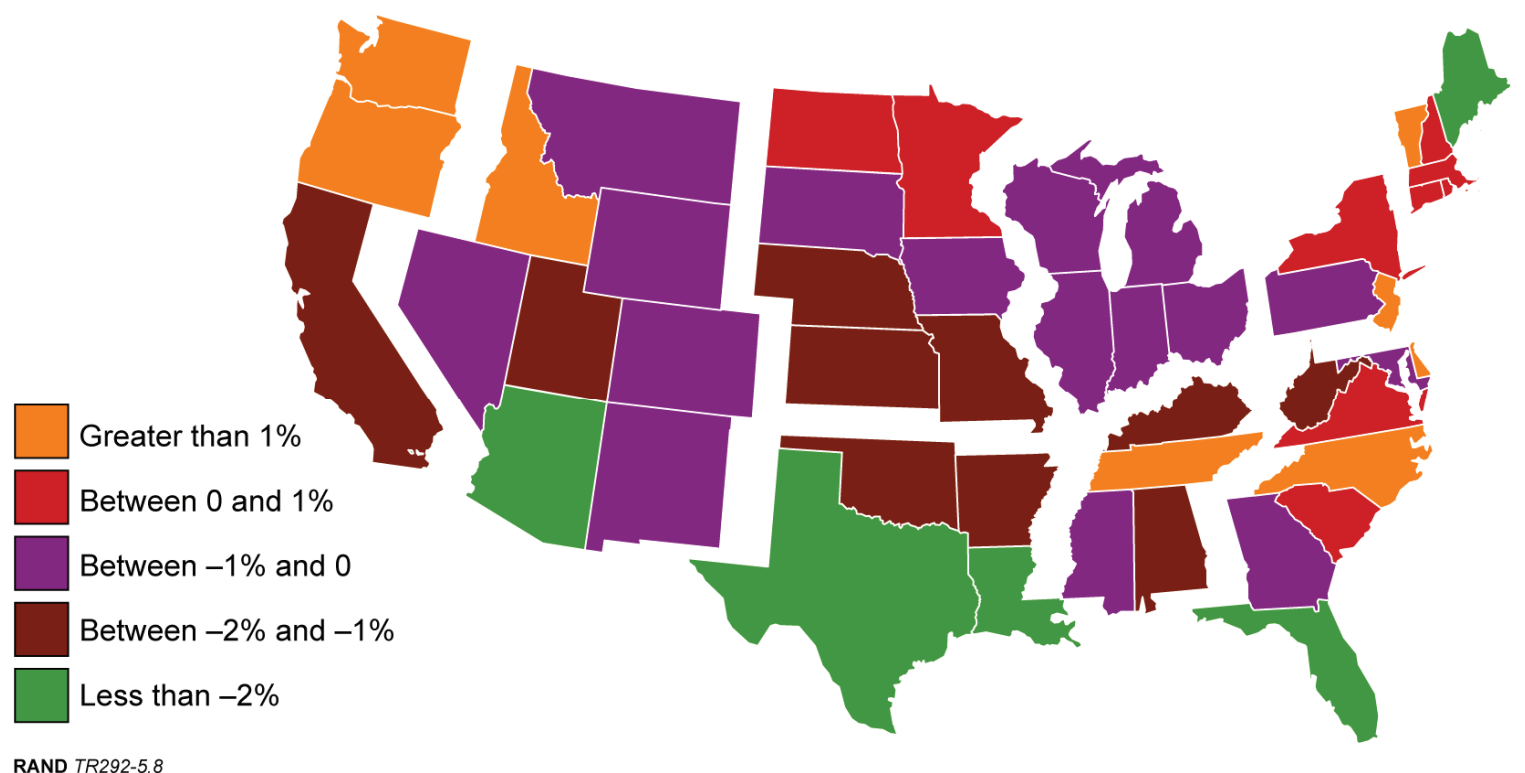

Figure 5.8: Trends in Natural-Gas Intensity at the State Level, 1977-2004

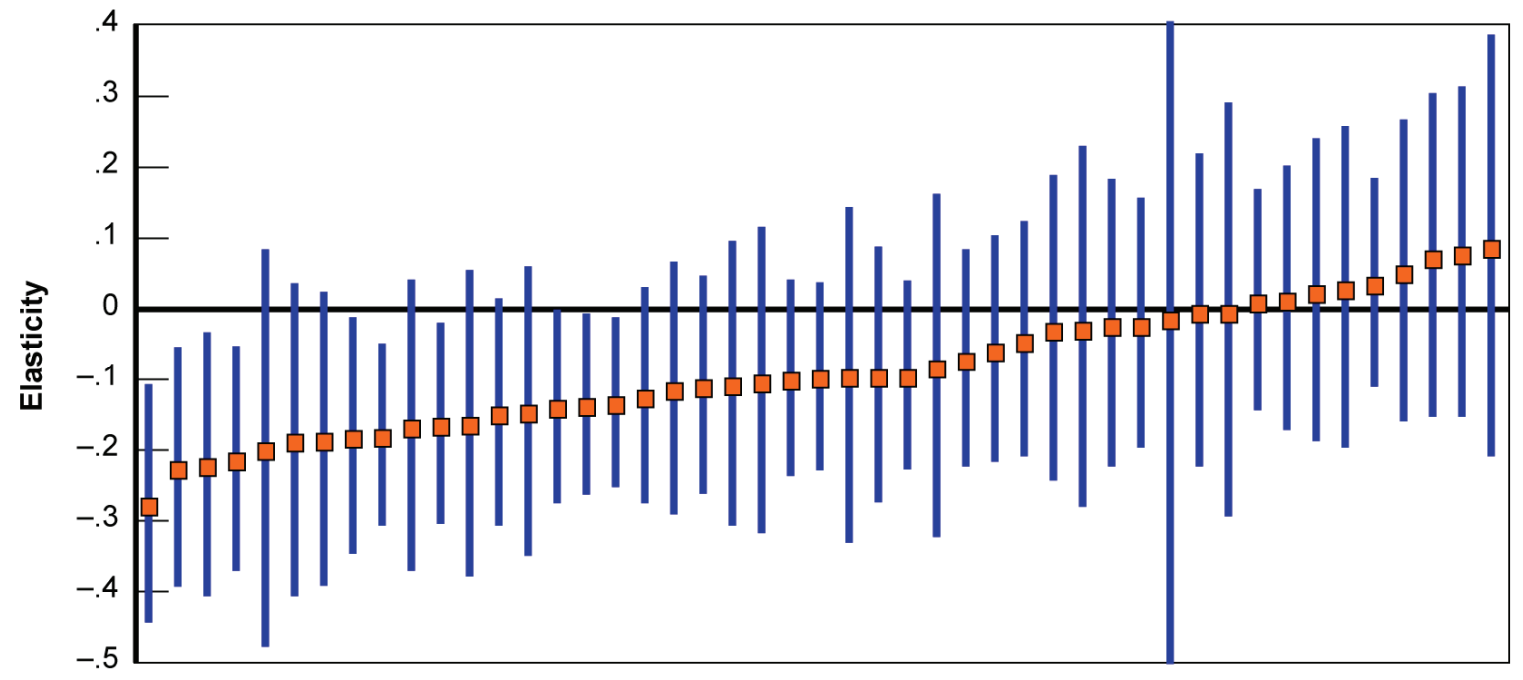

RAND TR292-5.9a

Figure 5.9a: Estimated Short-Run Price Elasticities for Natural Gas at the State Level, 1977-2004 


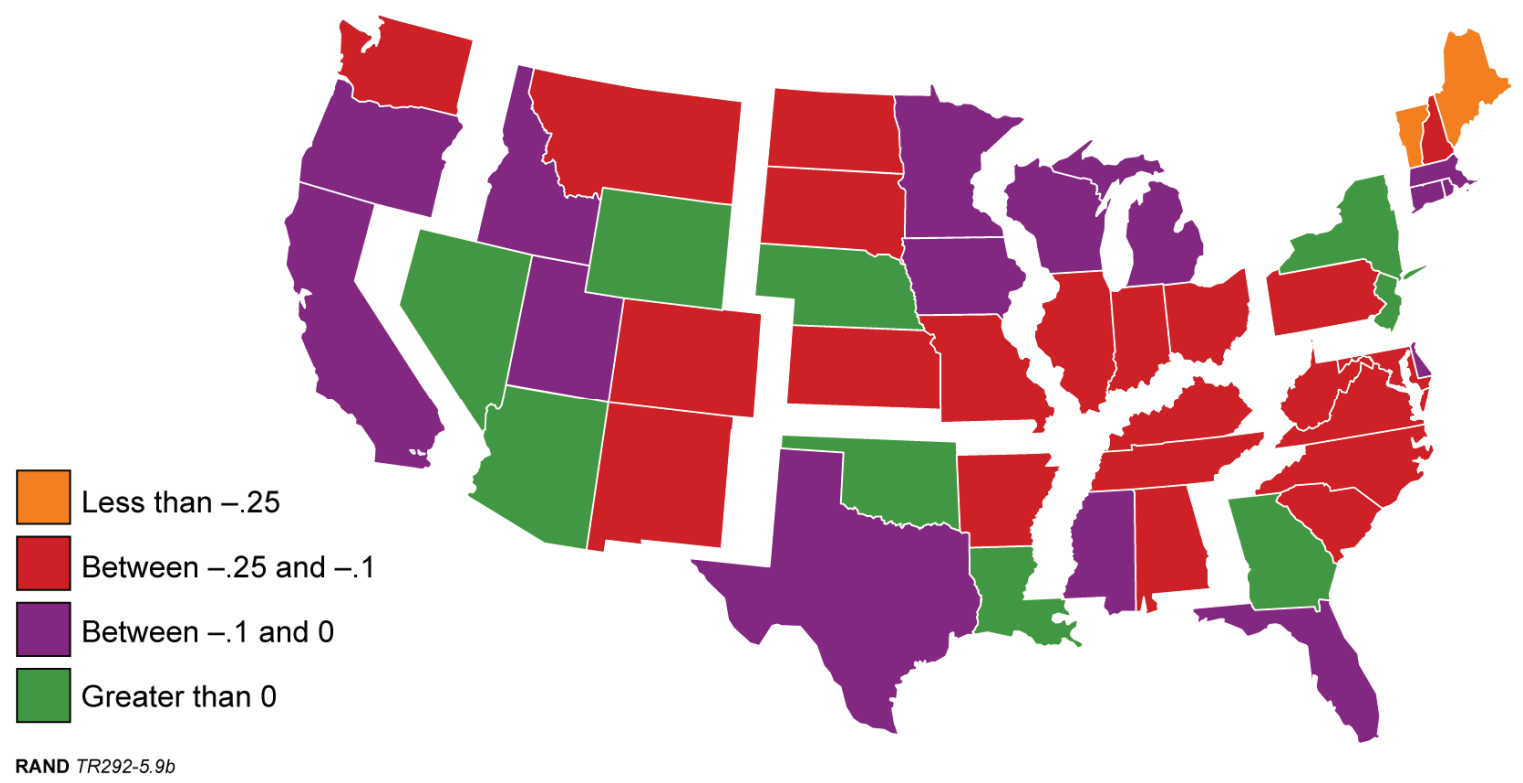

Figure 5.9b: Short-run Price Elasticities for Natural Gas

\section{State-Level Conclusions}

There are differences among the states in price elasticities and in some trends in energy use and other factors, but, for the most part, they are not significant. As was seen with the regional analysis, there is a difference between the results of the residential electricity analysis and those of commercial electricity and residential natural-gas analyses. For residential electricity use, there is enough consistency among states within regions that a state-level disaggregation would not likely produce different results than would regionallevel analyses for forecasting the estimated benefits of energy-efficient technologies.

For commercial electricity and residential natural gas, there is not much consistency among states, and there are significant amounts of variance in the estimates; therefore, it is not certain that one could use our approach to differentiate states to a degree that would be useful in forecasting estimates of energy-efficiency benefits. 


\section{Chapter 6: Utility-Level Analysis}

The utility-level analysis posed a number of analytical challenges, which limited the conclusions that we were able to draw from our analysis. While consumption and price data at the utility level were available in the database that we used, data on other factors that are key to the price-demand analysis (such as income and climate) were not. As such, we used state-level data in place of the unavailable utility-level data. Nevertheless, we continued with the experiment to see if there appear to be significant differences in how price and demand respond at the utility-scale level, simply to glean whatever information that might contribute to this study.

We did discover a few interesting things in this analysis. First, there is a lot of variation in elasticities among the utilities, which was not unexpected, although the price elasticities for about 65 percent of the sample are not statistically significant. Figure 6.1 illustrates the percentage of the sample of utilities that are in each region (shown in Figure 4.1), and of those, the percentage with estimated price elasticities that are statistically significant. There are no apparent regional consistencies, other than the South Atlantic and East North Central regions having the highest percentage of utilities with significant elasticities. For most regions, the percentage of utilities in the region and the percentage with significant estimates are very similar. At one end, the East North Central region had about 5 percent more utilities with statistically significant price elasticities, as a proportion of all utilities in the dataset, than the region's percent of the total number of utilities in the data set, and the Mountain region had more than 5 percent fewer utilities with statistically significant price elasticities.

The price-elasticity estimates are wide-ranging and have limited precision. The range of elasticities for the statistically significant estimates was 1.1 to -1.87 . The median was -0.57 , and the mean was -0.63 .

Size of a utility appears to be correlated with the elasticity estimate. The range of elasticity estimates for the largest utilities (the median is -0.25 , and the mean is -0.29 ) is 
similar to the range of estimates found in the state analysis. There is greater variability in the elasticity estimates observed in the small utilities, which results in a larger range of estimates.

Overall, we cannot conclude much from the utility-level analysis, other than the large amount of variation in price elasticities suggests that it may be useful to delve further into analyzing utility-level electricity demand. Further analysis may produce information that is valuable for planning and estimating energy efficiency at this level.

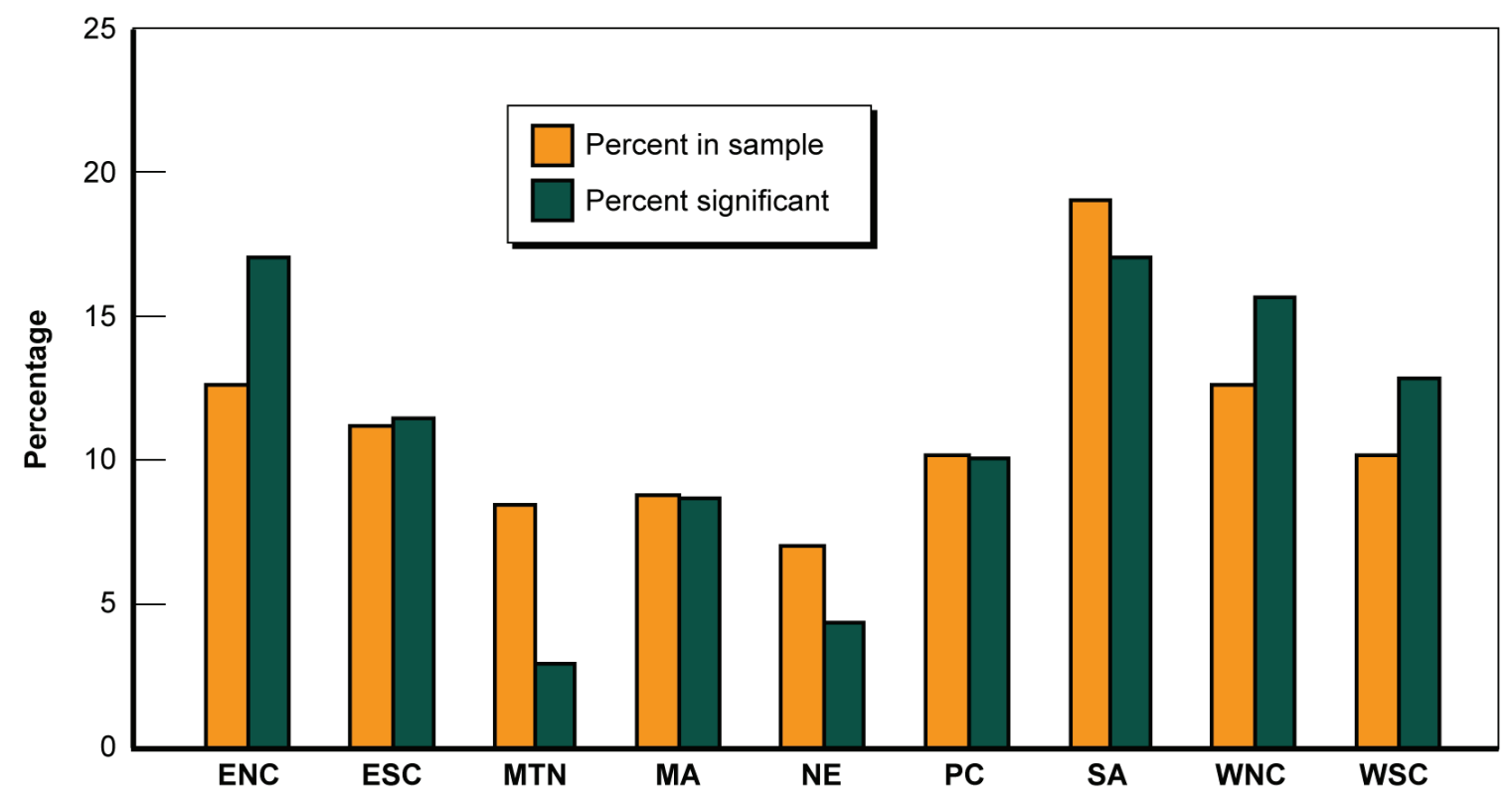
RAND TR292-6. 1

Figure 6.1: Percentage of Utilities in the Sample within Each Region and Percentage in Each Region with Significant Elasticities 


\section{Chapter 7: Conclusions, Final Thoughts, and Implications of Analysis}

This chapter reviews the results of our analysis and their implications and presents our recommendations for further analysis. The key findings from this study are as follows:

- There are state and regional differences in (1) electricity and natural-gas demand, (2) the relationship between changes in demand and changes in price (i.e., elasticity), and (3) factors that influence demand.

- It is difficult, with the data we have available, to show statistically significant differences at all levels for commercial electricity and residential natural gas, though our results do indicate there may be regional and state differences in how price and demand interact in each of those sectors.

- We found significant regional differences in the price-demand relationship for residential electricity, but also found consistencies in the price-demand relationship for residential electricity among states within regions.

- The price-demand relationships have not changed over the past couple of decadesour estimates are about the same as those from studies done in the 1980s.

- Price elasticity - -i.e., how demand reacts to changes in price overall- has continued to be small since the 1980s.

- Over the periods we examined (1977-2004 for residential electricity and natural gas, 1977-1999 for commercial electricity, and 1989-1999 for residential electricity at the utility level), some basic trends emerged: Demand for energy overall is increasing; in many cases, energy intensity is increasing, but price is decreasing; and, while expenditures on energy are increasing, energy expenditures as a share of consumers' income and as a share of commercial sector output are declining.

- The past few years have seen some changes in these patterns, and it is possible that some of these trends and relationships might exhibit further changes. 


\section{Should DOE Disaggregate Data for Estimating Energy-Efficiency Programs Benefits?}

The results of this study have a number of implications for the DOE's decisionmaking and policymaking. The basic question that was the impetus for this analysis was whether the DOE should disaggregate data (from the national level to the regional, state, or utility level) when estimating the benefits of its energy-efficiency programs. The answer to this question has a number of components.

We first made the case that certain factors might affect the impact that energy efficiency would have on overall demand. We also made the case that the price-demand relationship, or price elasticity, was important for estimating the impact of energyefficiency programs and technology. In examining demand in each sector (residential and commercial electricity demand and residential natural-gas demand), we found that there are some differences in regional trends - in particular, trends in the intensity of energy use. Energy efficiency might have a bigger impact on regions with rapidly growing intensity of use than on regions with intensity that is either declining or growing slowly.

In terms of the price-demand relationship, if increasing prices motivate investments in energy efficiency, then the impact of energy efficiency might be greater in regions or states that are the most elastic (i.e., those with the lowest negative price elasticities). In these regions and states, the price-demand relationship is the most robust, and changes in

price could lead to greater changes in energy efficiency, and vice-versa. Any estimates of the impact of energy-efficiency programs will be impacted by price elasticity, and if the elasticity differs significantly by region or state, the estimates of the impacts will differ accordingly.

In the case of the residential electricity sector, it is clear that there are regional differences. It also seems clear that the elasticities are relatively consistent among states within the regions and that, at least for the near term, disaggregating data on energyefficiency programs to the regional level should be sufficient to evaluate the different effects that energy efficiency could have in different regions of the country. 
The results are less clear for the commercial electricity sector. Few regions appear to have significantly different trends in the intensity of electricity use (specifically the Pacific Coast and perhaps the West North Central and East South Central regions, which have had slower growth). Statistically, it is difficult to distinguish among the other regions in terms of intensity of use, and there are no discernable differences in the price elasticities between regions. It does seem that the impact of energy efficiency in the Pacific Coast would differ from the impact in the rest of the country, and perhaps disaggregating Pacific Coast data from the national-level data is all that is needed to estimate the impact of certain DOE programs. On the other hand, there is some consistency in price elasticities among states within regions, such as what was seen in the residential electricity sector, although not to as great an extent. This finding does suggest that a state-level analysis would not be necessary in the short term.

The results are even less clear for the residential natural-gas sector. As in the commercial sector, only a couple of regions (again, the Pacific Coast and the West South Central region) seem to differ from the rest in all the factors we examined. But there is little consistency in the states within the DOE regions and little statistical difference among the estimated elasticities for each region. If one uses the estimated elasticities, the impact of energy-efficiency programs in the Pacific Coast and in the West South Central region would differ if one were to compare the two regions. This makes interpreting the findings on residential natural gas use more difficult than interpreting the findings for the other energy sectors. One finding of note is that the changes in demand for natural gas are smaller than those for electricity over the time period studied, so perhaps national-level analysis would be sufficient for determining the impact of energy-efficiency programs on demand in the residential natural-gas market.

\section{Price Elasticity of Demand}

The results on price elasticity are interesting. Our elasticity estimates are no different from those from ten to 20 years ago. This indicates that the relationship between price

and demand has not changed even though (1) 15 to 20 additional years of empirical data 
are available; (2) there have been changes and shifts in energy use, in particular the introduction of new electricity-using devices; (3) there have been large increases in airconditioning loads; and (4) appliances are more energy efficient than they were 15 to 20 years ago.

In addition, the elasticities remained the same over the past two decades-i.e., they remained low. In other words, demand did not tend to react much to changes in price. There are small, and somewhat consistent, changes, but on the surface it seems that there are few options for consumers or commercial businesses to switch to electricity or natural gas use in response to energy prices.

These observations, however, might be driven more by the trends in factors affecting intensity than by how consumers react to changes in price. Over the time period studied, we observed the following general trends:

- Energy prices heading downward

- Energy costs as a share of income also heading downward

- Energy use rising.

Given these trends, it is difficult to find significant variations in the price-demand relationship, because prices and demand have not varied much. Also, it is difficult to achieve improvements in energy efficiency when energy costs continue to decline, beyond those that "naturally" occur through technology improvements.

On the other hand, it is possible that the price-demand relationship is changing. First, just anecdotally, when California was facing energy problems in 2000 and 2001, a combination of factors led to a significant reduction in residential electricity use, with reductions in electricity demand estimated to be as high as 9 percent in response to government policy, media coverage, and rising prices. At least in a case such as that, consumers will change their demand behavior in the short term in response to energy prices and energy policy. 
In the past few years, we have witnessed a reversal of the downward price trends and, at the same time, we have seen a reversal in the upward trend in electricity intensity in a number of states. Overall, prices have not been declining as rapidly, and energy use has not been increasing as rapidly either. So, it is possible that with an increasing-price regime, one might see a different demand-price relationship than what would be observed in a decreasing-price regime. More study and analysis would be needed to uncover these trends. 


\section{Bibliography}

Bentzen, Jan, and Tom Engsted, "A Revival of the Autoregressive Distributed Lag Model in Estimating Energy Demand Relationships,” Energy, Vol. 26, 2001, pp. 45-55.

Bernstein, Mark, Kateryna Fonkych, Sam Loeb, and David S. Loughran, State-Level Changes in Energy Intensity and Their National Implications, Santa Monica, Calif.: RAND, MR-1616-DOE, 2003.

Bernstein, Mark, Robert J. Lempert, David S. Loughran, and David Ortiz, The Public Benefit of California's Investments in Energy Efficiency, Santa Monica, Calif.: RAND, MR-1212.0-CEC, 2000.

Bohi, Douglas R. and Mary Beth Zimmerman, “An Update on Econometric Studies of Energy Demand Behavior,” Annual Review of Energy, Vol. 9, 1984, pp. 105-154.

Dahl, Carol A., "Do Gasoline Demand Elasticities Vary?” Land Economics, Vol. 58, No. 3, August 1982, pp. 373-382.

Dahl, Carol A. and Thomas Sterner, "Analysing Gasoline Demand Elasticities: A Survey," Energy Economics, July 1991, pp. 203-210.

Dubin, Jeffrey A. and Daniel L. McFadden, “An Econometric Analysis of Residential Electric Appliance Holdings and Consumption," Econometrica, Vol. 52, No.2, March 1984, pp. 345-362.

Garcia-Cerutti, L. Miguel, "Estimating Elasticities of Residential Energy Demand from Panel County Data Using Dynamic Random Variables Models with Heteroskedastic and Correlated Error Terms," Resource and Energy Economics, Vol. 22, 2000, pp. 355-366.

Griffin, James M., and Craig T. Schulman, "Price Asymmetry in Energy Demand Module: A Proxy for Energy-Savings Technical Change," The Energy Journal, Vol. 26, No. 2, 2005, pp. 1-21.

Houthakker, H .S., Philip K. Verleger, Jr., and Dennis P. Sheehan, "Dynamic Demand Analyses for Gasoline and Residential Electricity," American Journal of Agricultural Economics, Vol. 56, No. 2, May 1974, pp. 412-418.

Hsing, Yu, "Estimation of Residential Demand for Electricity with the Cross-Sectionally Correlated and Time-wise Autoregressive Model," Resource and Energy Economics, Vol. 16, 1994, pp. 255-263. 
Maddala, G. S, Robert P. Trost, Hongyi Li, and Frederick Joutz, "Estimation of ShortRun and Long-Run Elasticities of Energy Demand from Panel Data Using Shrinkage Estimators," Journal of Business \& Economic Statistics, Vol. 15, No. 1, January 1997, pp. 90-101.

Mead, Walter J., Timothy D. Mount, Richard L. Gordon, and A. Myrick Freeman III, "Discussion on McDonald, Searl, Perry, Houthakker, Verleger, Jr., Sheehan, and Wilson," American Journal of Agricultural Economics, Vol. 56, No. 2, May 1974, pp. 427-435.

North American Electricity Reliability Council, "2005 Summer Assessment: Reliability of Bulk Electricity Supply in North America," May 2005.

O’Neill, Brian C., and Mausami Desai, “Accuracy of Past Projections of U.S. Energy Consumption," Energy Policy, Vol. 33, 2005, pp. 979-993.

Pesaran, M. Hashem, and Ron Smith, "Estimating Long-Run Relationships from Dynamic Heterogeneous Panels," Journal of Econometrics, Vol. 68, 1995, pp. 79-113.

Taylor, Lester D., "The Demand for Electricity: A Survey," The Bell Journal of Economics, Vol. 6, No. 1, Spring 1975, pp. 74-110.

U.S. Department of Energy, National Transmission Grid Study, Washington, D.C.: DOE, May 2002.

Wooldridge, Jeffrey, Econometric Analysis of Cross Section and Panel Data, Cambridge, Mass.: MIT Press, 2002.

Wooldridge, Jeffrey, Introductory Econometrics: A Modern Approach, Cincinnati, Ohio: South-Western College Publishing, 1994. 


\section{Appendix A}

\section{Details on the Methodology Used to Estimate Elasticities}

The primary goal of this study is to measure how the energy-demand relationship varies at different levels of spatial aggregation (i.e., at the national, regional, state, and utility level). We model the demand relationship as a function of four components:

- measured variables that vary across states and within states over time — such as energy prices, income, population, and climate

- fixed differences between states - unmeasured variables that do not change in the study period but that differ across states

- an aggregate time trend - one that accounts for unmeasured variables common to all states, such as federal policy

- a random error term that varies across and within states.

We estimate this model with the following fixed-effects specification:

$$
\mathrm{Q}_{\mathrm{i}, \mathrm{t}}^{\mathrm{D}_{\mathrm{t}}}=\mathrm{Q}_{\mathrm{i}, \mathrm{t}-1}^{\mathrm{D}} \gamma+\mathrm{X}_{\mathrm{i}, \mathrm{t}} \beta+\mathrm{X}_{\mathrm{i}, \mathrm{t}-1} \alpha+\mathrm{s}_{\mathrm{i}}+\mathrm{y}_{\mathrm{t}}+\varepsilon_{\mathrm{i}, \mathrm{t}}
$$

where $\mathrm{Q}_{\mathrm{i}, \mathrm{t}}^{\mathrm{D}}$ is $\log$ energy demand in state $i$ and year $t, \mathrm{Q}_{\mathrm{i}, \mathrm{t}}^{\mathrm{D}}$ is the lag value of $\log$ energy demand, $X_{i, t}$ is a set of measured covariates (e.g., energy prices, population, income, and climate) that affect energy demand, and $\mathrm{X}_{\mathrm{i}, \mathrm{t}-1}$ is the lag values of the covariates. The residual has three components:

- $s_{i}$ is an indicator variable that captures time-invariant differences in energy demand across states ("state fixed effects").

- $y_{t}$ is an indicator variable that captures time effects common to all states ("year fixed effects").

- $\varepsilon_{i, t}$ is a random error term.

We based this specification on the flow-adjustment model developed by Houthakker et al. (1974). In this model, demand is a function of prices, income, population, and climate.

$\mathrm{Q}^{\mathrm{D}^{*} \mathrm{i}, \mathrm{t}}=\mathrm{f}\left(\mathrm{P}_{\mathrm{i}, \mathrm{t}}, \mathrm{P}_{\mathrm{i}, \mathrm{t}}^{\mathrm{C}}, \mathrm{Y}_{\mathrm{i}, \mathrm{t}}\right.$, Pop $_{\mathrm{i}, \mathrm{t}}$, Climate $\left._{\mathrm{i}, \mathrm{t}}\right)$

where $\mathrm{Q}^{\mathrm{D}^{*}}$ denotes desired demand in time t. The model assumes the following adjustment process between periods:

$\mathrm{Q}_{\mathrm{i}, t}^{\mathrm{D}} \mathrm{Q}_{\mathrm{i}, \mathrm{t}-1}^{\mathrm{D}}=\left(\mathrm{Q}^{\mathrm{D}^{*}, t} \mathrm{Q}_{\mathrm{i}, \mathrm{t}-1}\right)^{\theta}$ 
where $0<\theta<1$. The estimating equation then becomes the following:

$\ln Q_{i, t}^{D_{i, t}}-\ln Q_{i, t-1}^{D}=\theta \ln Q^{D^{*}}{ }_{i, t}-\theta \ln Q^{D_{i, t-1}}$

$\ln \mathrm{Q}^{\mathrm{D}}{ }_{\mathrm{i}, \mathrm{t}}=\theta \ln \mathrm{Q}^{\mathrm{D}^{*}}{ }_{\mathrm{i}, \mathrm{t}}+\ln \mathrm{Q}^{\mathrm{D}}{ }_{\mathrm{i}, \mathrm{t}-1}-\theta \ln \mathrm{Q}^{\mathrm{D}}{ }_{\mathrm{i}, \mathrm{t}-1}$

$\ln \mathrm{Q}_{\mathrm{i}, \mathrm{t}}^{\mathrm{D}}=\theta \ln \mathrm{Q}^{\mathrm{D}^{*}, \mathrm{t}}+(1-\theta) \ln \mathrm{Q}_{\mathrm{i}, \mathrm{t}-1}^{\mathrm{D}}$

Then, by substituting in a linear function for $\mathrm{Q}^{\mathrm{D}^{*}}{ }_{\mathrm{i}, \mathrm{t}}$, the final form is the following:

$\ln \mathrm{Q}^{\mathrm{D}, \mathrm{t}}=\theta \ln \alpha+\theta \gamma \ln \mathrm{p}_{\mathrm{i}, \mathrm{t}}+\theta \beta \ln \mathrm{X}_{\mathrm{i}, \mathrm{t}}+\theta \beta \ln \mathrm{X}_{\mathrm{i}, \mathrm{t}-1}+(1-\theta) \ln \mathrm{Q}_{\mathrm{i}, \mathrm{t}-1 .}^{\mathrm{D}}$

In this model, the $\theta$ term reflects that current demand $\left(\mathrm{Q}^{\mathrm{D}} \mathrm{i}, \mathrm{t}\right)$ adjusts partially to changes in desired demand $\left(\mathrm{Q}^{\mathrm{D}^{*}}{ }_{\mathrm{i}, \mathrm{t}}\right)$. Energy demand does not fully adjust in the current period because it is a stock-flow process. In this stock-flow process, adjusting the stock usually takes more than one period but consumers can control the flow easily in the current period. Therefore, demand does not fully adjust within one period to changes in desired demand.

In more tangible terms, the "stock" refers to energy-consuming appliances that a consumer owns, such as a car, air conditioner, heater, and stove. The flow is the amount that the consumer uses the appliance. In this process, the consumer has immediate control over where the thermostat is set or how much he or she drives the car but these decisions can only affect energy consumption to a limited degree. If the consumer wants larger changes in energy demand, he or she must replace an expensive item like a car, heater, or air conditioner, which typically cannot happen immediately.

This explanation for the partial-adjustment process suggests that an ideal model for energy demand would explicitly represent consumer decisions on purchasing energyconsuming appliances and their levels of usage. Taylor (1975) discusses this issue and notes that most studies at that time had insufficient data on appliance purchases and usage to estimate such a model. Other studies have estimated price elasticity using models of this type, such as Dubin and Macfadden (1984). However, data limitations precluded estimating a similar model for different spatial scales. Therefore, we proceeded with Houthakker et. al.'s reduced-form model, which is commonly used in the literature.

By estimating the adjustment process $(\theta)$, we can estimate both short-run and long-run price elasticities. The short-run price elasticity is the long-run price elasticity $(\gamma)$ multiplied by the adjustment factor $(\theta)$, which in this model refers to $\theta \gamma$, the estimated coefficient on the current period price variable. The long-run elasticity is estimated by subtracting the coefficient on the lagged demand variable $(1-\theta)$ from one to get an estimate of $\theta$ and then dividing the coefficient of the current price $(\theta \gamma)$ by the estimate of $\theta$. 
We estimate any spatial differences in the energy-demand relationship by adding interaction terms between indicator variables for the spatial unit of interest (region, state, or utility) and the regressors of interest (price, quantity, and income). These interaction terms allow the estimated parameters to vary, and we can analyze if price elasticities differ across geographical units.

\section{Parameter Identification}

The variables of interest in this study, energy price and quantity, are jointly determined by the interaction of energy supply and demand, which creates problems for identifying parameters in the demand equation. Ideally, we would model the energy market with a system of equations for supply and demand. With a system of equations, we could isolate movements in the demand and supply curves and use this variation to estimate the parameters in each equation. We were unable to develop a system of equations for each spatial level used in the study and instead used a reduced-form model that can identify the parameters of the demand equation under the following assumptions:

- the model includes all the factors that affect energy demand

- price changes between periods are exogenous

- the error term does not contain autocorrelation

The following discussion explains why these assumptions are necessary and then examines their plausibility.

The first assumption is necessary because identifying parameters of the demand equation, and more specifically the effect of prices on quantity, requires holding the demand curve fixed and allowing shifts in the supply curve to establish the shape of the demand curve. If the model was missing a factor that affected demand, then shifts in both demand and supply could cause the observed shifts in price and quantity but the model would attribute the changes solely to shifts in supply. More simply, the estimates in the demand equation could suffer from omitted variables bias.

The second assumption is required to isolate the effect of price on demand. In a full system of equations, changes in price affect demand and feed back into the supply equation. Therefore, prices are endogenous and determined by the equilibrium between supply and demand. Without a supply equation to capture this feedback, the model cannot identify the parameter on the endogenous variable, unless prices enter the system exogenously. The following discussion will examine some situations where prices could plausibly enter the system as an exogenous variable.

The final assumption is needed because the lagged demand term can be written as a function of past values of the error term. If autocorrelation is present, it creates correlation between the error term and the lagged demand variable, which biases estimates of the coefficient on lagged demand. The equations below show how autocorrelation is a problem. 
The model equation is:

$Q^{D}{ }_{i, t}=Q_{i, t-1}^{D} \gamma+X_{i, t} \beta+X_{i, t-1} \alpha+s_{i}+y_{t}+\varepsilon_{i, t}$

which can be re-written as:

$Q^{D}{ }_{i, t}=\gamma\left(Q^{D}{ }_{i, t-2} \gamma+X_{i, t-1} \beta+X_{i, t-2} \alpha+s_{i}+y_{t}+\varepsilon_{i, t-1}\right)+X_{i, t} \beta+X_{i, t-1} \alpha+s_{i}+y_{t}+\varepsilon_{i, t}$

By continuing to substitute for the lagged demand term, this term could be re-written as a function of initial demand, lagged values of explanatory factors, and, most importantly, past values of the error term. Therefore, any autocorrelation in the error term $\left(\mathrm{E}\left(\varepsilon_{\mathrm{i}, \mathrm{t}}, \varepsilon_{\mathrm{i}, \mathrm{s}}\right)\right.$ $\neq 0$ where $\mathrm{t} \neq \mathrm{s}$ ) will create correlation between the lagged demand term and the error term, which will bias estimates of the coefficient on lagged demand, $\gamma$.

The assumptions stated above for parameter identification are strong but not implausible. The following discussion addresses each assumption.

\section{Assumption \#1 - Controlling for all factors affecting demand}

The model includes the own-price of the good, price of a substitute, and income, which are key variables in microeconomic decisions of demand. The model also controls for population and climate, which would also affect energy demand. In addition, the model includes lagged values of these factors, which controls for large period-to-period changes in explanatory variables. The model also controls for demand in the previous period, which in effect controls for the stock of energy-consuming appliances because the stock of appliances is unlikely to change significantly from year-to-year. Finally, the model includes fixed-effects for each cross-sectional unit and year.

The fixed-effects control for any unmeasured time-invariant effects on demand attributable to the cross-sectional unit. An example of an unmeasured time-invariant effect is energy demand patterns in states with federally-administered hydroelectric power sectors. Washington, Oregon, and Tennessee have exceptionally high per capita electricity use and low average prices. Some of this effect is due to prices, but each of these states have electricity markets dominated by large federal power agencies that have historically supplied the regions with inexpensive energy. The effect of these agencies is difficult to measure, and is likely to differ between states. Therefore, including an indicator variable for each state controls for the unique effects that agencies like the Bonneville Power Administration or Tennessee Valley Authority have on energy demand. In addition, the indicator variable controls for any other unmeasurable variables that affect energy demand. The year fixed effects control for any year-to-year variation in demand that occurs across all cross-section units. Examples of these effects are national legislation, macroeconomic trends, and national-level events that affect energy demand (war or terrorism attack). 
The explanatory variables comprise a relatively comprehensive set of control variables for energy demand. The very high $\mathrm{R}^{2}$ values $(>0.9)$ on the regressions indicate that the model fits the data well and explains a large amount of the variation in energy demand. One area where the model does not control for changes in demand is a state- or crosssection specific factor that changes over time. For instance, if a subset of states substantially changes their stock of energy-consuming appliances, then the model may not control for this change in demand. This situation contrasts with national consumer trends in purchasing new electronics, which the model can control for with year fixed effects.

\section{Assumption \#2 - Exogenous energy prices}

The assumption of exogenous energy prices is the strongest assumption but not implausible. A public utilities commission that sets consumer rates regulates most electricity and natural gas rates. These price schedules do not change regularly and the rate setting is not exogenous. Despite these shortcomings, there are portions of a consumer's utility bill that do vary annually and this source of variation is arguably exogenous. Most utility bills contain a component that passes through changes in fuel prices to customers. Since utility rate schedules do not change regularly, much of the period-to-period variation in what consumers actually pay for electricity and natural gas is fluctuations in the fuel cost. Because these fuels are typically purchased at prices determined on national or world markets, the change in prices from fuel costs is primarily exogenous variation.

\section{Assumption \#3 - No autocorrelation in the error term}

The discussion above showed that estimating the model with ordinary least squares (OLS) when autocorrelation is present will result in biased estimates. This assumption is testable and autocorrelation tests are performed on the regressions in the study. Alternate estimation methods are possible, notably instrumental variables and error component technique. In previous work, Houthakker et. al. (1974) found that OLS estimates with separate intercepts for cross-section units (fixed-effects) produced estimates that were comparable to the error component technique. Although, this finding is not generalizable to other data sets. Therefore, this analysis includes tests for autocorrelation.

We follow the test for first-order autocorrelation discussed in Wooldridge $(1994 ; 2002)$. In this test, we run an OLS regression of the dependent variable on the explanatory variables and obtain the residuals. We then run an OLS regression of the residuals on the explanatory variables and lagged residuals. The coefficient on the lagged residual term is a consistent estimate for $\rho$ and the t-statistic on the coefficient of the lagged residual term is a valid test for the null hypothesis $\rho=0$ (no autocorrelation), where $\rho$ represents the coefficient on the lagged error in an AR(1) model. In our results, we present the estimate of $\rho$ and the associated t-statistic.

As stated earlier, an ideal model would include a system of equations to model the demand and supply equations of each state's energy market. The limited scope of this 
study excluded an extensive analysis of supply and demand in each state. We followed Houthakker's demand model because it was widely used in the literature, we could estimate differences in short- and long-run elasticities, and determine if these parameters vary geographically. Under the assumptions stated above, the model will estimate the causal effect of prices on energy demand - the focus of this study and measure how this effect varies geographically. If these conditions are not met, the estimate will reflect the correlation between the observed prices and quantities

\section{Trend Analysis}

The regional data analysis for each energy market in Chapter Four displays regional trends for residential electricity, commercial electricity, and natural gas intensity, expenditures, and expenditures as a share of income. We estimate these trends using a deterministic time trend of the following form:

Ln dependent variable $=\beta_{0}+\beta_{1}$ year $+\varepsilon$

This model fits a linear time trend to our data. In most of the analyses done for this study, the trends were linear, and the model was a good fit, which was evidenced by $\mathrm{R}^{2}$ over 0.9 (the time trend). Appendix D displays the results from the trend analysis. 



\section{Appendix B}

\section{Data Sources}

The regression analyses done for this study used panel data for the 48 contiguous states. The time periods for each energy market analysis varied because of data limitations. The data on the residential electricity and natural gas markets spans 1977 to 2004 . The data on commercial electricity extends only from 1977 to 1999 . The data are from the following four sources: the DOE EIA, Bureau of Economic Analysis (BEA) of the Department of Commerce, the U.S. Census Bureau, and the National Oceanic and Atmospheric Administration (NOAA).

\section{Energy Data}

The sources for electricity data include the following EIA publications: State Energy Data Report 2001, Electric Power Annual, and Electric Power Monthly. By combining these data sources, we developed a state-level database of electricity consumption and prices for residential and commercial customers. The sources of natural-gas data include the following EIA publications: State Energy Data Report 2001, Natural Gas Annual, and Natural Gas Monthly. As was done for the electricity sector, for natural gas we created a state-level database on consumption and prices for residential customers.

\section{Economic Data}

We obtained economic data on gross state product, GDP deflator, and population from the Department of Commerce Bureau of Economic Analysis (BEA) "Regional Economic Accounts" Web site (see www.bea.gov/bea/regional/data.htm). We purchased data on commercial floorspace from McGraw-Hill Construction Dodge (http://dodge.construction.com).

\section{Climate Data}

The NOAA publishes state-level data on heating and cooling degree days. The degreeday measures quantify how far the daily average temperature deviates from 65 degrees. For instance, if a day's average temperature is 50 degrees, then the day has 15 heating degree days. If the average is 70 , then the day has five cooling degree days. We constructed an annual climate index by summing heating and cooling degree-day measures, which captures annual climate variation in each state. The data on degree days are available on the NOAA website (http://lwf.ncdc.noaa.gov/oa/documentlibrary/hes/hcs.html). 


\section{Appendix C: Variables and How They Were Constructed}

Table C.1: Residential Electricity Regression Analysis Variables

\begin{tabular}{ll}
\hline Variable & How Variable Was Constructed/Data Source \\
\hline Residential electricity consumption & Electricity consumption (Btus), residential sector (ESRCB), \\
& $1977-1999$ \\
& Source: EIA State Energy Data Report (2001) \\
& Electricity sales (megawatt hours), residential consumers, \\
$2000-2004$
\end{tabular}

Source: EIA Electric Power Annual (2003) and Electric Power Monthly (2004)

Real residential electricity prices $=$

Nominal residential electricity price / GDP deflator

Real residential natural gas prices

Nominal residential natural gas price / GDP deflator

Population

Real disposable income per capita $=$ Disposable Income per capita / GDP deflator

Climate index $=$ Heating degree days + Cooling degree days
Average price of electricity, residential sector (ESRCD), 1997-1999

Source: EIA State Energy Price and Expenditure Report (2001)

Average price of electricity, residential consumers, 20002004

Source: EIA Electric Power Annual (2003) and Electric Power Monthly (2004)

Average price of natural gas, residential sector (NGRCD), 1997-1999

Source: EIA State Energy Price and Expenditure Report (2001)

Average price of natural gas, residential consumers, 20002004

Source: EIA Natural Gas Annual (2003) and Natural Gas Monthly (2004)

State population

Source: BEA, Regional Accounts Data, "Annual State Personal Income," Population table (no date)

Disposable income per capita

Source: BEA, Regional Accounts Data, "Annual State Personal Income," Per capita disposable personal income table (no date)

Heating degree days, cooling degree days

Source: NOAA, National Climatic Data Center, "Heating and Cooling Degree Data" (no date) 
Table C.2: Commercial Electricity Regression Analysis Variables

Variable

Commercial electricity consumption
How Variable Was Constructed/ Data Source

Electricity consumption (Btus), commercial sector (ESCCB) 1977-1999

Source: EIA State Energy Data Report (2001)

Real Commercial Electricity Prices =

Nominal commercial electricity price / GDP deflator

Real Commercial Natural Gas Prices

Area of commercial floorspace

Real gross state product $=$

Gross state product / GDP deflator

Climate index $=$

Heating degree days + Cooling degree days
Average price of electricity, commercial sector (ESCCD) 1997-1999

Source: EIA State Energy Price and Expenditure Report (2001)

Average price of natural gas, commercial sector (NGCCD) 1997-1999

Source: EIA State Energy Price and Expenditure Report (2001)

Data purchased from McGraw-Hill Construction Dodge http://dodge.construction.com/-includes data on square footage of commercial floor space from 1977 1999 for each sate

Gross state product

Source: BEA, Regional Accounts Data, "Gross State Product," (no date)

Heating degree days, Cooling degree days

Source: NOAA, National Climatic Data Center, "Heating and Cooling Degree Data" (no date) 
Table C.3: Residential Natural-Gas Regression Analysis Variables

\begin{tabular}{|c|c|}
\hline Variable & How Variable Was Constructed/ Data Source \\
\hline \multirow[t]{4}{*}{ Residential natural gas consumption } & $\begin{array}{l}\text { Natural gas consumption (Btus), residential sector } \\
\text { (NGRCB), 1977-1999 }\end{array}$ \\
\hline & Source: EIA State Energy Data Report (2001) \\
\hline & $\begin{array}{l}\text { Natural gas sales (thousands of cubic feet), residential } \\
\text { consumers, } 2000-2004\end{array}$ \\
\hline & $\begin{array}{l}\text { Source: EIA Natural Gas Annual (2003) and Natural } \\
\text { Gas Monthly (2004) }\end{array}$ \\
\hline Real residential natural gas prices $=$ & $\begin{array}{l}\text { Average price of natural gas, residential sector (NGRCD) } \\
\text { 1997-1999 }\end{array}$ \\
\hline $\begin{array}{l}\text { Nominal residential natural gas price / } \\
\text { GDP deflator }\end{array}$ & $\begin{array}{l}\text { Source: EIA State Energy Price and Expenditure Report } \\
\text { (2001) }\end{array}$ \\
\hline
\end{tabular}

Average price of natural gas, residential consumers, 20002004

Source: EIA Natural Gas Annual (2003) and Natural Gas Monthly (2004)

Real residential electricity prices $=$

Nominal residential electricity price / GDP deflator

Average price of electricity, residential sector (ESRCD) 1997-1999

Source: EIA State Energy Price and Expenditure Report (2001)

Average price of electricity, residential consumers, 20002004

Source: EIA Electric Power Annual (2003) and Electric

Power Monthly (2004)

Population

State population

Source: BEA, Regional Accounts Data, "Annual State

Personal Income," Population table (no date)

Real disposable income per capita $=$

Disposable income per capita

Disposable income per capita / GDP deflator

Source: BEA, Regional Accounts Data, "Annual State Personal Income," Per capita disposable personal income table (no date)

Climate index $=$

Heating degree days, cooling degree days

Heating degree days + Cooling degree

Source: NOAA, National Climatic Data Center, "Heating days and Cooling Degree Data" (no date) 


\section{Appendix D: Regression Analysis Results}

In this appendix, we present the results from regression analysis at the national, regional, state, and utility levels of aggregation. We display the results for each energy market by level of aggregation.

\section{National-Level Results}

This section shows results for the residential electricity, commercial electricity, and residential natural gas markets. In the national level regressions, we estimate the model using panel data from the 48 contiguous states. We estimate the following model for these regressions:

$$
\mathrm{Q}_{\mathrm{i}, \mathrm{t}}^{\mathrm{D}_{\mathrm{t}}}=\mathrm{Q}_{\mathrm{i}, \mathrm{t}-1}^{\mathrm{D} \gamma}+\mathrm{X}_{\mathrm{i}, \mathrm{\beta}} \beta+\mathrm{X}_{\mathrm{i}, \mathrm{t}-1} \alpha+\mathrm{s}_{\mathrm{i}}+\mathrm{y}_{\mathrm{t}}+\varepsilon_{\mathrm{i}, \mathrm{t}}
$$

where $\mathrm{Q}_{\mathrm{i}, \mathrm{t}}^{\mathrm{D}}$ is $\log$ energy demand in state $i$ and year $t, \mathrm{Q}_{\mathrm{i}, \mathrm{t}}^{\mathrm{D}}$ is the lag value of $\log$ energy demand, $X_{i, t}$ is a set of measured covariates (e.g. energy prices, population, income, and climate) that affect energy demand, and $\mathrm{X}_{\mathrm{i}, t-1}$ is the lag values of the covariates. The $s_{i}$ term is a state-fixed effect estimated with an indicator variable. The $y_{t}$ term is a yearfixed effect also estimated with an indicator variable and $\varepsilon_{i, t}$ is a random error term.

\section{Residential Electricity}

The dependent variable in this regression was the log of electricity sold to residential electricity consumers. We controlled for the following variables:

- Lag value of dependent variable

- Log of residential electricity price

- Lag value of log of residential electricity price

- Log of per capita income

- Lag value of $\log$ of per capita income

- Log of state population

- Lag value of $\log$ of state population

- Log of residential natural gas price

- Lag value of log of residential natural gas price

- Log of climate index (heating degree days + cooling degree days)

The residential electricity market regression analysis covers the period from 1977-2004. The data from 2001 are excluded from the analysis because EIA had serious errors in the data for that year, which they have not corrected yet.

The results show that lagged quantity has a significant and positive effect on current period consumption. Current and lagged electricity prices are significant and negative. The estimates indicate that short run price elasticity $(-0.24)$ is inelastic and similar to previous estimates in the literature. The income, population, and natural gas variables are 
all insignificant in the current period and significant in the lagged period. The lagged values are all positive, which is expected. Income and population increases should correspond with greater electricity demand. In this case, we consider natural gas a substitute for electricity and the positive sign for the cross-price elasticity indicates it is a substitute. Finally, the climate index has a significant and positive effect on residential electricity demand.

Table D.1: Regression results from the residential electricity market

\begin{tabular}{|l|c|c|c|c|c|c|}
\hline & Coef. & $\begin{array}{c}\text { Robust } \\
\text { Std. Err. }\end{array}$ & $\mathrm{t}$ & $\mathrm{P}>|\mathrm{t}|$ & {$[95 \%$ Conf } & Interval] \\
\hline Lag quantity & 0.232 & 0.058 & 4.03 & 0 & 0.119 & 0.345 \\
Ln elec price & -0.243 & 0.049 & -4.96 & 0 & -0.339 & -0.147 \\
Lag elec price & -0.129 & 0.048 & -2.7 & 0.007 & -0.222 & -0.035 \\
Ln income & 0.003 & 0.076 & 0.04 & 0.968 & -0.146 & 0.152 \\
Lag income & 0.384 & 0.073 & 5.27 & 0 & 0.241 & 0.527 \\
Ln population & -0.225 & 0.285 & -0.79 & 0.43 & -0.783 & 0.334 \\
Lag population & 0.827 & 0.307 & 2.69 & 0.007 & 0.225 & 1.428 \\
Ln nat gas price & -0.005 & 0.028 & -0.16 & 0.873 & -0.06 & 0.051 \\
Lag nat gas price & 0.111 & 0.031 & 3.58 & 0 & 0.05 & 0.172 \\
Ln climate & 0.246 & 0.026 & 9.36 & 0 & 0.194 & 0.298 \\
\hline $\mathrm{R}^{2}=0.99$ & \\
$\mathrm{~N}=1237$
\end{tabular}

The adjusted R-squared for this model is very high—approximately 0.99 . A high Rsquared is typical with fixed effects models because the state and year effects included in the model usually have considerable explanatory power.

We tested for first-order autocorrelation in the error term. The estimate of $\rho$ was -0.009 with a t-statistic of -0.69 , which indicates first-order correlation is not present. We, therefore, conclude that autocorrelation does not affect consistency of the coefficient estimates or validity of the standard errors.

\section{Commercial Electricity}

The dependent variable in this regression was the log of electricity sold to commercial electricity consumers. We controlled for the following variables:

- Lag value of dependent variable

- Log of commercial electricity price

- Lag value of log of commercial electricity price

- Log of gross state product

- Lag value of log of gross state product

- Log of commercial floorspace 
- Lag value of $\log$ of commercial floorspace

- Log of commercial natural gas price

- Lag value of log of commercial natural gas price

- Log of climate index (heating degree days + cooling degree days)

Table D.2: Regression results from the commercial electricity market

\begin{tabular}{|l|c|c|c|c|c|c|}
\hline & Coef. & $\begin{array}{c}\text { Robust } \\
\text { Std. Err. }\end{array}$ & $\mathrm{t}$ & $\mathrm{P}>|\mathrm{t}|$ & [95\% Conf. & Interval] \\
\hline Lagged quantity & 0.785 & 0.034 & 22.81 & 0 & 0.717 & 0.852 \\
Ln elec price & -0.209 & 0.060 & -3.47 & 0.001 & -0.327 & -0.091 \\
Lag elec price & 0.148 & 0.052 & 2.85 & 0.004 & 0.046 & 0.250 \\
Ln nat gas price & -0.023 & 0.020 & -1.18 & 0.236 & -0.061 & 0.015 \\
Lag nat gas price & 0.049 & 0.022 & 2.19 & 0.029 & 0.005 & 0.093 \\
Ln commercial GSP & 0.155 & 0.124 & 1.25 & 0.211 & -0.088 & 0.398 \\
Lag commercial GSP & -0.039 & 0.122 & -0.32 & 0.747 & -0.279 & 0.200 \\
Ln floorspace & 0.504 & 0.339 & 1.49 & 0.138 & -0.162 & 1.169 \\
Lag floorspace & -0.421 & 0.305 & -1.38 & 0.169 & -1.020 & 0.179 \\
Ln climate & 0.233 & 0.039 & 5.92 & 0 & 0.156 & 0.310 \\
\hline$R^{2}=0.99$ & \\
$n=1034$
\end{tabular}

The commercial electricity market regression analysis covers the period from 1977-1999. Later data are not included in the analysis because of consistency problems with gross state product data collected by the Bureau of Economic Analysis. In addition, data from Tennessee were excluded from this regression.

The results show that lagged quantity has a significant and positive effect on current period consumption. The magnitude is larger than the estimate for residential electricity. Current electricity price is significant and negative. The estimate indicates that short run price elasticity $(-0.21)$ is also inelastic and similar to previous estimates in the literature. The lagged electricity price is positive and significant, which is not expected. The estimates for natural gas are insignificant for the current period and significant and positive for the lag period. Again, this suggests that natural gas is a substitute but the cross price elasticity is small. All of the GSP and floorspace variables were insignificant. Finally, the climate index has a significant and positive effect on commercial electricity demand. The magnitude is also similar to the residential electricity estimate.

The adjusted R-squared for this model is also very high-approximately 0.99 . This, again, indicates the state and year effects included in the model have considerable explanatory power.

We also tested for first-order autocorrelation in the error term. The estimate of $\rho$ was 0.021 with a t-statistic of 0.47 . These results suggest first-order correlation does not affect the coefficient estimates and standard errors in this model. 


\section{Residential Natural Gas}

The dependent variable in this regression was the log of natural gas sold to residential natural gas consumers. We controlled for the following variables:

- Lag value of dependent variable

- Log of residential natural gas price

- Lag value of $\log$ of residential natural gas price

- Log of per capita income

- Lag value of $\log$ of per capita income

- Log of state population

- Lag value of $\log$ of state population

- Log of residential electricity price

- Lag value of $\log$ of residential electricity price

- Log of climate index (heating degree days + cooling degree days)

Table D.3: Results from natural gas market regression analysis

\begin{tabular}{|l|c|c|c|c|c|c|}
\hline & Coef. & Std. Err. & $\mathrm{t}$ & $\mathrm{P}>|\mathrm{t}|$ & {$[95 \%$ Conf. } & Interval] \\
\hline Lag quantity & 0.577 & 0.024 & 24.44 & 0 & 0.531 & 0.623 \\
Ln nat gas price & -0.132 & 0.031 & -4.24 & 0 & -0.193 & -0.071 \\
Lag nat gas price & -0.106 & 0.031 & -3.42 & 0.001 & -0.167 & -0.045 \\
Ln elec price & 0.034 & 0.053 & 0.64 & 0.521 & -0.070 & 0.138 \\
Lag elec price & 0.146 & 0.052 & 2.8 & 0.005 & 0.044 & 0.248 \\
Ln income & 0.261 & 0.123 & 2.13 & 0.034 & 0.020 & 0.503 \\
Lag income & 0.167 & 0.113 & 1.48 & 0.139 & -0.054 & 0.388 \\
Ln population & 1.169 & 0.449 & 2.6 & 0.009 & 0.287 & 2.051 \\
Lag population & -0.717 & 0.449 & -1.6 & 0.11 & -1.598 & 0.163 \\
Ln climate & 0.181 & 0.042 & 4.29 & 0 & 0.098 & 0.264 \\
\hline$R^{2}=0.96$ \\
$\mathrm{n}=1210$
\end{tabular}

The residential natural gas market regression analysis covers the period from 1977-2004. The regression includes data from all time periods. It excludes the state of Maine from the analysis. Gas volumes sold in Maine are very small in absolute terms and relative to all other states. Since the absolute volumes traded are small, small changes had large effects in \% changes and disproportionately affected the price elasticity estimates. Since the market there is small compared to the rest of the country, the analysis excludes it.

The results show that the lagged quantity is significant and the magnitude is similar to the estimate in commercial electricity. Natural gas price is significant and negative in the current and lagged period. The estimate of short-term price elasticity is -0.132 , which is smaller in absolute value than the estimates for both electricity markets. The current price of electricity is insignificant but the lagged value is positive and significant. This is further evidence that electricity and natural gas are substitutes for residential consumers. 
The magnitude of the cross price elasticity is also small in this case. The estimates for income and population are positive and significant in the current period but insignificant in the lagged period. The elasticity for population (1.17) is large relative to the other estimates, which indicates population change has a strong effect on demand in this market.

The adjusted R-squared for this model is again very high — approximately 0.96 . The fixed effects included in the model also have considerable explanatory power for this market.

We tested for first-order autocorrelation and found that it may be present in the error term. The estimate of $\rho$ was -0.342 with a t-statistic of -6.75 . Based on this result, we estimated the model assuming an AR(1) structure in the error term, which should correct the standard errors. However, autocorrelation still affects consistency of the estimate on the lagged demand term.

\section{Regional-Level Results}

This section shows regional level results for the residential electricity, commercial electricity, and residential natural gas markets. In the regional level regressions, we estimate the model using panel data from the 48 contiguous states. We estimate the following model for these regressions:

$$
\begin{aligned}
& Q_{i, t}^{D_{i, t}}=Q_{i, t-1}^{D_{i}}+X_{i, t} \beta+X_{i, t-1} \alpha+\left(r_{i} x Q_{i, t-1}\right)_{Q}^{\prime}+\left(r_{i} x \ln \text { elec price } i_{i, t}\right) \beta_{P}^{\prime}+ \\
& \left(\mathrm{r}_{\mathrm{i}} \mathrm{X} \ln \text { income }_{\mathrm{i}, \mathrm{t}}\right) \beta_{\mathrm{I}}^{\prime}+\mathrm{s}_{\mathrm{i}}+\mathrm{y}_{\mathrm{t}}+\varepsilon_{\mathrm{i}, \mathrm{t}}
\end{aligned}
$$

where $\mathrm{Q}_{\mathrm{i}, \mathrm{t}}^{\mathrm{D}}$ is $\log$ energy demand in state $i$ and year $t, \mathrm{Q}_{\mathrm{i}, \mathrm{t}}^{\mathrm{D}}$ is the lag value of $\log$ energy demand, $X_{i, t}$ is a set of measured covariates (e.g. energy prices, population, income, and climate) that affect energy demand, and $\mathrm{X}_{\mathrm{i}, \mathrm{t}-\mathrm{i}}$ is the lag values of the covariates. The interaction terms interact a region indicator variable with lagged quantity, current prices, and current income. The corresponding region-specific coefficient estimates are $\left(\gamma+\gamma_{\mathrm{Q}}^{\prime}\right)$ for lagged quantity, $\left(\beta_{\mathrm{P}}+\beta_{\mathrm{P}}^{\prime}\right)$ for prices, and $\left(\beta_{\mathrm{I}}+\beta_{\mathrm{I}}^{\prime}\right)$ for income. The $s_{i}$ term is a statefixed effect estimated with an indicator variable. The $y_{t}$ term is year-fixed effect also estimated with an indicator variable and $\varepsilon_{i, t}$ is a random error term.

\section{Residential Electricity}

The table shows that demand response in the South Atlantic and East South Central is most elastic and the East North Central has the most inelastic demand response. All of the estimates are negative and statistically significant, except the East North Central. The estimates also indicate regional differences in electricity demand. The estimates for the South Atlantic and East South Central have statistically significant differences from the East North Central. A Wald Test on the South Atlantic and East North Central coefficients rejects the null hypothesis that they are equal $(\mathrm{F}(1,1130)=14.59 ; \mathrm{p}=$ 0.0001). A Wald Test on the East South Central and East North Central coefficients also 
rejects that they are equal $(\mathrm{F}(1,1130)=10.37 ; \mathrm{p}=0.0013)$. Overall, the regression results show clear statistically significant differences in price elasticities between the regions.

Table D.4: Estimated short-run price elasticities for the residential electricity market.

Short run price elasticity

$\begin{array}{lcccccc} & \text { Coef. } & \text { Std. Err. } & \mathrm{t} & \mathrm{P}>|\mathrm{t}| & {[95 \% \text { Conf. }} & \text { Interval] } \\ \text { South Atlantic } & -0.318 & 0.047 & -6.77 & 0 & -0.41 & -0.226 \\ \text { East South Central } & -0.266 & 0.071 & -3.74 & 0 & -0.405 & -0.126 \\ \text { Mid Atlantic } & -0.232 & 0.069 & -3.36 & 0.001 & -0.368 & -0.096 \\ \text { Mountain } & -0.211 & 0.038 & -5.55 & 0 & -0.285 & -0.136 \\ \text { New England } & -0.192 & 0.046 & -4.2 & 0 & -0.281 & -0.102 \\ \text { Pacific Coast } & -0.188 & 0.051 & -3.69 & 0 & -0.288 & -0.088 \\ \text { West North Central } & -0.163 & 0.054 & -3.02 & 0.003 & -0.269 & -0.057 \\ \text { West South Central } & -0.127 & 0.051 & -2.52 & 0.012 & -0.227 & -0.028 \\ \text { East North Central } & -0.054 & 0.053 & -1.01 & 0.312 & -0.158 & 0.051\end{array}$

We tested for first-order autocorrelation in the error term and the estimate of $\rho$ was -0.003 with a t-statistic of -0.26 . The estimate indicates that first-order autocorrelation does not affect the error term and this model. Therefore, autocorrelation does not affect the estimate of lagged demand and the inference based on the standard errors is valid.

Table D.5: Estimated long-run price elasticities for the residential electricity market.

$\begin{array}{lcccccc} & \text { Coef. } & \text { Std. Err. } & \mathrm{t} & \mathrm{P}>|\mathrm{t}| & {[95 \% \text { Conf. }} & \text { Interval] } \\ \text { East South Central } & -0.618 & 0.144 & -4.3 & 0 & -0.900 & -0.336 \\ \text { South Atlantic } & -0.352 & 0.051 & -6.86 & 0 & -0.453 & -0.251 \\ \text { New England } & -0.325 & 0.074 & -4.37 & 0 & -0.471 & -0.179 \\ \text { Mountain } & -0.267 & 0.048 & -5.52 & 0 & -0.362 & -0.172 \\ \text { Pacific Coast } & -0.254 & 0.078 & -3.27 & 0.001 & -0.407 & -0.101 \\ \text { Mid Atlantic } & -0.247 & 0.075 & -3.28 & 0.001 & -0.395 & -0.099 \\ \text { West North Central } & -0.244 & 0.081 & -3.01 & 0.003 & -0.403 & -0.085 \\ \text { West South Central } & -0.174 & 0.070 & -2.48 & 0.013 & -0.311 & -0.036 \\ \text { East North Central } & -0.058 & 0.057 & -1.02 & 0.309 & -0.169 & 0.054\end{array}$

Long run price elasticities are calculated by dividing the coefficient estimate on current electricity prices by $1-$ the coefficient of lagged quantity. The long-run elasticities are larger for all of the regions, which is expected and follows the general findings from previous research. The pattern of results is also similar to the short-run elasticity results. The East South Central and South Atlantic regions have the most elastic demand and the East North Central is the most inelastic. Again, all of the estimates have the expected sign and significant, except for the East North Central. 


\section{Commercial Electricity}

We used the same regression model to estimate the regional-level commercial electricity market.

Table D.6: Short-run price elasticities for commercial electricity with and without Tennessee

Short-Run Price Elasticity - with Tennessee

$\begin{array}{lcccccc} & \text { Coef. } & \text { Std. Err. } & \mathrm{t} & \mathrm{P}>|\mathrm{t}| & {[95 \% \text { Conf. Interval] }} \\ \text { East South Central } & -0.759 & 0.322 & -2.36 & 0.019 & -1.391 & -0.127 \\ \text { Pacific Coast } & -0.364 & 0.099 & -3.67 & 0 & -0.559 & -0.169 \\ \text { New England } & -0.273 & 0.101 & -2.71 & 0.007 & -0.470 & -0.076 \\ \text { Mountain } & -0.258 & 0.126 & -2.04 & 0.042 & -0.505 & -0.010 \\ \text { West South Central } & -0.250 & 0.114 & -2.19 & 0.029 & -0.475 & -0.026 \\ \text { East North Central } & -0.237 & 0.111 & -2.13 & 0.033 & -0.455 & -0.019 \\ \text { West North Central } & -0.233 & 0.132 & -1.76 & 0.078 & -0.491 & 0.026 \\ \text { South Atlantic } & -0.226 & 0.106 & -2.13 & 0.034 & -0.435 & -0.017 \\ \text { Mid Atlantic } & -0.215 & 0.081 & -2.64 & 0.009 & -0.374 & -0.055\end{array}$

Short-Run Price Elasticity - without Tennessee

\begin{tabular}{lcccccc} 
& Coef. & Std. Err. & $\mathrm{t}$ & $\mathrm{P}>|\mathrm{t}|$ & \multicolumn{2}{c}{$[95 \%$ Conf. } \\
Pacific Coast & -0.306 & 0.076 & -4.04 & 0 & -0.455 & -0.158 \\
East South Central & -0.271 & 0.120 & -2.25 & 0.024 & -0.507 & -0.035 \\
New England & -0.212 & 0.079 & -2.69 & 0.007 & -0.367 & -0.057 \\
East North Central & -0.181 & 0.089 & -2.04 & 0.042 & -0.356 & -0.007 \\
Mid Atlantic & -0.180 & 0.058 & -3.11 & 0.002 & -0.293 & -0.066 \\
West South Central & -0.179 & 0.084 & -2.12 & 0.034 & -0.345 & -0.014 \\
Mountain & -0.178 & 0.102 & -1.74 & 0.082 & -0.377 & 0.022 \\
West North Central & -0.166 & 0.109 & -1.52 & 0.128 & -0.380 & 0.048 \\
South Atlantic & -0.158 & 0.082 & -1.94 & 0.053 & -0.318 & 0.002
\end{tabular}

The table shows that the data from Tennessee affect all of the results, especially the East South Central region. The EIA appears to have an error in this data series. In 2001, Tennessee's commercial electricity output doubles and then returns to previous levels in 2002. Due to this apparent error, we excluded Tennessee from the national-level results.

The estimates in the without Tennessee case are similar to the residential electric market except no region is markedly lower than the others. With a much closer range of estimates, none of these regional estimates have statistically significant differences between them. However, most are significantly different from zero (six out of nine). Overall, the estimates suggest that price elasticities vary between regions but the magnitude of the differences is not very large. In addition, the differences are difficult to detect with a sample of this size. 
We tested for first-order autocorrelation in the models including and excluding Tennessee. In the model including Tennessee, the estimate of $\rho$ was 0.071 with a tstatistic of 1.18. In the model excluding Tennessee, the estimate of $\rho$ was 0.078 with a tstatistic of 1.26. These estimates suggest first-order autocorrelation was not a problem in either model.

Table D.7: Long-run price elasticity estimates for commercial electricity

Long-Run Price Elasticity - with Tennessee

$\begin{array}{lcccccc} & \text { Coef. } & \text { Std. Err. } & \mathrm{t} & \mathrm{P}>|\mathrm{t}| & {[95 \% \text { Conf. }} & \text { Interval] } \\ \text { East South Central } & -3.106 & 1.595 & -1.95 & 0.052 & -6.236 & 0.025 \\ \text { Mid Atlantic } & -1.737 & 1.598 & -1.09 & 0.277 & -4.872 & 1.398 \\ \text { Pacific Coast } & -1.578 & 1.018 & -1.55 & 0.121 & -3.576 & 0.419 \\ \text { New England } & -1.519 & 1.118 & -1.36 & 0.175 & -3.713 & 0.676 \\ \text { South Atlantic } & -1.508 & 0.745 & -2.02 & 0.043 & -2.969 & -0.046 \\ \text { East North Central } & -1.156 & 0.644 & -1.8 & 0.073 & -2.419 & 0.107 \\ \text { Mountain } & -0.901 & 0.448 & -2.01 & 0.044 & -1.781 & -0.022 \\ \text { West North Central } & -0.830 & 0.573 & -1.45 & 0.148 & -1.955 & 0.294 \\ \text { West South Central } & -0.497 & 0.269 & -1.85 & 0.065 & -1.025 & 0.031\end{array}$

Long-Run Price Elasticity - without Tennessee

$\begin{array}{lcccccc} & \text { Coef. } & \text { Std. Err. } & \mathrm{t} & \mathrm{P}>|\mathrm{t}| & {[95 \% \text { Conf. }} & \text { Interval] } \\ \text { Mid Atlantic } & -1.422 & 1.149 & -1.24 & 0.216 & -3.677 & 0.832 \\ \text { Pacific Coast } & -1.365 & 0.864 & -1.58 & 0.114 & -3.060 & 0.330 \\ \text { New England } & -1.254 & 0.988 & -1.27 & 0.205 & -3.193 & 0.686 \\ \text { South Atlantic } & -1.140 & 0.604 & -1.89 & 0.059 & -2.326 & 0.045 \\ \text { East South Central } & -0.995 & 0.524 & -1.9 & 0.058 & -2.024 & 0.033 \\ \text { East North Central } & -0.882 & 0.502 & -1.76 & 0.079 & -1.866 & 0.103 \\ \text { Mountain } & -0.626 & 0.351 & -1.78 & 0.075 & -1.315 & 0.063 \\ \text { West North Central } & -0.589 & 0.459 & -1.28 & 0.2 & -1.489 & 0.311 \\ \text { West South Central } & -0.371 & 0.208 & -1.78 & 0.075 & -0.779 & 0.038\end{array}$

The long-run estimates are considerably larger in absolute magnitude than the short-run estimates and also larger than the residential electricity long-run estimates. Comparison between the two models shows that including Tennessee increases the magnitude of the estimates, especially for the East South Central region. When excluding this state, the magnitudes of the estimates drop, but no estimate is statistically significant from zero. The confidence intervals show that the variance of the estimates is large and they lack precision. 


\section{Residential Natural Gas}

Tables D.8 and D.9 compare short-run and long-run elasticity estimates for regressions that include and exclude the state of Maine. Maine sells very low volumes of natural gas and small changes in the market can have large relative effects. It appears that the elasticity estimate is considerably larger in Maine for this reason and comparison across the tables shows that including this state has a substantial effect on the results.

Table D.8: Short run price elasticity for natural gas

Short-Run Price Elasticity - with Maine

$\begin{array}{lcccccc} & \text { Coef. } & \text { Std. Err. } & \mathrm{t} & \mathrm{P}>|\mathrm{t}| & {[95 \% \text { Conf. }} & \text { Interval] } \\ \text { New England } & -0.336 & 0.064 & -5.28 & 0 & -0.461 & -0.211 \\ \text { Mid Atlantic } & -0.227 & 0.094 & -2.4 & 0.016 & -0.412 & -0.042 \\ \text { Pacific Coast } & -0.184 & 0.072 & -2.55 & 0.011 & -0.325 & -0.043 \\ \text { Mountain } & -0.183 & 0.050 & -3.63 & 0 & -0.282 & -0.084 \\ \text { West North Central } & -0.170 & 0.053 & -3.24 & 0.001 & -0.273 & -0.067 \\ \text { East North Central } & -0.155 & 0.062 & -2.49 & 0.013 & -0.277 & -0.033 \\ \text { East South Central } & -0.142 & 0.071 & -2.01 & 0.045 & -0.281 & -0.003 \\ \text { South Atlantic } & -0.114 & 0.057 & -2 & 0.046 & -0.225 & -0.002 \\ \text { West South Central } & -0.078 & 0.068 & -1.13 & 0.258 & -0.212 & 0.057\end{array}$

Short-Run Price Elasticity - without Maine

$\begin{array}{lcccccc} & \text { Coef. } & \text { Std. Err. } & \mathrm{t} & \mathrm{P}>|\mathrm{t}| & {[95 \% \text { Conf. }} & \text { Interval] } \\ \text { Mid Atlantic } & -0.174 & 0.081 & -2.15 & 0.032 & -0.332 & -0.015 \\ \text { Mountain } & -0.164 & 0.043 & -3.85 & 0 & -0.248 & -0.080 \\ \text { Pacific Coast } & -0.163 & 0.062 & -2.63 & 0.009 & -0.285 & -0.042 \\ \text { West North Central } & -0.138 & 0.044 & -3.11 & 0.002 & -0.226 & -0.051 \\ \text { New England } & -0.127 & 0.064 & -1.98 & 0.048 & -0.253 & -0.001 \\ \text { East North Central } & -0.120 & 0.053 & -2.26 & 0.024 & -0.225 & -0.016 \\ \text { East South Central } & -0.100 & 0.061 & -1.64 & 0.101 & -0.219 & 0.019 \\ \text { South Atlantic } & -0.073 & 0.048 & -1.5 & 0.133 & -0.168 & 0.022 \\ \text { West South Central } & -0.049 & 0.059 & -0.84 & 0.4 & -0.165 & 0.066\end{array}$


Table D.9: Short run price elasticity for natural gas

Long-Run Price Elasticity - with Maine

$\begin{array}{lcccccc} & \text { Coef. } & \text { Std. Err. } & \mathrm{t} & \mathrm{P}>|\mathrm{t}| & \text { [95\% Conf. } & \text { Interval] } \\ \text { Pacific Coast } & -0.630 & 0.261 & -2.41 & 0.016 & -1.142 & -0.118 \\ \text { New England } & -0.593 & 0.115 & -5.15 & 0 & -0.819 & -0.367 \\ \text { Mid Atlantic } & -0.469 & 0.192 & -2.44 & 0.015 & -0.847 & -0.091 \\ \text { Mountain } & -0.440 & 0.123 & -3.57 & 0 & -0.681 & -0.198 \\ \text { East South Central } & -0.396 & 0.222 & -1.78 & 0.075 & -0.833 & 0.040 \\ \text { West North Central } & -0.298 & 0.093 & -3.19 & 0.001 & -0.481 & -0.115 \\ \text { South Atlantic } & -0.241 & 0.122 & -1.96 & 0.05 & -0.481 & 0.000 \\ \text { East North Central } & -0.232 & 0.098 & -2.37 & 0.018 & -0.423 & -0.040 \\ \text { West South Central } & -0.126 & 0.114 & -1.1 & 0.27 & -0.350 & 0.098\end{array}$

Long-Run Price Elasticity - without Maine

$\begin{array}{lcccccc} & \text { Coef. } & \text { Std. Err. } & \mathrm{t} & \mathrm{P}>|\mathrm{t}| & {[95 \% \text { Conf. }} & \text { Interval] } \\ \text { Pacific Coast } & -0.452 & 0.173 & -2.61 & 0.009 & -0.791 & -0.112 \\ \text { Mountain } & -0.355 & 0.092 & -3.84 & 0 & -0.536 & -0.174 \\ \text { Mid Atlantic } & -0.338 & 0.153 & -2.2 & 0.028 & -0.638 & -0.037 \\ \text { New England } & -0.305 & 0.158 & -1.93 & 0.054 & -0.614 & 0.005 \\ \text { East South Central } & -0.247 & 0.161 & -1.54 & 0.125 & -0.562 & 0.068 \\ \text { West North Central } & -0.220 & 0.071 & -3.11 & 0.002 & -0.358 & -0.081 \\ \text { East North Central } & -0.171 & 0.078 & -2.19 & 0.029 & -0.323 & -0.018 \\ \text { South Atlantic } & -0.141 & 0.095 & -1.49 & 0.136 & -0.327 & 0.045 \\ \text { West South Central } & -0.071 & 0.085 & -0.83 & 0.406 & -0.239 & 0.097\end{array}$

The results show that including Maine in the analysis increases the absolute magnitude of all the elasticity estimates, especially the New England region. Since it is a tiny market compared to the other states, we will focus on the results excluding this state and have also excluded Maine in the other regressions for this market.

The residential natural gas estimates are all negative, as expected, but smaller in absolute magnitude than the electricity markets. Fewer regions are statistically significant also. Five regions are significant for both the short-run and long-run estimates.

The tests for first-order autocorrelation in the error term suggest autocorrelation exists in both models. In the model including Maine, the estimate of $\rho$ was -0.195 with a t-statistic of -3.11. In the model excluding Maine, the estimate of $\rho$ was -0.369 with a t-statistic of -6.75. In response to these findings, we estimated the results presented above assuming an $\operatorname{AR}(1)$ structure in the error terms. 


\section{State-Level Results}

This section shows state-level regression results for the residential electricity, commercial electricity, and residential natural gas markets. The state-level regression is similar to the region-level model except the interaction terms are at the state level. We estimate the following model for these regressions:

$$
\begin{aligned}
& Q_{i, t}^{D}=Q_{i, t-1}^{D} \gamma+X_{i, t} \beta+X_{i, t-1} \alpha+\left(s_{i} x Q_{i, t-1}^{D}\right) \gamma_{Q}^{\prime}+\left(s_{i} x \ln \text { elec price }{ }_{i, t}\right) \beta_{P}^{\prime}+ \\
& \left(s_{i} x \ln \text { income }_{i, t}\right) \beta_{I}^{\prime}+s_{i}+y_{t}+\varepsilon_{i, t}
\end{aligned}
$$

where $\mathrm{Q}^{\mathrm{D}}{ }_{\mathrm{i}, \mathrm{t}}$ is $\log$ energy demand in state $i$ and year $t, \mathrm{Q}_{\mathrm{i}, \mathrm{t}}^{\mathrm{D}}$ is the lag value of log energy demand, $\mathrm{X}_{\mathrm{i}, \mathrm{t}}$ is a set of measured covariates (e.g. energy prices, population, income, and climate) that affect energy demand, and $\mathrm{X}_{\mathrm{i}, \mathrm{t}-\mathrm{i}}$ is the lag values of the covariates. The interaction terms interact a state indicator variable with lagged quantity, current prices, and current income. The corresponding state-specific coefficient estimates are $\left(\gamma^{\prime}+\gamma_{Q}^{\prime}\right)$ for lagged quantity, $\left(\beta_{\mathrm{P}}+\beta_{\mathrm{P}}^{\prime}\right)$ for prices, and $\left(\beta_{\mathrm{I}}+\beta_{\mathrm{I}}^{\prime}\right)$ for income. The $s_{i}$ term is a statefixed effect estimated with an indicator variable. The $y_{t}$ term is year-fixed effect also estimated with an indicator variable and $\varepsilon_{i, t}$ is a random error term.

\section{Residential Electricity}

Table D.10: State-level results for short-run price elasticity.

Delaware

Arkansas

Tennessee

Georgia

New Hampshire

California

Missouri

Maine

Oregon

New Jersey

Florida

Michigan

Mississippi

Alabama

Pennsylvania

Virginia

South Dakota

Ohio

New York
Short run price elasticity

Region Coeff Std. Error T-stat P-value 95\% Conf Interval

$\begin{array}{lrrrrrr}\text { SA } & -1.026 & 0.106 & -9.71 & 0 & -1.234 & -0.819 \\ \text { WSC } & -0.618 & 0.137 & -4.51 & 0 & -0.886 & -0.349 \\ \text { ESC } & -0.352 & 0.137 & -2.58 & 0.01 & -0.621 & -0.084 \\ \text { SA } & -0.352 & 0.158 & -2.22 & 0.026 & -0.662 & -0.041 \\ \text { NE } & -0.347 & 0.086 & -4.05 & 0 & -0.516 & -0.179 \\ \text { PC } & -0.322 & 0.101 & -3.17 & 0.002 & -0.521 & -0.123 \\ \text { WNC } & -0.296 & 0.118 & -2.51 & 0.012 & -0.527 & -0.065 \\ \text { NE } & -0.275 & 0.076 & -3.61 & 0 & -0.425 & -0.126 \\ \text { PC } & -0.258 & 0.100 & -2.57 & 0.01 & -0.455 & -0.061 \\ \text { MA } & -0.231 & 0.094 & -2.47 & 0.014 & -0.415 & -0.047 \\ \text { SA } & -0.218 & 0.092 & -2.38 & 0.017 & -0.398 & -0.039 \\ \text { ENC } & -0.206 & 0.298 & -0.69 & 0.489 & -0.791 & 0.378 \\ \text { ESC } & -0.204 & 0.146 & -1.4 & 0.162 & -0.490 & 0.082 \\ \text { ESC } & -0.190 & 0.110 & -1.72 & 0.086 & -0.407 & 0.027 \\ \text { MA } & -0.151 & 0.101 & -1.49 & 0.138 & -0.349 & 0.048 \\ \text { SA } & -0.148 & 0.174 & -0.85 & 0.398 & -0.490 & 0.195 \\ \text { WNC } & -0.141 & 0.123 & -1.15 & 0.25 & -0.382 & 0.099 \\ \text { ENC } & -0.135 & 0.140 & -0.97 & 0.333 & -0.410 & 0.139 \\ \text { MA } & -0.125 & 0.119 & -1.06 & 0.291 & -0.358 & 0.107\end{array}$




$\begin{array}{llllllll}\text { North Carolina } & \text { SA } & -0.113 & 0.115 & -0.98 & 0.326 & -0.340 & 0.113 \\ \text { Massachusetts } & \text { NE } & -0.108 & 0.105 & -1.03 & 0.304 & -0.315 & 0.098 \\ \text { Rhode Island } & \text { NE } & -0.103 & 0.092 & -1.12 & 0.262 & -0.283 & 0.077 \\ \text { Illinois } & \text { ENC } & -0.090 & 0.070 & -1.3 & 0.195 & -0.227 & 0.046 \\ \text { Connecticut } & \text { NE } & -0.090 & 0.077 & -1.17 & 0.243 & -0.240 & 0.061 \\ \text { Washington } & \text { PC } & -0.079 & 0.061 & -1.3 & 0.195 & -0.199 & 0.041 \\ \text { lowa } & \text { WNC } & -0.074 & 0.128 & -0.58 & 0.562 & -0.324 & 0.176 \\ \text { Texas } & \text { WSC } & -0.062 & 0.077 & -0.81 & 0.419 & -0.213 & 0.089 \\ \text { Arizona } & \mathrm{M} & -0.059 & 0.094 & -0.63 & 0.532 & -0.243 & 0.125 \\ \text { Montana } & \mathrm{M} & -0.056 & 0.119 & -0.47 & 0.637 & -0.289 & 0.177 \\ \text { Indiana } & \mathrm{ENC} & -0.054 & 0.094 & -0.58 & 0.564 & -0.239 & 0.130 \\ \text { North Dakota } & \text { WNC } & -0.046 & 0.093 & -0.49 & 0.624 & -0.229 & 0.137 \\ \text { Oklahoma } & \text { WSC } & -0.004 & 0.080 & -0.06 & 0.956 & -0.161 & 0.152 \\ \text { Louisiana } & \text { WSC } & 0.048 & 0.071 & 0.68 & 0.497 & -0.091 & 0.187 \\ \text { New Mexico } & \mathrm{M} & 0.049 & 0.099 & 0.49 & 0.622 & -0.145 & 0.242 \\ \text { West Virginia } & \mathrm{SA} & 0.052 & 0.177 & 0.29 & 0.769 & -0.295 & 0.398 \\ \text { Nevada } & \mathrm{M} & 0.057 & 0.073 & 0.79 & 0.431 & -0.085 & 0.200 \\ \text { Kentucky } & \mathrm{ESC} & 0.082 & 0.110 & 0.75 & 0.453 & -0.133 & 0.297 \\ \text { South Carolina } & \mathrm{SA} & 0.084 & 0.100 & 0.84 & 0.402 & -0.113 & 0.281 \\ \text { Idaho } & \mathrm{M} & 0.089 & 0.087 & 1.02 & 0.308 & -0.082 & 0.261 \\ \text { Vermont } & \mathrm{NE} & 0.109 & 0.208 & 0.52 & 0.602 & -0.300 & 0.517 \\ \text { Utah } & \mathrm{M} & 0.120 & 0.073 & 1.64 & 0.102 & -0.024 & 0.264 \\ \text { Kansas } & \text { WNC } & 0.128 & 0.077 & 1.66 & 0.097 & -0.023 & 0.280 \\ \text { Maryland } & \mathrm{SA} & 0.136 & 0.171 & 0.8 & 0.427 & -0.199 & 0.471 \\ \text { Minnesota } & \text { WNC } & 0.140 & 0.134 & 1.05 & 0.294 & -0.122 & 0.402 \\ \text { Wisconsin } & \mathrm{ENC} & 0.154 & 0.085 & 1.81 & 0.071 & -0.013 & 0.321 \\ \text { Nebraska } & \text { WNC } & 0.178 & 0.123 & 1.46 & 0.146 & -0.062 & 0.419 \\ \text { Wyoming } & \mathrm{M} & 0.219 & 0.097 & 2.27 & 0.023 & 0.030 & 0.409 \\ \text { Colorado } & \mathrm{M} & 0.599 & 0.129 & 4.64 & 0 & 0.345 & 0.852\end{array}$

The results show a wide range in estimates at the state level. Most estimates have the expected negative sign, but eleven states are in the positive range. Most of the positive estimates are near zero and their confidence intervals include the negative range. Wyoming and Colorado are significant, positive, and relatively large in absolute magnitude. Delaware and Arkansas have the largest magnitudes in the negative range. Between these two ends of the range, thirty states have negative elasticities in the range seen in the national- and regional-level results (near 0 to -0.3 ). In this range, the confidence interval for most states includes the national-level estimate $(-0.24)$.

The states with elasticities in the extreme parts of the range indicate a possible omitted variable. Colorado experienced a sharp growth in electricity demand in the early 1980's, which was coincident with a period of rising prices. This short increase is unexplained by other regressors in the model. Houthakker et. al. (1974) noticed a correlation between rural states and low/positive elasticities. The same pattern occurs in these results. Nearly all the states with positive elasticities are predominantly rural. 
Table D.11: Long Run Price Elasticity

\begin{tabular}{|c|c|c|c|c|c|c|c|}
\hline & & & & & & & \\
\hline Delaware & SA & -0.999 & 0.093 & -10.73 & 0 & -1.182 & -0.816 \\
\hline Arkansas & WSC & -0.539 & 0.069 & -7.8 & 0 & -0.675 & -0.404 \\
\hline California & PC & -0.492 & 0.273 & -1.8 & 0.072 & -1.027 & 0.044 \\
\hline New Hampshire & NE & -0.470 & 0.127 & -3.69 & 0 & -0.720 & -0.220 \\
\hline Maine & NE & -0.437 & 0.144 & -3.03 & 0.002 & -0.720 & -0.154 \\
\hline Tennessee & ESC & -0.401 & 0.131 & -3.07 & 0.002 & -0.658 & -0.145 \\
\hline Georgia & SA & -0.313 & 0.114 & -2.75 & 0.006 & -0.536 & -0.090 \\
\hline Missouri & WNC & -0.263 & 0.092 & -2.86 & 0.004 & -0.444 & -0.083 \\
\hline Florida & SA & -0.244 & 0.085 & -2.87 & 0.004 & -0.411 & -0.077 \\
\hline Michigan & ENC & -0.244 & 0.310 & -0.79 & 0.432 & -0.853 & 0.365 \\
\hline New Jersey & MA & -0.240 & 0.100 & -2.41 & 0.016 & -0.436 & -0.045 \\
\hline Mississippi & ESC & -0.238 & 0.180 & -1.32 & 0.186 & -0.591 & 0.115 \\
\hline Oregon & $\mathrm{PC}$ & -0.236 & 0.098 & -2.41 & 0.016 & -0.429 & -0.044 \\
\hline Alabama & ESC & -0.221 & 0.114 & -1.94 & 0.053 & -0.444 & 0.003 \\
\hline Virginia & SA & -0.184 & 0.213 & -0.86 & 0.388 & -0.601 & 0.234 \\
\hline New York & MA & -0.178 & 0.169 & -1.05 & 0.293 & -0.509 & 0.154 \\
\hline South Dakota & WNC & -0.166 & 0.152 & -1.09 & 0.277 & -0.465 & 0.133 \\
\hline Rhode Island & NE & -0.164 & 0.162 & -1.01 & 0.313 & -0.481 & 0.154 \\
\hline Pennsylvania & MA & -0.163 & 0.110 & -1.49 & 0.137 & -0.379 & 0.052 \\
\hline Washington & PC & -0.161 & 0.149 & -1.08 & 0.279 & -0.453 & 0.131 \\
\hline Massachusetts & NE & -0.150 & 0.160 & -0.93 & 0.35 & -0.464 & 0.165 \\
\hline Ohio & ENC & -0.136 & 0.138 & -0.98 & 0.327 & -0.407 & 0.136 \\
\hline Connecticut & NE & -0.123 & 0.101 & -1.21 & 0.225 & -0.321 & 0.076 \\
\hline North Carolina & SA & -0.109 & 0.102 & -1.06 & 0.288 & -0.310 & 0.092 \\
\hline lowa & WNC & -0.092 & 0.161 & -0.57 & 0.568 & -0.408 & 0.224 \\
\hline Texas & WSC & -0.081 & 0.100 & -0.81 & 0.418 & -0.276 & 0.115 \\
\hline Montana & $M$ & -0.079 & 0.174 & -0.46 & 0.648 & -0.420 & 0.261 \\
\hline Illinois & ENC & -0.076 & 0.052 & -1.46 & 0.145 & -0.179 & 0.026 \\
\hline Arizona & $M$ & -0.066 & 0.104 & -0.63 & 0.528 & -0.270 & 0.138 \\
\hline Indiana & ENC & -0.056 & 0.095 & -0.59 & 0.557 & -0.243 & 0.131 \\
\hline North Dakota & WNC & -0.055 & 0.113 & -0.49 & 0.625 & -0.277 & 0.167 \\
\hline Oklahoma & WSC & -0.005 & 0.094 & -0.06 & 0.956 & -0.190 & 0.179 \\
\hline Nevada & $M$ & 0.046 & 0.057 & 0.81 & 0.418 & -0.066 & 0.158 \\
\hline West Virginia & SA & 0.053 & 0.179 & 0.29 & 0.769 & -0.299 & 0.404 \\
\hline New Mexico & $M$ & 0.059 & 0.119 & 0.5 & 0.62 & -0.175 & 0.293 \\
\hline Louisiana & WSC & 0.060 & 0.086 & 0.7 & 0.486 & -0.108 & 0.228 \\
\hline South Carolina & SA & 0.089 & 0.106 & 0.84 & 0.401 & -0.119 & 0.297 \\
\hline Idaho & $M$ & 0.106 & 0.104 & 1.02 & 0.309 & -0.098 & 0.310 \\
\hline Utah & $M$ & 0.123 & 0.075 & 1.64 & 0.102 & -0.025 & 0.271 \\
\hline Kentucky & ESC & 0.134 & 0.174 & 0.77 & 0.441 & -0.207 & 0.475 \\
\hline Kansas & WNC & 0.143 & 0.084 & 1.71 & 0.088 & -0.021 & 0.307 \\
\hline Minnesota & WNC & 0.202 & 0.196 & 1.03 & 0.303 & -0.183 & 0.586 \\
\hline Nebraska & WNC & 0.206 & 0.135 & 1.52 & 0.129 & -0.060 & 0.471 \\
\hline Maryland & SA & 0.206 & 0.255 & 0.81 & 0.419 & -0.294 & 0.706 \\
\hline
\end{tabular}




$\begin{array}{lllllrrr}\text { Vermont } & \text { NE } & 0.281 & 0.580 & 0.48 & 0.629 & -0.857 & 1.419 \\ \text { Wyoming } & \text { M } & 0.296 & 0.127 & 2.33 & 0.02 & 0.047 & 0.545 \\ \text { Wisconsin } & \text { ENC } & 0.302 & 0.183 & 1.65 & 0.099 & -0.057 & 0.661 \\ \text { Colorado } & \mathrm{M} & 0.666 & 0.105 & 6.36 & 0 & 0.461 & 0.872\end{array}$

The long run elasticity estimates show greater variability. Only 12 states have statistically significant estimates and two of those are positive. Similar to the other markets, long run price elasticities are generally greater than the short run estimates.

We tested for first-order autocorrelation in the state-level residential electricity model and found it does not appear to affect the error term. The estimate of $\rho$ was -0.004 with a tstatistic of -0.89 . The results indicate that autocorrelation does not affect consistency of estimates on the lagged demand term and that inference based on the existing standard errors is valid.

\section{Commercial Electricity}

Table D.12: Short-run elasticity estimates for commercial electricity

Short Run Commercial Electricity

$\begin{array}{lcccccc} & \text { Coef. } & \text { Std. Err. } & \mathrm{t} & \mathrm{P}>|\mathrm{t}| & \text { Conf. } & \text { Interval] } \\ \text { Tennessee } & -3.363 & 2.314 & -1.45 & 0.147 & -7.90 & 1.18 \\ \text { Maryland } & -1.086 & 0.946 & -1.15 & 0.251 & -2.94 & 0.77 \\ \text { Nevada } & -1.016 & 0.668 & -1.52 & 0.129 & -2.33 & 0.30 \\ \text { Michigan } & -0.948 & 0.583 & -1.63 & 0.105 & -2.09 & 0.20 \\ \text { Vermont } & -0.805 & 0.212 & -3.79 & 0 & -1.22 & -0.39 \\ \text { Alabama } & -0.656 & 0.288 & -2.28 & 0.023 & -1.22 & -0.09 \\ \text { South Carolina } & -0.506 & 0.195 & -2.59 & 0.01 & -0.89 & -0.12 \\ \text { Oregon } & -0.477 & 0.103 & -4.62 & 0 & -0.68 & -0.27 \\ \text { Illinois } & -0.450 & 0.144 & -3.13 & 0.002 & -0.73 & -0.17 \\ \text { Montana } & -0.425 & 0.515 & -0.83 & 0.409 & -1.44 & 0.59 \\ \text { Rhode Island } & -0.400 & 0.107 & -3.75 & 0 & -0.61 & -0.19 \\ \text { Idaho } & -0.337 & 0.282 & -1.2 & 0.232 & -0.89 & 0.22 \\ \text { Washington } & -0.326 & 0.255 & -1.28 & 0.201 & -0.83 & 0.17 \\ \text { Massachusetts } & -0.311 & 0.099 & -3.15 & 0.002 & -0.50 & -0.12 \\ \text { New Jersey } & -0.310 & 0.109 & -2.85 & 0.004 & -0.52 & -0.10 \\ \text { lowa } & -0.309 & 0.183 & -1.69 & 0.092 & -0.67 & 0.05 \\ \text { Maine } & -0.307 & 0.106 & -2.9 & 0.004 & -0.52 & -0.10 \\ \text { Texas } & -0.281 & 0.112 & -2.51 & 0.012 & -0.50 & -0.06 \\ \text { Arizona } & -0.246 & 0.193 & -1.27 & 0.203 & -0.63 & 0.13 \\ \text { Kansas } & -0.237 & 0.113 & -2.1 & 0.036 & -0.46 & -0.02 \\ \text { Ohio } & -0.220 & 0.215 & -1.02 & 0.306 & -0.64 & 0.20 \\ \text { California } & -0.201 & 0.123 & -1.63 & 0.104 & -0.44 & 0.04 \\ \text { Connecticut } & -0.192 & 0.114 & -1.69 & 0.092 & -0.42 & 0.03\end{array}$




$\begin{array}{lcccccc}\text { Virginia } & -0.192 & 0.138 & -1.39 & 0.164 & -0.46 & 0.08 \\ \text { Delaware } & -0.186 & 0.163 & -1.14 & 0.256 & -0.51 & 0.14 \\ \text { New Mexico } & -0.183 & 0.158 & -1.16 & 0.246 & -0.49 & 0.13 \\ \text { Minnesota } & -0.173 & 0.183 & -0.95 & 0.344 & -0.53 & 0.19 \\ \text { Mississippi } & -0.165 & 0.224 & -0.74 & 0.462 & -0.60 & 0.27 \\ \text { West Virginia } & -0.155 & 0.120 & -1.29 & 0.197 & -0.39 & 0.08 \\ \text { Utah } & -0.152 & 0.140 & -1.08 & 0.279 & -0.43 & 0.12 \\ \text { New York } & -0.150 & 0.086 & -1.75 & 0.081 & -0.32 & 0.02 \\ \text { Oklahoma } & -0.108 & 0.153 & -0.7 & 0.482 & -0.41 & 0.19 \\ \text { Arkansas } & -0.108 & 0.153 & -0.7 & 0.481 & -0.41 & 0.19 \\ \text { Louisiana } & -0.098 & 0.119 & -0.83 & 0.408 & -0.33 & 0.13 \\ \text { Pennsylvania } & -0.091 & 0.073 & -1.24 & 0.216 & -0.23 & 0.05 \\ \text { Florida } & -0.070 & 0.121 & -0.58 & 0.561 & -0.31 & 0.17 \\ \text { North Dakota } & -0.055 & 0.453 & -0.12 & 0.903 & -0.94 & 0.83 \\ \text { Kentucky } & -0.053 & 0.122 & -0.44 & 0.664 & -0.29 & 0.19 \\ \text { Wisconsin } & -0.033 & 0.199 & -0.17 & 0.868 & -0.42 & 0.36 \\ \text { North Carolina } & -0.028 & 0.106 & -0.26 & 0.793 & -0.24 & 0.18 \\ \text { Missouri } & -0.022 & 0.136 & -0.16 & 0.872 & -0.29 & 0.25 \\ \text { Colorado } & 0.016 & 0.140 & 0.12 & 0.907 & -0.26 & 0.29 \\ \text { Wyoming } & 0.042 & 0.132 & 0.32 & 0.749 & -0.22 & 0.30 \\ \text { Indiana } & 0.102 & 0.174 & 0.59 & 0.556 & -0.24 & 0.44 \\ \text { New Hampshire } & 0.146 & 0.341 & 0.43 & 0.669 & -0.52 & 0.81 \\ \text { Nebraska } & 0.172 & 0.157 & 1.1 & 0.273 & -0.14 & 0.48 \\ \text { Georgia } & 0.219 & 0.117 & 1.88 & 0.061 & -0.01 & 0.45 \\ \text { South Dakota } & 0.335 & 0.581 & 0.58 & 0.564 & -0.80 & 1.48\end{array}$

The state-level estimates lack precision. In comparison to the residential data, the commercial electricity quantity data have much greater variability, which results in less precise estimates for price elasticity. As a result, only nine states have statistically significant results. A data error appears to cause the large estimate for Tennessee. This data problem was discussed in the regional level section.

The estimates are distributed more evenly throughout the range compared to residential electricity. There are also fewer positive estimates and none of the positive estimates are significant.

Table D.13: Long Run Commercial Electricity Elasticity Estimates

$\begin{array}{lcccccc} & \text { Coef. } & \text { Std. Err. } & \mathrm{t} & \mathrm{P}>|\mathrm{t}| & \begin{array}{c}{[95 \%} \\ \text { Conf. }\end{array} & \text { Interval] } \\ \text { Tennessee } & -10.338 & 4.001 & -2.58 & 0.01 & -18.19 & -2.48 \\ \text { Maryland } & -7.467 & 3.332 & -2.24 & 0.025 & -14.01 & -0.93 \\ \text { Alabama } & -4.892 & 4.255 & -1.15 & 0.251 & -13.24 & 3.46 \\ \text { Nevada } & -1.730 & 0.859 & -2.01 & 0.044 & -3.42 & -0.04 \\ \text { Michigan } & -1.496 & 0.537 & -2.79 & 0.005 & -2.55 & -0.44 \\ \text { Rhode Island } & -1.315 & 1.232 & -1.07 & 0.286 & -3.73 & 1.10 \\ \text { Ohio } & -1.243 & 1.500 & -0.83 & 0.407 & -4.19 & 1.70\end{array}$




\begin{tabular}{|c|c|c|c|c|c|c|}
\hline Washington & -1.210 & 2.205 & -0.55 & 0.583 & -5.54 & 3.12 \\
\hline Montana & -1.177 & 1.349 & -0.87 & 0.383 & -3.82 & 1.47 \\
\hline Massachusetts & -1.010 & 0.719 & -1.4 & 0.161 & -2.42 & 0.40 \\
\hline Vermont & -0.899 & 0.318 & -2.83 & 0.005 & -1.52 & -0.28 \\
\hline Illinois & -0.804 & 0.248 & -3.24 & 0.001 & -1.29 & -0.32 \\
\hline New Jersey & -0.740 & 0.431 & -1.72 & 0.086 & -1.59 & 0.11 \\
\hline Oregon & -0.678 & 0.497 & -1.36 & 0.173 & -1.65 & 0.30 \\
\hline South Carolina & -0.623 & 0.146 & -4.28 & 0 & -0.91 & -0.34 \\
\hline Connecticut & -0.516 & 0.540 & -0.96 & 0.34 & -1.57 & 0.54 \\
\hline Delaware & -0.514 & 0.622 & -0.83 & 0.409 & -1.73 & 0.71 \\
\hline lowa & -0.493 & 0.276 & -1.79 & 0.074 & -1.04 & 0.05 \\
\hline West Virginia & -0.489 & 0.401 & -1.22 & 0.223 & -1.28 & 0.30 \\
\hline Pennsylvania & -0.412 & 0.493 & -0.84 & 0.404 & -1.38 & 0.56 \\
\hline Minnesota & -0.396 & 0.459 & -0.86 & 0.389 & -1.30 & 0.51 \\
\hline Utah & -0.394 & 0.474 & -0.83 & 0.406 & -1.32 & 0.54 \\
\hline Texas & -0.384 & 0.158 & -2.44 & 0.015 & -0.69 & -0.07 \\
\hline Mississippi & -0.379 & 0.550 & -0.69 & 0.491 & -1.46 & 0.70 \\
\hline New Mexico & -0.372 & 0.468 & -0.79 & 0.428 & -1.29 & 0.55 \\
\hline Kansas & -0.371 & 0.277 & -1.34 & 0.182 & -0.91 & 0.17 \\
\hline Idaho & -0.366 & 0.381 & -0.96 & 0.337 & -1.11 & 0.38 \\
\hline Virginia & -0.365 & 0.297 & -1.23 & 0.22 & -0.95 & 0.22 \\
\hline Maine & -0.348 & 0.154 & -2.26 & 0.024 & -0.65 & -0.05 \\
\hline Arizona & -0.330 & 0.258 & -1.28 & 0.201 & -0.84 & 0.18 \\
\hline California & -0.301 & 0.266 & -1.13 & 0.259 & -0.82 & 0.22 \\
\hline New York & -0.297 & 0.257 & -1.15 & 0.249 & -0.80 & 0.21 \\
\hline Oklahoma & -0.147 & 0.227 & -0.65 & 0.516 & -0.59 & 0.30 \\
\hline North Dakota & -0.145 & 1.248 & -0.12 & 0.908 & -2.59 & 2.30 \\
\hline Arkansas & -0.132 & 0.215 & -0.62 & 0.539 & -0.55 & 0.29 \\
\hline Louisiana & -0.130 & 0.172 & -0.76 & 0.449 & -0.47 & 0.21 \\
\hline Florida & -0.118 & 0.201 & -0.59 & 0.558 & -0.51 & 0.28 \\
\hline Kentucky & -0.080 & 0.212 & -0.38 & 0.707 & -0.50 & 0.34 \\
\hline North Carolina & -0.066 & 0.265 & -0.25 & 0.802 & -0.59 & 0.45 \\
\hline Missouri & -0.057 & 0.366 & -0.16 & 0.875 & -0.78 & 0.66 \\
\hline Wisconsin & -0.034 & 0.208 & -0.16 & 0.871 & -0.44 & 0.37 \\
\hline Colorado & 0.038 & 0.325 & 0.12 & 0.907 & -0.60 & 0.68 \\
\hline Wyoming & 0.153 & 0.470 & 0.33 & 0.745 & -0.77 & 1.08 \\
\hline New Hampshire & 0.306 & 0.579 & 0.53 & 0.597 & -0.83 & 1.44 \\
\hline Georgia & 0.327 & 0.173 & 1.89 & 0.059 & -0.01 & 0.67 \\
\hline Indiana & 0.353 & 0.651 & 0.54 & 0.587 & -0.92 & 1.63 \\
\hline South Dakota & 0.434 & 0.651 & 0.67 & 0.505 & -0.84 & 1.71 \\
\hline Nebraska & 0.441 & 0.354 & 1.25 & 0.213 & -0.25 & 1.14 \\
\hline
\end{tabular}

The long run commercial electricity estimates appear sensitive to the model specification. Given this model, when the coefficient of lagged quantity nears one, the denominator of the expression decreases and the estimate can become very large. This occurs in the first three states on the list: Tennessee, Maryland, and Alabama. 
The remaining estimates are generally larger than the short run estimates. The states also remain in relatively similar positions to the short run estimates.

We tested for first-order autocorrelation in the state-level commercial electricity model and found it does not appear to affect the error term. The estimate of $\rho$ was 0.018 with a t-statistic of 0.50 . The results indicate that autocorrelation does not affect consistency of estimates on the lagged demand term and that inference based on the existing standard errors is valid.

\section{Natural Gas}

Table D.14: Regression results for short run residential natural gas elasticity.

\section{Short Run Natural Gas}

$\begin{array}{lcccccc} & & & & & {[95 \%} & \\ \text { Maine } & \text { Coef. } & \text { Std. Err. } & \mathrm{t} & \mathrm{P}>|\mathrm{t}| & \text { Conf. } & \text { Interval] } \\ \text { Vermont } & -0.745 & 0.467 & -1.59 & 0.111 & -1.662 & 0.172 \\ \text { Illinois } & -0.281 & 0.084 & -3.35 & 0.001 & -0.445 & -0.117 \\ \text { New Hampshire } & -0.229 & 0.084 & -2.72 & 0.007 & -0.394 & -0.064 \\ \text { Montana } & -0.225 & 0.093 & -2.41 & 0.016 & -0.408 & -0.042 \\ \text { South Carolina } & -0.217 & 0.079 & -2.75 & 0.006 & -0.372 & -0.062 \\ \text { New Mexico } & -0.202 & 0.141 & -1.43 & 0.154 & -0.479 & 0.076 \\ \text { Virginia } & -0.190 & 0.111 & -1.71 & 0.088 & -0.408 & 0.028 \\ \text { West Virginia } & -0.189 & 0.104 & -1.81 & 0.07 & -0.393 & 0.015 \\ \text { North Dakota } & -0.184 & 0.083 & -2.22 & 0.027 & -0.347 & -0.021 \\ \text { Alabama } & -0.183 & 0.063 & -2.88 & 0.004 & -0.308 & -0.059 \\ \text { Kansas } & -0.170 & 0.103 & -1.64 & 0.101 & -0.372 & 0.033 \\ \text { Washington } & -0.167 & 0.071 & -2.37 & 0.018 & -0.305 & -0.028 \\ \text { Arkansas } & -0.166 & 0.109 & -1.53 & 0.125 & -0.380 & 0.047 \\ \text { North Carolina } & -0.151 & 0.080 & -1.89 & 0.059 & -0.308 & 0.006 \\ \text { Missouri } & -0.149 & 0.102 & -1.46 & 0.145 & -0.350 & 0.052 \\ \text { Indiana } & -0.143 & 0.068 & -2.11 & 0.035 & -0.276 & -0.010 \\ \text { Kentucky } & -0.139 & 0.063 & -2.21 & 0.027 & -0.263 & -0.015 \\ \text { Ohio } & -0.137 & 0.059 & -2.31 & 0.021 & -0.253 & -0.021 \\ \text { Pennsylvania } & -0.127 & 0.076 & -1.68 & 0.093 & -0.276 & 0.021 \\ \text { South Dakota } & -0.117 & 0.089 & -1.31 & 0.19 & -0.291 & 0.058 \\ \text { Tennessee } & -0.112 & 0.077 & -1.46 & 0.144 & -0.263 & 0.039 \\ \text { Maryland } & -0.110 & 0.101 & -1.09 & 0.277 & -0.308 & 0.088 \\ \text { Colorado } & -0.106 & 0.109 & -0.97 & 0.331 & -0.319 & 0.108 \\ \text { Minnesota } & -0.102 & 0.069 & -1.48 & 0.14 & -0.237 & 0.033 \\ \text { California } & -0.100 & 0.066 & -1.52 & 0.129 & -0.229 & 0.029 \\ \text { lowa } & -0.098 & 0.119 & -0.82 & 0.41 & -0.332 & 0.135 \\ \text { Wisconsin } & -0.098 & 0.090 & -1.09 & 0.278 & -0.275 & 0.079 \\ \text { Rhode Island } & -0.098 & 0.066 & -1.49 & 0.138 & -0.227 & 0.031 \\ \text { Idaho } & -0.085 & 0.122 & -0.7 & 0.485 & -0.323 & 0.154 \\ \text { Mississippi } & -0.074 & 0.076 & -0.98 & 0.329 & -0.223 & 0.075 \\ \text { Michigan } & -0.061 & 0.080 & -0.76 & 0.448 & -0.217 & 0.096 \\ & -0.047 & 0.083 & -0.57 & 0.57 & -0.209 & 0.115\end{array}$




$\begin{array}{lllllll}\text { Utah } & -0.031 & 0.108 & -0.29 & 0.771 & -0.244 & 0.181 \\ \text { Connecticut } & -0.029 & 0.128 & -0.23 & 0.819 & -0.281 & 0.222 \\ \text { Delaware } & -0.024 & 0.102 & -0.24 & 0.812 & -0.224 & 0.175 \\ \text { Oregon } & -0.024 & 0.088 & -0.27 & 0.786 & -0.198 & 0.149 \\ \text { Florida } & -0.016 & 0.255 & -0.06 & 0.951 & -0.516 & 0.484 \\ \text { Texas } & -0.006 & 0.111 & -0.05 & 0.958 & -0.224 & 0.212 \\ \text { Massachusetts } & -0.005 & 0.148 & -0.04 & 0.971 & -0.295 & 0.284 \\ \text { Louisiana } & 0.009 & 0.077 & 0.11 & 0.909 & -0.143 & 0.161 \\ \text { Nevada } & 0.011 & 0.093 & 0.12 & 0.904 & -0.172 & 0.195 \\ \text { Georgia } & 0.023 & 0.107 & 0.21 & 0.833 & -0.188 & 0.233 \\ \text { New York } & 0.027 & 0.114 & 0.24 & 0.814 & -0.197 & 0.250 \\ \text { Nebraska } & 0.034 & 0.073 & 0.46 & 0.642 & -0.109 & 0.177 \\ \text { Oklahoma } & 0.050 & 0.107 & 0.47 & 0.641 & -0.160 & 0.260 \\ \text { New Jersey } & 0.072 & 0.115 & 0.63 & 0.53 & -0.153 & 0.297 \\ \text { Wyoming } & 0.077 & 0.117 & 0.66 & 0.509 & -0.152 & 0.307 \\ \text { Arizona } & 0.086 & 0.150 & 0.57 & 0.566 & -0.208 & 0.381\end{array}$

The short-run estimates are mostly lower in the natural gas market than the electricity markets, with the exception of Maine which was discussed earlier. The overall precision of the estimates is also limited, which is shown by only ten states with statistically significant results. The natural gas market, like the commercial electricity market, had much greater variability in demand. Therefore, the limited precision is not surprising.

Table D.15: Regression results for long-run price elasticities for residential natural gas

$\begin{array}{lcccccc}\text { Long Run Natural Gas } & & & & & \\ & \text { Coef. } & \text { Std. Err. } & \mathrm{t} & \mathrm{P}>|\mathrm{t}| & {[95 \% \text { Conf. }} & \text { Interval] } \\ \text { Maine } & -1.826 & 0.891 & -2.05 & 0.041 & -3.575 & -0.078 \\ \text { Vermont } & -0.577 & 0.189 & -3.06 & 0.002 & -0.947 & -0.207 \\ \text { New Hampshire } & -0.430 & 0.232 & -1.86 & 0.064 & -0.885 & 0.024 \\ \text { Virginia } & -0.322 & 0.179 & -1.8 & 0.072 & -0.672 & 0.028 \\ \text { South Carolina } & -0.299 & 0.248 & -1.2 & 0.228 & -0.787 & 0.188 \\ \text { Montana } & -0.287 & 0.101 & -2.83 & 0.005 & -0.486 & -0.088 \\ \text { New Mexico } & -0.281 & 0.144 & -1.96 & 0.05 & -0.563 & 0.000 \\ \text { North Carolina } & -0.279 & 0.212 & -1.32 & 0.187 & -0.695 & 0.136 \\ \text { West Virginia } & -0.270 & 0.129 & -2.1 & 0.036 & -0.523 & -0.018 \\ \text { Illinois } & -0.243 & 0.100 & -2.44 & 0.015 & -0.438 & -0.047 \\ \text { North Dakota } & -0.230 & 0.087 & -2.64 & 0.009 & -0.402 & -0.059 \\ \text { Washington } & -0.214 & 0.147 & -1.45 & 0.147 & -0.503 & 0.075 \\ \text { Missouri } & -0.174 & 0.081 & -2.16 & 0.031 & -0.332 & -0.016 \\ \text { Kentucky } & -0.171 & 0.073 & -2.34 & 0.02 & -0.315 & -0.028 \\ \text { Kansas } & -0.168 & 0.072 & -2.34 & 0.019 & -0.310 & -0.027 \\ \text { Tennessee } & -0.167 & 0.169 & -0.99 & 0.323 & -0.498 & 0.165 \\ \text { Indiana } & -0.163 & 0.078 & -2.08 & 0.037 & -0.317 & -0.009 \\ \text { Rhode Island } & -0.163 & 0.234 & -0.7 & 0.487 & -0.622 & 0.296\end{array}$




$\begin{array}{lllllll}\text { Alabama } & -0.159 & 0.090 & -1.77 & 0.077 & -0.336 & 0.017 \\ \text { South Dakota } & -0.142 & 0.107 & -1.33 & 0.183 & -0.352 & 0.067 \\ \text { Arkansas } & -0.141 & 0.075 & -1.87 & 0.062 & -0.289 & 0.007 \\ \text { Maryland } & -0.134 & 0.136 & -0.99 & 0.323 & -0.400 & 0.132 \\ \text { Minnesota } & -0.133 & 0.088 & -1.5 & 0.134 & -0.306 & 0.041 \\ \text { California } & -0.132 & 0.166 & -0.8 & 0.425 & -0.458 & 0.193 \\ \text { Ohio } & -0.132 & 0.081 & -1.64 & 0.101 & -0.291 & 0.026 \\ \text { Pennsylvania } & -0.124 & 0.098 & -1.27 & 0.205 & -0.315 & 0.068 \\ \text { Colorado } & -0.122 & 0.075 & -1.63 & 0.104 & -0.270 & 0.025 \\ \text { lowa } & -0.114 & 0.109 & -1.04 & 0.296 & -0.329 & 0.100 \\ \text { Wisconsin } & -0.110 & 0.075 & -1.46 & 0.145 & -0.257 & 0.038 \\ \text { Idaho } & -0.104 & 0.112 & -0.94 & 0.35 & -0.323 & 0.115 \\ \text { Mississippi } & -0.079 & 0.110 & -0.72 & 0.471 & -0.295 & 0.136 \\ \text { Michigan } & -0.075 & 0.131 & -0.57 & 0.567 & -0.333 & 0.182 \\ \text { Utah } & -0.061 & 0.213 & -0.29 & 0.776 & -0.478 & 0.357 \\ \text { Connecticut } & -0.042 & 0.184 & -0.23 & 0.818 & -0.402 & 0.318 \\ \text { Delaware } & -0.036 & 0.153 & -0.24 & 0.813 & -0.337 & 0.264 \\ \text { Oregon } & -0.028 & 0.104 & -0.27 & 0.788 & -0.232 & 0.176 \\ \text { Florida } & -0.020 & 0.317 & -0.06 & 0.951 & -0.642 & 0.603 \\ \text { Massachusetts } & -0.009 & 0.256 & -0.04 & 0.971 & -0.512 & 0.494 \\ \text { Texas } & -0.008 & 0.159 & -0.05 & 0.958 & -0.320 & 0.303 \\ \text { Louisiana } & 0.011 & 0.093 & 0.11 & 0.909 & -0.171 & 0.193 \\ \text { Nevada } & 0.021 & 0.175 & 0.12 & 0.905 & -0.323 & 0.365 \\ \text { Georgia } & 0.022 & 0.105 & 0.21 & 0.834 & -0.185 & 0.229 \\ \text { New York } & 0.029 & 0.124 & 0.24 & 0.812 & -0.213 & 0.272 \\ \text { Nebraska } & 0.038 & 0.081 & 0.47 & 0.64 & -0.121 & 0.197 \\ \text { Oklahoma } & 0.056 & 0.120 & 0.47 & 0.641 & -0.179 & 0.291 \\ \text { New Jersey } & 0.082 & 0.129 & 0.63 & 0.528 & -0.172 & 0.335 \\ \text { Wyoming } & 0.092 & 0.127 & 0.73 & 0.465 & -0.156 & 0.341 \\ \text { Arizona } & 0.119 & 0.220 & 0.54 & 0.588 & -0.312 & 0.550\end{array}$

Similar to other markets, the long-run estimates are generally larger than the short run estimates. The precision of these estimates is also limited, which is shown by the large standard errors and that only ten states have statistically significant estimates. The natural gas market also had much greater variation in prices and quantity during this period, which appears to affect the results at this level of aggregation. With the exception of Maine, the range of estimates is smaller than the electricity markets, which corresponds to the generally smaller (in absolute magnitude) values of the estimates when compared to the other markets.

We tested for first-order autocorrelation in the state-level residential natural gas model and found it does not appear to affect the error term. The estimate of $\rho$ was -0.12 with a t-statistic of -1.75. The results indicate that autocorrelation does not affect consistency of estimates on the lagged demand term and that inference based on the existing standard errors is valid. 


\section{Utility-level results}

Table D.16: Short run elasticity estimates for residential electricity at the utility level

\begin{tabular}{|c|c|c|c|c|c|c|c|}
\hline Utility & & & & & & 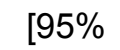 & \\
\hline Number & region & Coef. & Std. Err. & $\mathrm{t}$ & $P>|t|$ & Conf. & Interval] \\
\hline 182 & ENC & -1.563 & 0.472 & -3.31 & 0.001 & -2.490 & -0.637 \\
\hline 208 & ENC & -1.081 & 0.633 & -1.71 & 0.088 & -2.323 & 0.160 \\
\hline 186 & ENC & -1.061 & 0.521 & -2.04 & 0.042 & -2.082 & -0.039 \\
\hline 191 & ENC & -0.697 & 0.275 & -2.54 & 0.011 & -1.237 & -0.158 \\
\hline 18 & ENC & -0.584 & 0.279 & -2.1 & 0.036 & -1.13 & -0.04 \\
\hline 75 & ENC & -0.480 & 0.498 & -0.96 & 0.335 & -1.46 & 0.50 \\
\hline 134 & ENC & -0.392 & 0.257 & -1.53 & 0.127 & -0.896 & 0.112 \\
\hline 153 & ENC & -0.314 & 0.238 & -1.32 & 0.188 & -0.781 & 0.154 \\
\hline 35 & ENC & -0.250 & 0.160 & -1.57 & 0.118 & -0.56 & 0.06 \\
\hline 73 & ENC & -0.243 & 0.135 & -1.8 & 0.072 & -0.51 & 0.02 \\
\hline 177 & ENC & -0.217 & 0.622 & -0.35 & 0.728 & -1.438 & 1.004 \\
\hline 67 & ENC & -0.167 & 0.245 & -0.68 & 0.495 & -0.65 & 0.31 \\
\hline 41 & ENC & -0.150 & 0.353 & -0.43 & 0.671 & -0.84 & 0.54 \\
\hline 44 & ENC & -0.137 & 0.291 & -0.47 & 0.637 & -0.71 & 0.43 \\
\hline 17 & ENC & -0.131 & 0.469 & -0.28 & 0.78 & -1.05 & 0.79 \\
\hline 76 & ENC & -0.105 & 0.337 & -0.31 & 0.756 & -0.77 & 0.56 \\
\hline 38 & ENC & -0.097 & 0.427 & -0.23 & 0.82 & -0.93 & 0.74 \\
\hline 26 & ENC & -0.091 & 0.359 & -0.25 & 0.8 & -0.80 & 0.61 \\
\hline 96 & ENC & -0.082 & 0.331 & -0.25 & 0.803 & -0.73 & 0.57 \\
\hline 105 & ENC & -0.070 & 0.175 & -0.4 & 0.689 & -0.41 & 0.27 \\
\hline 28 & ENC & -0.045 & 0.399 & -0.11 & 0.909 & -0.83 & 0.74 \\
\hline 33 & ENC & -0.033 & 0.320 & -0.1 & 0.917 & -0.66 & 0.59 \\
\hline 206 & ENC & -0.004 & 0.517 & -0.01 & 0.994 & -1.019 & 1.011 \\
\hline 133 & ENC & 0.024 & 0.490 & 0.05 & 0.96 & -0.936 & 0.985 \\
\hline 207 & ENC & 0.109 & 0.355 & 0.31 & 0.758 & -0.587 & 0.806 \\
\hline 129 & ENC & 0.211 & 0.563 & 0.37 & 0.708 & -0.894 & 1.315 \\
\hline 130 & ENC & 0.952 & 1.475 & 0.65 & 0.519 & -1.941 & 3.845 \\
\hline 103 & ESC & -1.514 & 0.410 & -3.69 & 0 & -2.32 & -0.71 \\
\hline 113 & ESC & -1.222 & 0.397 & -3.08 & 0.002 & -2.00 & -0.44 \\
\hline 47 & ESC & -1.126 & 0.675 & -1.67 & 0.096 & -2.45 & 0.20 \\
\hline 120 & ESC & -1.064 & 0.625 & -1.7 & 0.089 & -2.291 & 0.163 \\
\hline 30 & ESC & -1.046 & 0.689 & -1.52 & 0.129 & -2.40 & 0.31 \\
\hline 198 & ESC & -0.958 & 0.414 & -2.32 & 0.021 & -1.770 & -0.147 \\
\hline 40 & ESC & -0.884 & 0.857 & -1.03 & 0.302 & -2.56 & 0.80 \\
\hline 110 & ESC & -0.766 & 0.389 & -1.97 & 0.049 & -1.53 & 0.00 \\
\hline 92 & ESC & -0.680 & 0.598 & -1.14 & 0.256 & -1.85 & 0.49 \\
\hline 86 & ESC & -0.528 & 0.394 & -1.34 & 0.181 & -1.30 & 0.25 \\
\hline 179 & ESC & -0.499 & 0.230 & -2.17 & 0.03 & -0.950 & -0.048 \\
\hline 69 & ESC & -0.486 & 0.592 & -0.82 & 0.411 & -1.65 & 0.67 \\
\hline 98 & ESC & -0.439 & 0.835 & -0.53 & 0.599 & -2.08 & 1.20 \\
\hline 193 & ESC & -0.299 & 0.386 & -0.77 & 0.439 & -1.055 & 0.458 \\
\hline 172 & ESC & -0.297 & 0.276 & -1.07 & 0.283 & -0.839 & 0.245 \\
\hline 1 & ESC & -0.200 & 0.522 & -0.38 & 0.701 & -1.22 & 0.82 \\
\hline
\end{tabular}




\begin{tabular}{|c|c|c|c|c|c|c|c|}
\hline 23 & ESC & -0.192 & 0.521 & -0.37 & 0.713 & -1.21 & 0.83 \\
\hline 107 & ESC & -0.178 & 0.548 & -0.32 & 0.746 & -1.25 & 0.90 \\
\hline 93 & ESC & -0.088 & 0.226 & -0.39 & 0.699 & -0.53 & 0.36 \\
\hline 210 & ESC & -0.018 & 0.801 & -0.02 & 0.982 & -1.589 & 1.552 \\
\hline 57 & ESC & 0.148 & 0.745 & 0.2 & 0.843 & -1.31 & 1.61 \\
\hline 91 & ESC & 0.317 & 0.338 & 0.94 & 0.348 & -0.35 & 0.98 \\
\hline 112 & ESC & 0.402 & 0.612 & 0.66 & 0.511 & -0.80 & 1.60 \\
\hline 200 & ESC & 1.389 & 0.305 & 4.55 & 0 & 0.790 & 1.987 \\
\hline 211 & M & -1.206 & 0.394 & -3.06 & 0.002 & -1.979 & -0.433 \\
\hline 94 & $M$ & -1.084 & 0.629 & -1.72 & 0.085 & -2.32 & 0.15 \\
\hline 140 & $M$ & -0.980 & 0.401 & -2.45 & 0.015 & -1.767 & -0.194 \\
\hline 155 & $M$ & -0.696 & 0.248 & -2.81 & 0.005 & -1.183 & -0.210 \\
\hline 171 & M & -0.694 & 0.586 & -1.18 & 0.237 & -1.844 & 0.456 \\
\hline 184 & M & -0.663 & 0.607 & -1.09 & 0.274 & -1.854 & 0.527 \\
\hline 164 & M & -0.547 & 0.403 & -1.36 & 0.174 & -1.338 & 0.243 \\
\hline 151 & M & -0.368 & 1.027 & -0.36 & 0.72 & -2.382 & 1.647 \\
\hline 53 & $M$ & -0.325 & 0.725 & -0.45 & 0.655 & -1.75 & 1.10 \\
\hline 122 & $M$ & -0.262 & 0.075 & -3.51 & 0 & -0.409 & -0.116 \\
\hline 152 & $M$ & -0.260 & 0.396 & -0.66 & 0.512 & -1.036 & 0.516 \\
\hline 32 & $\mathrm{M}$ & -0.233 & 0.649 & -0.36 & 0.72 & -1.51 & 1.04 \\
\hline 5 & $M$ & -0.221 & 0.372 & -0.59 & 0.552 & -0.95 & 0.51 \\
\hline 118 & $M$ & -0.096 & 0.187 & -0.51 & 0.61 & -0.463 & 0.272 \\
\hline 196 & $M$ & -0.061 & 0.305 & -0.2 & 0.842 & -0.660 & 0.538 \\
\hline 25 & $M$ & -0.014 & 0.253 & -0.06 & 0.955 & -0.51 & 0.48 \\
\hline 104 & M & -0.001 & 0.283 & 0 & 0.996 & -0.56 & 0.55 \\
\hline 71 & $M$ & 0.467 & 0.298 & 1.57 & 0.117 & -0.12 & 1.05 \\
\hline 202 & MA & -0.800 & 0.429 & -1.87 & 0.062 & -1.641 & 0.041 \\
\hline 109 & MA & -0.792 & 0.625 & -1.27 & 0.205 & -2.02 & 0.43 \\
\hline 37 & $\mathrm{MA}$ & -0.712 & 0.600 & -1.19 & 0.235 & -1.89 & 0.46 \\
\hline 100 & MA & -0.639 & 0.418 & -1.53 & 0.126 & -1.46 & 0.18 \\
\hline 160 & MA & -0.417 & 0.383 & -1.09 & 0.277 & -1.169 & 0.336 \\
\hline 125 & MA & -0.345 & 0.321 & -1.07 & 0.284 & -0.975 & 0.286 \\
\hline 147 & MA & -0.341 & 0.284 & -1.2 & 0.23 & -0.897 & 0.216 \\
\hline 145 & MA & -0.308 & 0.477 & -0.65 & 0.518 & -1.244 & 0.627 \\
\hline 213 & MA & -0.230 & 0.301 & -0.76 & 0.446 & -0.821 & 0.361 \\
\hline 85 & MA & -0.177 & 0.364 & -0.49 & 0.626 & -0.89 & 0.54 \\
\hline 157 & MA & -0.117 & 0.475 & -0.25 & 0.805 & -1.050 & 0.815 \\
\hline 49 & MA & -0.089 & 0.240 & -0.37 & 0.711 & -0.56 & 0.38 \\
\hline 161 & MA & -0.003 & 0.492 & -0.01 & 0.996 & -0.967 & 0.962 \\
\hline 16 & MA & 0.077 & 0.478 & 0.16 & 0.872 & -0.86 & 1.02 \\
\hline 137 & MA & 0.099 & 0.329 & 0.3 & 0.763 & -0.546 & 0.744 \\
\hline 146 & MA & 0.125 & 0.146 & 0.86 & 0.39 & -0.161 & 0.412 \\
\hline 7 & MA & 0.171 & 0.180 & 0.95 & 0.341 & -0.18 & 0.52 \\
\hline 144 & MA & 0.302 & 0.323 & 0.94 & 0.35 & -0.332 & 0.936 \\
\hline 126 & MA & 0.350 & 0.296 & 1.18 & 0.238 & -0.231 & 0.932 \\
\hline 20 & NE & -0.722 & 0.421 & -1.72 & 0.086 & -1.55 & 0.10 \\
\hline 119 & NE & -0.596 & 0.569 & -1.05 & 0.296 & -1.713 & 0.521 \\
\hline 65 & NE & -0.546 & 0.149 & -3.65 & 0 & -0.84 & -0.25 \\
\hline 22 & $\mathrm{NE}$ & -0.391 & 0.278 & -1.41 & 0.159 & -0.94 & 0.15 \\
\hline 123 & NE & -0.360 & 0.229 & -1.57 & 0.117 & -0.809 & 0.090 \\
\hline
\end{tabular}




\begin{tabular}{|c|c|c|c|c|c|c|c|}
\hline 194 & $\mathrm{NE}$ & -0.197 & 0.535 & -0.37 & 0.712 & -1.246 & 0.851 \\
\hline 34 & $\mathrm{NE}$ & -0.196 & 0.212 & -0.93 & 0.355 & -0.61 & 0.22 \\
\hline 36 & $\mathrm{NE}$ & -0.154 & 0.348 & -0.44 & 0.659 & -0.84 & 0.53 \\
\hline 14 & $\mathrm{NE}$ & -0.091 & 0.254 & -0.36 & 0.721 & -0.59 & 0.41 \\
\hline 46 & $\mathrm{NE}$ & -0.019 & 0.272 & -0.07 & 0.946 & -0.55 & 0.52 \\
\hline 4 & $\mathrm{NE}$ & 0.063 & 0.416 & 0.15 & 0.88 & -0.75 & 0.88 \\
\hline 154 & $\mathrm{NE}$ & 0.072 & 0.723 & 0.1 & 0.92 & -1.346 & 1.491 \\
\hline 10 & $\mathrm{NE}$ & 0.191 & 0.333 & 0.57 & 0.566 & -0.46 & 0.84 \\
\hline 204 & $\mathrm{NE}$ & 0.197 & 0.400 & 0.49 & 0.622 & -0.587 & 0.981 \\
\hline 106 & $\mathrm{NE}$ & 0.849 & 0.908 & 0.93 & 0.35 & -0.93 & 2.63 \\
\hline 139 & PC & -1.215 & 0.094 & -12.96 & 0 & -1.399 & -1.031 \\
\hline 24 & PC & -0.961 & 0.035 & -27.6 & 0 & -1.03 & -0.89 \\
\hline 2 & $P C$ & -0.770 & 0.144 & -5.35 & 0 & -1.05 & -0.49 \\
\hline 173 & PC & -0.595 & 0.568 & -1.05 & 0.295 & -1.711 & 0.520 \\
\hline 158 & $P C$ & -0.488 & 0.486 & -1 & 0.315 & -1.440 & 0.465 \\
\hline 101 & PC & -0.471 & 0.269 & -1.75 & 0.081 & -1.00 & 0.06 \\
\hline 64 & PC & -0.444 & 0.324 & -1.37 & 0.171 & -1.08 & 0.19 \\
\hline 166 & PC & -0.430 & 0.366 & -1.18 & 0.24 & -1.147 & 0.287 \\
\hline 176 & PC & -0.279 & 0.365 & -0.76 & 0.444 & -0.995 & 0.437 \\
\hline 39 & PC & -0.219 & 0.228 & -0.96 & 0.336 & -0.67 & 0.23 \\
\hline 188 & $P C$ & -0.156 & 0.379 & -0.41 & 0.682 & -0.899 & 0.588 \\
\hline 27 & PC & -0.119 & 0.431 & -0.28 & 0.783 & -0.96 & 0.73 \\
\hline 142 & PC & -0.119 & 0.335 & -0.35 & 0.724 & -0.776 & 0.539 \\
\hline 170 & $P C$ & 0.014 & 0.377 & 0.04 & 0.971 & -0.726 & 0.754 \\
\hline 74 & PC & 0.068 & 0.303 & 0.23 & 0.822 & -0.53 & 0.66 \\
\hline 163 & $P C$ & 0.144 & 0.511 & 0.28 & 0.778 & -0.859 & 1.147 \\
\hline 201 & $P C$ & 0.279 & 0.552 & 0.5 & 0.614 & -0.805 & 1.362 \\
\hline 11 & $P C$ & 0.324 & 0.181 & 1.79 & 0.073 & -0.03 & 0.68 \\
\hline 159 & PC & 0.404 & 0.548 & 0.74 & 0.461 & -0.671 & 1.479 \\
\hline 115 & PC & 0.475 & 0.421 & 1.13 & 0.26 & -0.35 & 1.30 \\
\hline 148 & PC & 0.670 & 0.402 & 1.66 & 0.096 & -0.120 & 1.459 \\
\hline 52 & PC & 0.756 & 0.515 & 1.47 & 0.142 & -0.25 & 1.77 \\
\hline 197 & SA & -1.477 & 0.743 & -1.99 & 0.047 & -2.935 & -0.020 \\
\hline 178 & SA & -1.434 & 0.542 & -2.65 & 0.008 & -2.497 & -0.371 \\
\hline 29 & SA & -1.299 & 0.474 & -2.74 & 0.006 & -2.23 & -0.37 \\
\hline 63 & SA & -1.232 & 0.725 & -1.7 & 0.09 & -2.65 & 0.19 \\
\hline 199 & SA & -1.150 & 0.635 & -1.81 & 0.07 & -2.396 & 0.096 \\
\hline 187 & SA & -1.087 & 0.525 & -2.07 & 0.039 & -2.118 & -0.056 \\
\hline 95 & SA & -1.073 & 0.621 & -1.73 & 0.085 & -2.29 & 0.15 \\
\hline 31 & SA & -1.038 & 0.238 & -4.36 & 0 & -1.50 & -0.57 \\
\hline 97 & SA & -1.032 & 0.621 & -1.66 & 0.097 & -2.25 & 0.19 \\
\hline 127 & SA & -0.890 & 0.660 & -1.35 & 0.178 & -2.186 & 0.405 \\
\hline 169 & SA & -0.884 & 0.366 & -2.42 & 0.016 & -1.602 & -0.167 \\
\hline 84 & SA & -0.878 & 0.566 & -1.55 & 0.121 & -1.99 & 0.23 \\
\hline 168 & SA & -0.854 & 0.290 & -2.94 & 0.003 & -1.423 & -0.284 \\
\hline 189 & SA & -0.827 & 0.607 & -1.36 & 0.173 & -2.018 & 0.363 \\
\hline 83 & SA & -0.814 & 0.306 & -2.66 & 0.008 & -1.41 & -0.21 \\
\hline 15 & SA & -0.734 & 0.583 & -1.26 & 0.208 & -1.88 & 0.41 \\
\hline 128 & SA & -0.686 & 0.297 & -2.31 & 0.021 & -1.270 & -0.103 \\
\hline 60 & SA & -0.678 & 0.368 & -1.84 & 0.066 & -1.40 & 0.05 \\
\hline
\end{tabular}




\begin{tabular}{|c|c|c|c|c|c|c|c|}
\hline 48 & SA & -0.542 & 0.673 & -0.8 & 0.421 & -1.86 & 0.78 \\
\hline 72 & SA & -0.540 & 0.504 & -1.07 & 0.284 & -1.53 & 0.45 \\
\hline 116 & SA & -0.472 & 0.298 & -1.58 & 0.113 & -1.06 & 0.11 \\
\hline 190 & SA & -0.458 & 0.501 & -0.91 & 0.361 & -1.441 & 0.525 \\
\hline 62 & SA & -0.447 & 0.320 & -1.4 & 0.162 & -1.07 & 0.18 \\
\hline 174 & SA & -0.438 & 0.541 & -0.81 & 0.418 & -1.498 & 0.623 \\
\hline 66 & SA & -0.304 & 0.334 & -0.91 & 0.363 & -0.96 & 0.35 \\
\hline 58 & SA & -0.299 & 0.373 & -0.8 & 0.422 & -1.03 & 0.43 \\
\hline 56 & SA & -0.272 & 0.366 & -0.74 & 0.458 & -0.99 & 0.45 \\
\hline 82 & SA & -0.243 & 0.354 & -0.69 & 0.492 & -0.94 & 0.45 \\
\hline 54 & SA & -0.195 & 0.388 & -0.5 & 0.614 & -0.96 & 0.57 \\
\hline 141 & SA & -0.164 & 0.102 & -1.61 & 0.108 & -0.363 & 0.036 \\
\hline 214 & SA & -0.160 & 0.388 & -0.41 & 0.681 & -0.921 & 0.602 \\
\hline 12 & SA & -0.129 & 0.212 & -0.61 & 0.544 & -0.55 & 0.29 \\
\hline 9 & SA & -0.124 & 0.426 & -0.29 & 0.772 & -0.96 & 0.71 \\
\hline 175 & SA & -0.123 & 0.273 & -0.45 & 0.651 & -0.658 & 0.412 \\
\hline 149 & SA & -0.004 & 0.431 & -0.01 & 0.993 & -0.850 & 0.842 \\
\hline 209 & SA & 0.004 & 0.473 & 0.01 & 0.994 & -0.925 & 0.933 \\
\hline 43 & SA & 0.038 & 0.405 & 0.09 & 0.925 & -0.76 & 0.83 \\
\hline 59 & SA & 0.041 & 0.448 & 0.09 & 0.928 & -0.84 & 0.92 \\
\hline 205 & SA & 0.234 & 0.383 & 0.61 & 0.541 & -0.517 & 0.986 \\
\hline 42 & SA & 0.241 & 1.088 & 0.22 & 0.825 & -1.89 & 2.38 \\
\hline 162 & SA & 0.488 & 0.374 & 1.31 & 0.192 & -0.245 & 1.221 \\
\hline 78 & WNC & -1.746 & 1.057 & -1.65 & 0.099 & -3.82 & 0.33 \\
\hline 192 & WNC & -1.127 & 0.243 & -4.64 & 0 & -1.604 & -0.651 \\
\hline 131 & WNC & -0.654 & 0.332 & -1.97 & 0.049 & -1.307 & -0.002 \\
\hline 88 & WNC & -0.622 & 0.261 & -2.39 & 0.017 & -1.13 & -0.11 \\
\hline 90 & WNC & -0.615 & 0.364 & -1.69 & 0.091 & -1.33 & 0.10 \\
\hline 150 & WNC & -0.552 & 0.188 & -2.94 & 0.003 & -0.920 & -0.184 \\
\hline 114 & WNC & -0.495 & 0.749 & -0.66 & 0.509 & -1.96 & 0.97 \\
\hline 132 & WNC & -0.476 & 0.447 & -1.06 & 0.287 & -1.353 & 0.401 \\
\hline 77 & WNC & -0.471 & 0.336 & -1.4 & 0.162 & -1.13 & 0.19 \\
\hline 183 & WNC & -0.463 & 0.115 & -4.02 & 0 & -0.688 & -0.237 \\
\hline 111 & WNC & -0.440 & 0.303 & -1.45 & 0.146 & -1.03 & 0.15 \\
\hline 136 & WNC & -0.425 & 0.373 & -1.14 & 0.255 & -1.157 & 0.308 \\
\hline 89 & WNC & -0.352 & 0.221 & -1.59 & 0.111 & -0.79 & 0.08 \\
\hline 79 & WNC & -0.200 & 0.522 & -0.38 & 0.701 & -1.22 & 0.82 \\
\hline 80 & WNC & -0.200 & 0.522 & -0.38 & 0.701 & -1.22 & 0.82 \\
\hline 81 & WNC & -0.200 & 0.522 & -0.38 & 0.701 & -1.22 & 0.82 \\
\hline 3 & WNC & -0.190 & 0.411 & -0.46 & 0.643 & -1.00 & 0.62 \\
\hline 108 & WNC & -0.153 & 0.427 & -0.36 & 0.719 & -0.99 & 0.68 \\
\hline 87 & WNC & -0.124 & 0.404 & -0.31 & 0.758 & -0.92 & 0.67 \\
\hline 195 & WNC & -0.070 & 0.455 & -0.15 & 0.878 & -0.962 & 0.822 \\
\hline 138 & WNC & -0.052 & 0.419 & -0.13 & 0.901 & -0.874 & 0.769 \\
\hline 185 & WNC & 0.041 & 0.406 & 0.1 & 0.921 & -0.757 & 0.838 \\
\hline 121 & WNC & 0.179 & 0.268 & 0.67 & 0.504 & -0.346 & 0.704 \\
\hline 99 & WNC & 0.489 & 0.717 & 0.68 & 0.496 & -0.92 & 1.90 \\
\hline 212 & WNC & 1.109 & 0.779 & 1.42 & 0.155 & -0.420 & 2.638 \\
\hline 51 & WNC & 1.404 & 0.422 & 3.32 & 0.001 & 0.58 & 2.23 \\
\hline 135 & WSC & -1.226 & 0.591 & -2.07 & 0.038 & -2.385 & -0.067 \\
\hline
\end{tabular}




$\begin{array}{cccccccc}6 & \text { WSC } & -0.917 & 0.283 & -3.24 & 0.001 & -1.47 & -0.36 \\ 215 & \text { WSC } & -0.632 & 0.354 & -1.78 & 0.075 & -1.326 & 0.063 \\ 102 & \text { WSC } & -0.615 & 0.344 & -1.79 & 0.074 & -1.29 & 0.06 \\ 124 & \text { WSC } & -0.613 & 0.254 & -2.42 & 0.016 & -1.111 & -0.115 \\ 13 & \text { WSC } & -0.517 & 0.726 & -0.71 & 0.476 & -1.94 & 0.91 \\ 55 & \text { WSC } & -0.485 & 0.335 & -1.45 & 0.148 & -1.14 & 0.17 \\ 167 & \text { WSC } & -0.484 & 0.437 & -1.11 & 0.268 & -1.340 & 0.373 \\ 45 & \text { WSC } & -0.464 & 0.265 & -1.75 & 0.08 & -0.98 & 0.06 \\ 19 & \text { WSC } & -0.450 & 0.448 & -1 & 0.315 & -1.33 & 0.43 \\ 181 & \text { WSC } & -0.318 & 0.331 & -0.96 & 0.338 & -0.968 & 0.332 \\ 156 & \text { WSC } & -0.286 & 0.440 & -0.65 & 0.516 & -1.150 & 0.578 \\ 165 & \text { WSC } & -0.272 & 0.404 & -0.67 & 0.502 & -1.065 & 0.522 \\ 21 & \text { WSC } & -0.154 & 0.292 & -0.53 & 0.597 & -0.73 & 0.42 \\ 68 & \text { WSC } & -0.108 & 0.234 & -0.46 & 0.646 & -0.57 & 0.35 \\ 70 & \text { WSC } & -0.091 & 0.508 & -0.18 & 0.858 & -1.09 & 0.91 \\ 180 & \text { WSC } & 0.023 & 0.587 & 0.04 & 0.969 & -1.129 & 1.174 \\ 8 & \text { WSC } & 0.066 & 0.406 & 0.16 & 0.872 & -0.73 & 0.86 \\ 203 & \text { WSC } & 0.447 & 0.205 & 2.18 & 0.03 & 0.044 & 0.851 \\ 61 & \text { WSC } & 0.452 & 0.317 & 1.43 & 0.154 & -0.17 & 1.07 \\ 50 & \text { WSC } & 0.486 & 0.427 & 1.14 & 0.255 & -0.35 & 1.32 \\ 143 & \text { WSC } & 0.614 & 0.440 & 1.39 & 0.163 & -0.250 & 1.477\end{array}$

The utility results also have a wide range of price elasticity estimates. The minimum value is -1.75 and the maximum is 1.40 . In general, the estimates are representative of the results from the state-level analysis in residential electricity. Most estimates are negative and in the inelastic range. Some are positive in each region. Overall, these results suffer from a lack of precision also. Only about $17 \%$ of the utilities in the sample were statistically significant. Some of this variation in the estimates may be explained by the large differences in the size of utilities.

We tested for first-order autocorrelation in the error term and the results indicate it may be present. The estimate of $\rho$ for the utility-level model was -0.32 with a t-statistic of -3.27. The results suggest first-order autocorrelation in the error term and we, therefore, ran the model to account for an $\mathrm{AR}(1)$ structure in the error term.

\section{Results from Energy Use Trend Analysis}

The trend analysis fits a linear trend to the variable of interest. Many of the trends in the data were linear and the model fit well. In some cases, particularly the natural gas market, the trends were not linear and the model had a poorer fit.

This section will now display the trend analysis results first for the region level and then at the state level. 


\section{Region-Level Results}

The model has the form:

$\ln \mathrm{y}_{\mathrm{it}}=\alpha+$ year $_{\mathrm{t}} \beta+$ region $_{\mathrm{i}} \delta_{\mathrm{i}}+\left(\right.$ (region $_{\mathrm{i}} \mathrm{x}$ year $\left._{\mathrm{t}}\right) \beta_{\mathrm{i}}+\varepsilon_{\mathrm{it}}$

The model includes an indicator variable for region and an interaction term between region and year. These terms allow the slope of the trend and y-intercept to vary freely for each region.

\section{Residential Electricity}

Table D.17: Regional trends in residential electricity energy intensity

$\begin{array}{lcccccc} & \text { Coef } & \text { Std. Err. } & \mathrm{t} & \mathrm{P}>|\mathrm{t}| & 95 \% \text { Conf } & \text { Interval } \\ \text { South Atlantic } & 1.94 \% & 0.08 \% & 25.7 & 0.0 & 1.79 \% & 2.09 \% \\ \text { East South Central } & 1.79 \% & 0.11 \% & 16.8 & 0.0 & 1.59 \% & 2.00 \% \\ \text { West South Central } & 1.59 \% & 0.11 \% & 14.9 & 0.0 & 1.38 \% & 1.80 \% \\ \text { West North Central } & 1.45 \% & 0.08 \% & 18.0 & 0.0 & 1.29 \% & 1.61 \% \\ \text { East North Central } & 1.40 \% & 0.10 \% & 14.6 & 0.0 & 1.21 \% & 1.58 \% \\ \text { Mid Atlantic } & 1.33 \% & 0.12 \% & 10.8 & 0.0 & 1.09 \% & 1.57 \% \\ \text { New England } & 0.91 \% & 0.09 \% & 10.4 & 0.0 & 0.73 \% & 1.08 \% \\ \text { Mountain } & 0.80 \% & 0.08 \% & 10.6 & 0.0 & 0.65 \% & 0.95 \% \\ \text { Pacific Coast } & -0.12 \% & 0.12 \% & -1.0 & 0.3 & -0.36 \% & 0.12 \%\end{array}$

Intensity is measured as quantity of residential electricity per capita. The table shows per capita electricity use is growing fastest in the South Atlantic and Central regions. Growth in per capita electricity use is negligible in the Pacific Coast region.

Table D.18: Regional trends in residential electricity expenditures

$\begin{array}{lcccccc} & \text { Coef } & \text { Std. Err. } & \mathrm{t} & \mathrm{P}>|\mathrm{t}| & 95 \% \text { Conf } & \text { Interval } \\ \text { New England } & 0.717 \% & 0.111 \% & 6.49 & 0 & 0.500 \% & 0.934 \% \\ \text { Pacific Coast } & 0.680 \% & 0.156 \% & 4.35 & 0 & 0.373 \% & 0.987 \% \\ \text { East South Central } & 0.624 \% & 0.135 \% & 4.61 & 0 & 0.358 \% & 0.890 \% \\ \text { South Atlantic } & 0.621 \% & 0.096 \% & 6.48 & 0 & 0.433 \% & 0.809 \% \\ \text { West South Central } & 0.518 \% & 0.135 \% & 3.83 & 0 & 0.253 \% & 0.784 \% \\ \text { Mid Atlantic } & 0.316 \% & 0.156 \% & 2.02 & 0.04 & 0.009 \% & 0.623 \% \\ \text { West North Central } & 0.143 \% & 0.102 \% & 1.4 & 0.16 & -0.058 \% & 0.344 \% \\ \text { East North Central } & 0.122 \% & 0.121 \% & 1.01 & 0.32 & -0.116 \% & 0.359 \% \\ \text { Mountain } & 0.008 \% & 0.096 \% & 0.09 & 0.93 & -0.180 \% & 0.196 \%\end{array}$


Expenditures are growing fastest in the New England and Pacific Coast regions. Growth in expenditures is negligible in the Mountain region. Overall, the growth rates are all less than $1 \%$.

Table D.19: Regional trends in residential electricity expenditures as a share of income

$\begin{array}{lcccccc} & \text { Coef } & \text { Std. Err. } & \mathrm{t} & \mathrm{P}>|\mathrm{t}| & 95 \% \text { Conf } & \text { Interval } \\ \text { Mid Atlantic } & -1.99 \% & 0.17 \% & -12.08 & 0 & -2.32 \% & -1.67 \% \\ \text { West North Central } & -1.98 \% & 0.11 \% & -18.32 & 0 & -2.19 \% & -1.77 \% \\ \text { East North Central } & -1.90 \% & 0.13 \% & -14.83 & 0 & -2.15 \% & -1.65 \% \\ \text { Mountain } & -1.83 \% & 0.10 \% & -18.07 & 0 & -2.03 \% & -1.63 \% \\ \text { New England } & -1.82 \% & 0.12 \% & -15.58 & 0 & -2.05 \% & -1.59 \% \\ \text { East South Central } & -1.80 \% & 0.14 \% & -12.57 & 0 & -2.08 \% & -1.52 \% \\ \text { South Atlantic } & -1.71 \% & 0.10 \% & -16.9 & 0 & -1.91 \% & -1.51 \% \\ \text { West South Central } & -1.46 \% & 0.14 \% & -10.24 & 0 & -1.74 \% & -1.18 \% \\ \text { Pacific Coast } & -1.19 \% & 0.17 \% & -7.21 & 0 & -1.51 \% & -0.87 \%\end{array}$

The trends in expenditures as a share of income show that income growth is faster than the increase in energy expenditures. Therefore, energy expenditures as a portion of household budgets is generally decreasing. The regional differences in the rate of decrease vary by about 1\%. Expenditures as a share of income are declining fastest in the Mid Atlantic at about 2\%. Decline is slowest in the Pacific Coast region at approximately $1 \%$.

\section{Commercial Electricity}

Table D.20: Regional trends in commercial energy intensity

\begin{tabular}{lcccccc} 
Regional commercial energy intensity trends & \multicolumn{4}{c}{ R-square $=0.57$} \\
& Coef. & Std. Err. & $\mathrm{t}$ & $\mathrm{P}>|\mathrm{t}|$ & {$[95 \%$ Conf. } & Interval] \\
New England & $2.32 \%$ & $0.20 \%$ & 11.42 & 0 & $1.92 \%$ & $2.72 \%$ \\
West North Central & $2.18 \%$ & $0.30 \%$ & 7.15 & 0 & $1.58 \%$ & $2.77 \%$ \\
South Atlantic & $1.97 \%$ & $0.20 \%$ & 9.9 & 0 & $1.58 \%$ & $2.36 \%$ \\
Mid Atlantic & $1.78 \%$ & $0.25 \%$ & 7.01 & 0 & $1.28 \%$ & $2.28 \%$ \\
East North Central & $1.49 \%$ & $0.20 \%$ & 7.58 & 0 & $1.10 \%$ & $1.87 \%$ \\
Mountain & $1.48 \%$ & $0.29 \%$ & 5.19 & 0 & $0.92 \%$ & $2.04 \%$ \\
West South Central & $0.96 \%$ & $0.25 \%$ & 3.81 & 0 & $0.47 \%$ & $1.45 \%$ \\
East South Central & $0.94 \%$ & $0.46 \%$ & 2.04 & 0.041 & $0.04 \%$ & $1.84 \%$ \\
Pacific Coast & $0.25 \%$ & $0.32 \%$ & 0.8 & 0.425 & $-0.37 \%$ & $0.88 \%$
\end{tabular}

Intensity is measured as quantity of commercial electricity per unit of commercial floorspace. The results show statistically significant differences in the annual growth rates. The Pacific Coast rate is near zero, whereas the annual growth rates are over $2 \%$ in New England and the West North Central. All the trend estimates are statistically 
significant, except the Pacific Coast region. However, the model fit is only moderate, which is shown by the adjusted R-squared of 0.57 .

\section{Natural Gas}

Table D.21: Regional energy intensity trends for residential natural gas.

\begin{tabular}{|c|c|c|c|c|c|c|}
\hline \multicolumn{5}{|c|}{ Regional Trend in Natural Gas Energy Intensity } & \multirow{2}{*}{\multicolumn{2}{|c|}{ R-squared $\quad 0.4302$}} \\
\hline & Coef. & Std. Err. & & $P>|t|$ & & \\
\hline Pacific Coa & $1.09 \%$ & $0.60 \%$ & 1.84 & 0.067 & $-0.08 \%$ & $2.26 \%$ \\
\hline Mid Atlantic & $0.45 \%$ & $0.17 \%$ & 2.7 & 0.007 & . & $0.78 \%$ \\
\hline ew Englan & 0.1 & $3 \%$ & 0.14 & 0.892 & & $.26 \%$ \\
\hline hou & $-0.41 \%$ & $0.39 \%$ & -1.06 & 0.288 & & $0.35 \%$ \\
\hline ou & $-0.45 \%$ & 0.7 & -0.6 & 0.52 & & $0.95 \%$ \\
\hline as & $-0.47 \%$ & $\%$ & -2.41 & 0.016 & -0 & $-0.09 \%$ \\
\hline as & $-0.57 \%$ & $0.31 \%$ & -1.87 & 0.062 & -1 & $0.03 \%$ \\
\hline Ves & $-0.60 \%$ & 0.2 & 66 & 0.008 & -1 & $-0.16 \%$ \\
\hline Vest South Central & $-2.05 \%$ & $0.28 \%$ & -7.41 & 0 & $-2.60 \%$ & $-1.51 \%$ \\
\hline
\end{tabular}

In this case, we measured energy intensity as the quantity of natural gas consumed per capita. The results show much different regional trends. Residential natural gas energy intensity is increasing in the Pacific Coast, Mid Atlantic, and New England regions. The trend is a slight decline in the South Atlantic and Central regions, except for the West South Central where intensity is declining over $2 \%$ per year.

The model fit is only fair in this case. The r-squared for this model is 0.43 . The natural gas trends generally have two peaks, which is why the linear fit is limited.

Table D.22: Regional trends in natural gas energy expenditures

$\begin{array}{lccccccc}\text { Regional Trend in Natural Gas Energy Expenditures } & \text { R-squared } & 0.3345 \\ & \text { Coef. } & \text { Std. Err. } & t & P>|t| & \text { [95\% Conf. Interval] } \\ \text { Pacific Coast } & 1.01 \% & 0.45 \% & 2.25 & 0.025 & 0.13 \% & 1.89 \% \\ \text { Mid Atlantic } & 0.75 \% & 0.20 \% & 3.85 & 0 & 0.37 \% & 1.14 \% \\ \text { East South Central } & 0.70 \% & 0.34 \% & 2.06 & 0.04 & 0.03 \% & 1.36 \% \\ \text { South Atlantic } & 0.47 \% & 0.64 \% & 0.74 & 0.458 & -0.78 \% & 1.73 \% \\ \text { West North Central } & 0.14 \% & 0.25 \% & 0.55 & 0.579 & -0.36 \% & 0.64 \% \\ \text { New England } & -0.04 \% & 1.08 \% & -0.04 & 0.971 & -2.16 \% & 2.08 \% \\ \text { Mountain } & -0.15 \% & 0.28 \% & -0.53 & 0.595 & -0.71 \% & 0.41 \% \\ \text { East North Central } & -0.15 \% & 0.23 \% & -0.65 & 0.517 & -0.61 \% & 0.31 \% \\ \text { West South Central } & -0.56 \% & 0.29 \% & -1.93 & 0.054 & -1.14 \% & 0.01 \%\end{array}$

The trend is rising expenditures in the Pacific Coast, Mid Atlantic, East South Central, South Atlantic, and West North Central regions. Expenditures are falling in the New England, Mountain, East North Central, and West South Central regions. For most 
regions, the trend is near or less than $0.5 \%$ in absolute magnitude. Therefore, the estimates show that expenditures are relatively stable for most people.

The model fit is marginal in this case. Natural gas prices had several spikes and dropoffs, which is a nonlinear pattern. The expenditure data follow the price trend closely. Therefore, the linear fit is marginal for this variable.

Table D.23: Annual trends for natural gas expenditures as a share of income

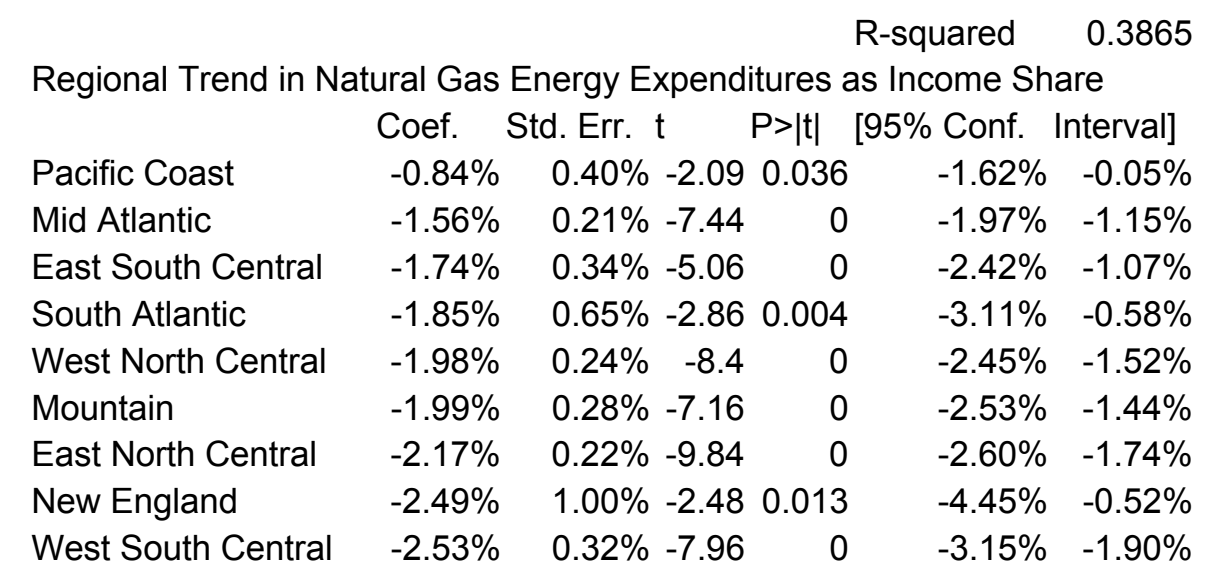

The results show that expenditures as a share of income are falling in all regions. The most rapid decline is in the West South Central. The Pacific Coast trend has the most moderate decline. Again, the model fit is only marginal for the reasons stated above.

\section{State-Level Results}

The model has the form:

$\ln \mathrm{y}_{\mathrm{it}}=\alpha+$ year $_{\mathrm{t}} \beta+$ state $_{\mathrm{i}} \delta_{\mathrm{i}}+\left(\right.$ state $_{\mathrm{i}} \mathrm{x}$ year $\left._{\mathrm{t}}\right) \beta_{\mathrm{i}}+\varepsilon_{\mathrm{it}}$

The model includes an indicator variable for each state and an interaction term between state and year. These terms allow the slope of the trend and y-intercept to vary freely for each state. 


\section{Residential Electricity}

Table D.24: Residential electricity energy intensity

\begin{tabular}{|c|c|c|c|c|c|c|}
\hline \multicolumn{7}{|c|}{ Residential Energy Intensity } \\
\hline & Coef. & Std. Err. & $P>|t|$ & & onf. & val] \\
\hline West Virginia & $2.51 \%$ & $0.05 \%$ & 49.2 & 0 & $2.41 \%$ & $2.61 \%$ \\
\hline Delaware & $2.49 \%$ & $0.23 \%$ & 10.81 & 0 & $2.04 \%$ & $2.95 \%$ \\
\hline Kentucky & $2.43 \%$ & $0.08 \%$ & 29.32 & 0 & $2.26 \%$ & $2.59 \%$ \\
\hline Maryland & $2.42 \%$ & $0.13 \%$ & 18.68 & 0 & $2.17 \%$ & $2.68 \%$ \\
\hline Mississippi & $2.23 \%$ & $0.08 \%$ & 26.32 & 0 & $2.06 \%$ & $2.39 \%$ \\
\hline Alabama & $2.18 \%$ & $0.09 \%$ & 23.46 & 0 & $2.00 \%$ & $2.36 \%$ \\
\hline South Carolina & $2.16 \%$ & $0.07 \%$ & 29.65 & 0 & $2.01 \%$ & $2.30 \%$ \\
\hline Louisiana & $2.14 \%$ & $0.07 \%$ & 32.43 & 0 & $2.01 \%$ & $2.27 \%$ \\
\hline Missouri & $2.10 \%$ & $0.11 \%$ & 19.84 & 0 & $1.89 \%$ & $2.31 \%$ \\
\hline Kansas & $1.97 \%$ & $0.13 \%$ & 14.98 & 0 & $1.71 \%$ & $2.22 \%$ \\
\hline Georgia & $1.95 \%$ & $0.08 \%$ & 24.76 & 0 & $1.79 \%$ & $2.10 \%$ \\
\hline New Mexico & $1.88 \%$ & $0.08 \%$ & 23.37 & 0 & $1.72 \%$ & $2.04 \%$ \\
\hline Virginia & $1.85 \%$ & $0.07 \%$ & 28.03 & 0 & $1.72 \%$ & $1.97 \%$ \\
\hline Pennsylvania & $1.76 \%$ & $0.05 \%$ & 36.67 & 0 & $1.66 \%$ & $1.85 \%$ \\
\hline North Dakota & $1.76 \%$ & $0.12 \%$ & 14.68 & 0 & $1.52 \%$ & $1.99 \%$ \\
\hline North Carolina & $1.71 \%$ & $0.06 \%$ & 27 & 0 & $1.59 \%$ & $1.84 \%$ \\
\hline Wyoming & $1.71 \%$ & $0.19 \%$ & 8.93 & 0 & $1.33 \%$ & $2.08 \%$ \\
\hline Texas & $1.64 \%$ & $0.10 \%$ & 17.04 & 0 & $1.45 \%$ & $1.83 \%$ \\
\hline Florida & $1.64 \%$ & $0.08 \%$ & 20.98 & 0 & $1.49 \%$ & $1.79 \%$ \\
\hline Massachusetts & $1.63 \%$ & $0.06 \%$ & 25.06 & 0 & $1.50 \%$ & $1.75 \%$ \\
\hline Arkansas & $1.62 \%$ & $0.17 \%$ & 9.55 & 0 & $1.29 \%$ & $1.96 \%$ \\
\hline Ohio & $1.62 \%$ & $0.04 \%$ & 38.3 & 0 & $1.54 \%$ & $1.70 \%$ \\
\hline Indiana & $1.62 \%$ & $0.05 \%$ & 35.62 & 0 & $1.53 \%$ & $1.71 \%$ \\
\hline Nebraska & $1.61 \%$ & $0.10 \%$ & 15.85 & 0 & $1.41 \%$ & $1.81 \%$ \\
\hline Oklahoma & $1.60 \%$ & $0.11 \%$ & 14.27 & 0 & $1.38 \%$ & $1.82 \%$ \\
\hline New Jersey & $1.59 \%$ & $0.06 \%$ & 27.69 & 0 & $1.48 \%$ & $1.71 \%$ \\
\hline Arizona & $1.52 \%$ & $0.07 \%$ & 22.08 & 0 & $1.39 \%$ & $1.66 \%$ \\
\hline Rhode Island & $1.49 \%$ & $0.05 \%$ & 31.61 & 0 & $1.40 \%$ & $1.58 \%$ \\
\hline New York & $1.42 \%$ & $0.05 \%$ & 30.3 & 0 & $1.33 \%$ & $1.51 \%$ \\
\hline Michigan & $1.40 \%$ & $0.07 \%$ & 19.1 & 0 & $1.25 \%$ & $1.54 \%$ \\
\hline Colorado & $1.37 \%$ & $0.21 \%$ & 6.44 & 0 & $0.95 \%$ & $1.79 \%$ \\
\hline Connecticut & $1.37 \%$ & $0.06 \%$ & 24.85 & 0 & $1.26 \%$ & $1.48 \%$ \\
\hline Minnesota & $1.34 \%$ & $0.08 \%$ & 16.31 & 0 & $1.18 \%$ & $1.51 \%$ \\
\hline Utah & $1.22 \%$ & $0.08 \%$ & 14.57 & 0 & $1.05 \%$ & $1.38 \%$ \\
\hline Illinois & $1.19 \%$ & $0.10 \%$ & 11.66 & 0 & $0.99 \%$ & $1.39 \%$ \\
\hline Wisconsin & $1.18 \%$ & $0.08 \%$ & 14.22 & 0 & $1.02 \%$ & $1.34 \%$ \\
\hline South Dakota & $1.16 \%$ & $0.11 \%$ & 10.4 & 0 & $0.94 \%$ & $1.37 \%$ \\
\hline lowa & $1.06 \%$ & $0.08 \%$ & 12.6 & 0 & $0.90 \%$ & $1.23 \%$ \\
\hline Montana & $0.79 \%$ & $0.14 \%$ & 5.51 & 0 & $0.51 \%$ & $1.07 \%$ \\
\hline Tennessee & $0.69 \%$ & $0.12 \%$ & 5.66 & 0 & $0.45 \%$ & $0.93 \%$ \\
\hline
\end{tabular}




$\begin{array}{lrrrrrr}\text { New Hampshire } & 0.61 \% & 0.10 \% & 6.18 & 0 & 0.42 \% & 0.80 \% \\ \text { Maine } & 0.60 \% & 0.12 \% & 4.82 & 0 & 0.35 \% & 0.84 \% \\ \text { Vermont } & 0.32 \% & 0.17 \% & 1.92 & 0.055 & -0.01 \% & 0.65 \% \\ \text { California } & 0.28 \% & 0.07 \% & 3.99 & 0 & 0.14 \% & 0.42 \% \\ \text { Nevada } & 0.07 \% & 0.12 \% & 0.59 & 0.554 & -0.16 \% & 0.30 \% \\ \text { Oregon } & 0.00 \% & 0.08 \% & 0.01 & 0.994 & -0.16 \% & 0.16 \% \\ \text { Idaho } & -0.01 \% & 0.11 \% & -0.11 & 0.915 & -0.23 \% & 0.20 \% \\ \text { Washington } & -0.57 \% & 0.16 \% & -3.48 & 0.001 & -0.89 \% & -0.25 \%\end{array}$

The results show that per capita residential electricity use is growing quickly in southern states. All of the states with a growth rate over 2\% are in the South Atlantic and East South Central regions. The growth rate is considerably smaller (less than $0.5 \%$ ) in Vermont, California, Nevada, Oregon, Idaho, and Washington. Notably, Oregon, Idaho, and Washington have zero growth or declining per capita use.

Table D.25: Trends in expenditures on residential electricity as a share of income

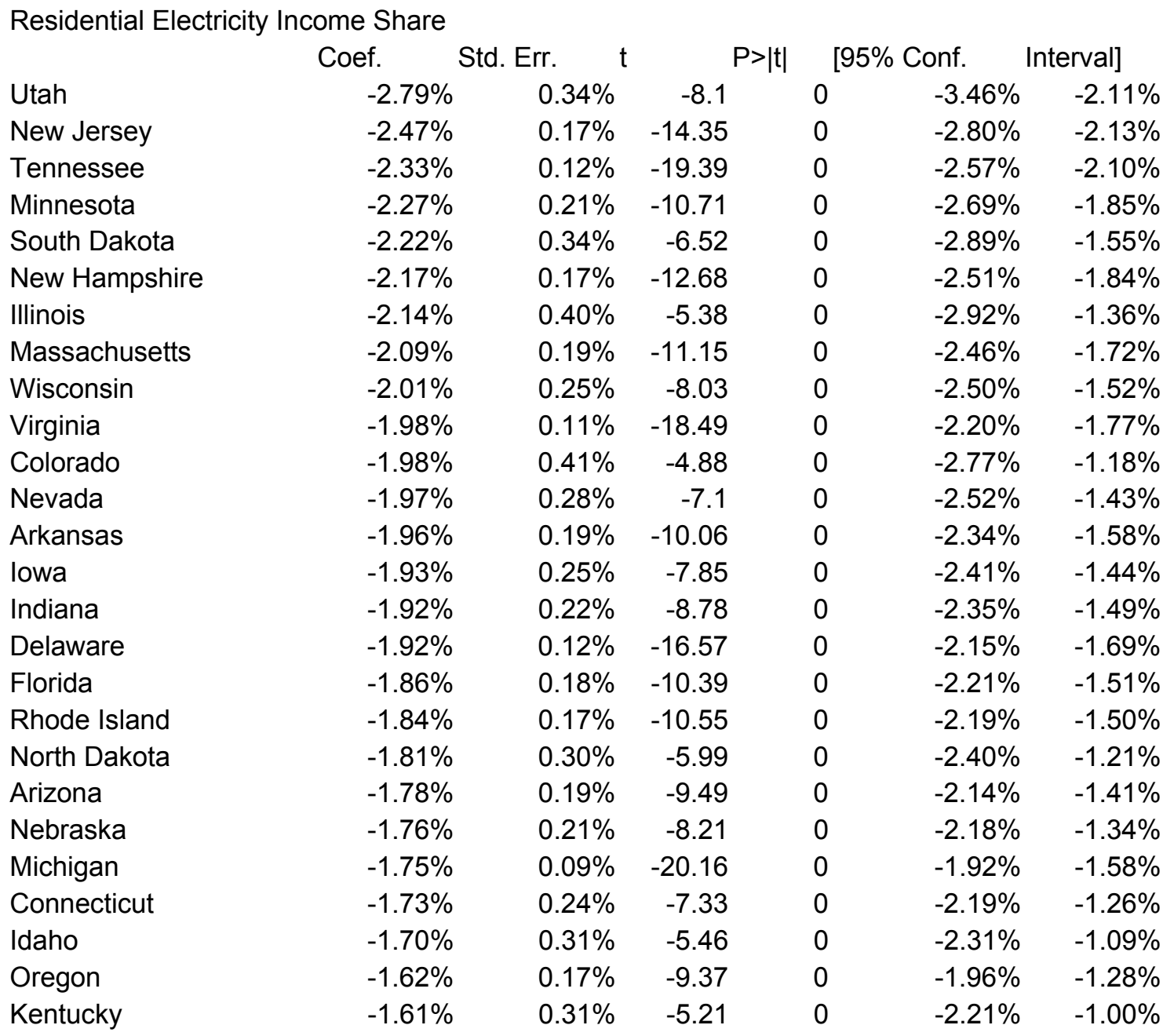




$\begin{array}{lrrrrrr}\text { Missouri } & -1.58 \% & 0.21 \% & -7.69 & 0 & -1.99 \% & -1.18 \% \\ \text { North Carolina } & -1.58 \% & 0.17 \% & -9.48 & 0 & -1.90 \% & -1.25 \% \\ \text { Alabama } & -1.55 \% & 0.17 \% & -8.97 & 0 & -1.89 \% & -1.21 \% \\ \text { Vermont } & -1.50 \% & 0.17 \% & -8.81 & 0 & -1.83 \% & -1.16 \% \\ \text { New Mexico } & -1.49 \% & 0.27 \% & -5.59 & 0 & -2.02 \% & -0.97 \% \\ \text { Ohio } & -1.49 \% & 0.19 \% & -7.87 & 0 & -1.86 \% & -1.12 \% \\ \text { Maryland } & -1.42 \% & 0.20 \% & -7.01 & 0 & -1.82 \% & -1.02 \% \\ \text { Georgia } & -1.41 \% & 0.12 \% & -12.09 & 0 & -1.64 \% & -1.18 \% \\ \text { Kansas } & -1.38 \% & 0.35 \% & -3.98 & 0 & -2.05 \% & -0.70 \% \\ \text { Oklahoma } & -1.35 \% & 0.26 \% & -5.15 & 0 & -1.86 \% & -0.84 \% \\ \text { Pennsylvania } & -1.33 \% & 0.16 \% & -8.22 & 0 & -1.65 \% & -1.01 \% \\ \text { New York } & -1.33 \% & 0.14 \% & -9.74 & 0 & -1.59 \% & -1.06 \% \\ \text { Mississippi } & -1.33 \% & 0.15 \% & -8.7 & 0 & -1.62 \% & -1.03 \% \\ \text { South Carolina } & -1.29 \% & 0.18 \% & -7.26 & 0 & -1.64 \% & -0.94 \% \\ \text { Texas } & -1.29 \% & 0.25 \% & -5.22 & 0 & -1.77 \% & -0.80 \% \\ \text { West Virginia } & -1.12 \% & 0.18 \% & -6.41 & 0 & -1.47 \% & -0.78 \% \\ \text { Washington } & -1.10 \% & 0.48 \% & -2.27 & 0.023 & -2.04 \% & -0.15 \% \\ \text { Maine } & -1.04 \% & 0.25 \% & -4.12 & 0 & -1.53 \% & -0.54 \% \\ \text { California } & -0.73 \% & 0.19 \% & -3.86 & 0 & -1.10 \% & -0.36 \% \\ \text { Louisiana } & -0.59 \% & 0.39 \% & -1.51 & 0.131 & -1.36 \% & 0.18 \% \\ \text { Wyoming } & -0.33 \% & 0.51 \% & -0.65 & 0.517 & -1.34 \% & 0.67 \% \\ \text { Montana } & -0.27 \% & 0.23 \% & -1.14 & 0.255 & -0.73 \% & 0.19 \% \\ & & & & & & \end{array}$

The trends are declining in all states but the rates are considerably different. Nine states are declining at $2 \%$ per year or more. Four states are declining slower than $0.75 \%$. There is a relatively even distribution of states between these points.

\section{Commercial Electricity}

We only estimated trends for commercial electricity energy intensity. We measure energy intensity for this variable is the amount of commercial electricity used per unit of commercial floorspace.

Table D.26: Estimates of the annual trend in commercial energy intensity

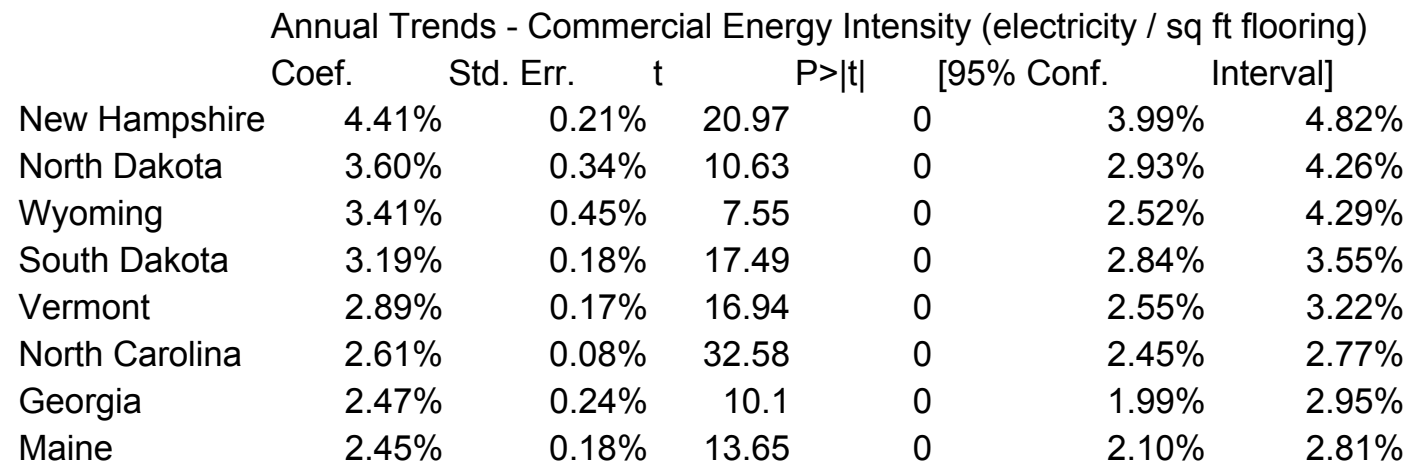




\begin{tabular}{|c|c|c|c|c|c|c|}
\hline Alabama & $2.40 \%$ & $0.29 \%$ & 8.43 & 0 & $1.85 \%$ & $2.96 \%$ \\
\hline Delaware & $2.35 \%$ & $0.21 \%$ & 11.27 & 0 & $1.94 \%$ & $2.76 \%$ \\
\hline Maryland & $2.34 \%$ & $0.69 \%$ & 3.41 & 0.001 & $0.99 \%$ & $3.68 \%$ \\
\hline Mississippi & $2.32 \%$ & $0.27 \%$ & 8.75 & 0 & $1.80 \%$ & $2.84 \%$ \\
\hline Michigan & $2.24 \%$ & $0.25 \%$ & 9.03 & 0 & $1.76 \%$ & $2.73 \%$ \\
\hline Missouri & $2.11 \%$ & $0.11 \%$ & 18.8 & 0 & $1.89 \%$ & $2.33 \%$ \\
\hline West Virginia & $2.06 \%$ & $0.11 \%$ & 19.46 & 0 & $1.85 \%$ & $2.27 \%$ \\
\hline New Mexico & $2.04 \%$ & $0.18 \%$ & 11.63 & 0 & $1.69 \%$ & $2.38 \%$ \\
\hline Nebraska & $2.01 \%$ & $0.17 \%$ & 12.11 & 0 & $1.68 \%$ & $2.34 \%$ \\
\hline Utah & $1.99 \%$ & $0.18 \%$ & 11.21 & 0 & $1.64 \%$ & $2.33 \%$ \\
\hline New Jersey & $1.95 \%$ & $0.11 \%$ & 18.44 & 0 & $1.74 \%$ & $2.16 \%$ \\
\hline Pennsylvania & $1.81 \%$ & $0.07 \%$ & 25.32 & 0 & $1.67 \%$ & $1.95 \%$ \\
\hline Minnesota & $1.70 \%$ & $0.10 \%$ & 17.38 & 0 & $1.51 \%$ & $1.89 \%$ \\
\hline Indiana & $1.63 \%$ & $0.12 \%$ & 13.33 & 0 & $1.39 \%$ & $1.87 \%$ \\
\hline Rhode Island & $1.62 \%$ & $0.11 \%$ & 14.08 & 0 & $1.39 \%$ & $1.84 \%$ \\
\hline Ohio & $1.59 \%$ & $0.14 \%$ & 11.42 & 0 & $1.31 \%$ & $1.86 \%$ \\
\hline New York & $1.58 \%$ & $0.07 \%$ & 21.73 & 0 & $1.44 \%$ & $1.72 \%$ \\
\hline Colorado & $1.57 \%$ & $0.26 \%$ & 6.02 & 0 & $1.06 \%$ & $2.08 \%$ \\
\hline Montana & $1.55 \%$ & $0.54 \%$ & 2.86 & 0.004 & $0.49 \%$ & $2.61 \%$ \\
\hline Florida & $1.53 \%$ & $0.09 \%$ & 16.53 & 0 & $1.35 \%$ & $1.72 \%$ \\
\hline Kansas & $1.41 \%$ & $0.07 \%$ & 19.97 & 0 & $1.28 \%$ & $1.55 \%$ \\
\hline Arkansas & $1.38 \%$ & $0.15 \%$ & 9.41 & 0 & $1.09 \%$ & $1.66 \%$ \\
\hline Wisconsin & $1.35 \%$ & $0.10 \%$ & 13.99 & 0 & $1.16 \%$ & $1.54 \%$ \\
\hline Kentucky & $1.31 \%$ & $0.07 \%$ & 17.86 & 0 & $1.17 \%$ & $1.45 \%$ \\
\hline Texas & $1.30 \%$ & $0.09 \%$ & 15.27 & 0 & $1.13 \%$ & $1.47 \%$ \\
\hline Connecticut & $1.29 \%$ & $0.09 \%$ & 15 & 0 & $1.12 \%$ & $1.46 \%$ \\
\hline Massachusetts & $1.26 \%$ & $0.08 \%$ & 15.03 & 0 & $1.10 \%$ & $1.43 \%$ \\
\hline Virginia & $1.22 \%$ & $0.07 \%$ & 17.12 & 0 & $1.08 \%$ & $1.36 \%$ \\
\hline lowa & $1.21 \%$ & $0.14 \%$ & 8.48 & 0 & $0.93 \%$ & $1.48 \%$ \\
\hline South Carolina & $1.18 \%$ & $0.14 \%$ & 8.62 & 0 & $0.91 \%$ & $1.45 \%$ \\
\hline Washington & $0.86 \%$ & $0.28 \%$ & 3.06 & 0.002 & $0.31 \%$ & $1.42 \%$ \\
\hline Oklahoma & $0.69 \%$ & $0.17 \%$ & 3.97 & 0 & $0.35 \%$ & $1.03 \%$ \\
\hline Arizona & $0.64 \%$ & $0.18 \%$ & 3.58 & 0 & $0.29 \%$ & $0.99 \%$ \\
\hline Illinois & $0.63 \%$ & $0.14 \%$ & 4.59 & 0 & $0.36 \%$ & $0.90 \%$ \\
\hline Oregon & $0.56 \%$ & $0.22 \%$ & 2.59 & 0.01 & $0.14 \%$ & $0.99 \%$ \\
\hline Idaho & $0.47 \%$ & $0.18 \%$ & 2.61 & 0.009 & $0.12 \%$ & $0.83 \%$ \\
\hline Louisiana & $0.47 \%$ & $0.08 \%$ & 5.54 & 0 & $0.30 \%$ & $0.64 \%$ \\
\hline Nevada & $0.20 \%$ & $0.61 \%$ & 0.34 & 0.737 & $-0.98 \%$ & $1.39 \%$ \\
\hline California & $-0.66 \%$ & $0.10 \%$ & -6.63 & 0 & $-0.86 \%$ & $-0.47 \%$ \\
\hline Tennessee & $-2.27 \%$ & $1.71 \%$ & -1.33 & 0.185 & $-5.64 \%$ & $1.09 \%$ \\
\hline
\end{tabular}

The trend is increasing in almost all states and New Hampshire, North Dakota, Wyoming, and South Dakota have rapid growth over 3\%. Ten states are growing at less than $1 \%$. California and Tennessee have negative trends. 


\section{Natural Gas}

Table D.27: Estimated trends for residential natural gas energy intensity

$$
\text { R-square }=0.97
$$

Natural Gas Energy Intensity Trends

\begin{tabular}{|c|c|c|c|c|c|c|}
\hline \multirow[b]{2}{*}{ Vermont } & Coef. & Std. Err. $\quad t$ & \multicolumn{2}{|c|}{$P>|t|$} & [95\% Conf. & Interval] \\
\hline & $3.09 \%$ & $0.20 \%$ & 15.5 & 0 & $2.70 \%$ & $3.48 \%$ \\
\hline Washington & $2.66 \%$ & $0.35 \%$ & 7.67 & 0 & $1.98 \%$ & $3.34 \%$ \\
\hline Idaho & $2.60 \%$ & $0.57 \%$ & 4.59 & 0 & $1.49 \%$ & $3.72 \%$ \\
\hline Oregon & $2.53 \%$ & $0.34 \%$ & 7.43 & 0 & $1.87 \%$ & $3.20 \%$ \\
\hline New Jersey & $1.57 \%$ & $0.13 \%$ & 11.72 & 0 & $1.31 \%$ & $1.84 \%$ \\
\hline North Carolina & $1.39 \%$ & $0.21 \%$ & 6.54 & 0 & $0.97 \%$ & $1.80 \%$ \\
\hline Tennessee & $1.16 \%$ & $0.17 \%$ & 6.7 & 0 & $0.82 \%$ & $1.50 \%$ \\
\hline New Hampshire & $0.98 \%$ & $0.14 \%$ & 7.06 & 0 & $0.71 \%$ & $1.25 \%$ \\
\hline Connecticut & $0.83 \%$ & $0.11 \%$ & 7.31 & 0 & $0.61 \%$ & $1.05 \%$ \\
\hline Rhode Island & $0.81 \%$ & $0.14 \%$ & 5.78 & 0 & $0.54 \%$ & $1.09 \%$ \\
\hline North Dakota & $0.60 \%$ & $0.26 \%$ & 2.31 & 0.021 & $0.09 \%$ & $1.10 \%$ \\
\hline Virginia & $0.56 \%$ & $0.20 \%$ & 2.88 & 0.004 & $0.18 \%$ & $0.95 \%$ \\
\hline Massachusetts & $0.55 \%$ & $0.18 \%$ & 3.11 & 0.002 & $0.20 \%$ & $0.90 \%$ \\
\hline New York & $0.44 \%$ & $0.09 \%$ & 4.68 & 0 & $0.25 \%$ & $0.62 \%$ \\
\hline Delaware & $0.23 \%$ & $0.16 \%$ & 1.42 & 0.157 & $-0.09 \%$ & $0.55 \%$ \\
\hline Minnesota & $0.19 \%$ & $0.14 \%$ & 1.37 & 0.172 & $-0.08 \%$ & $0.47 \%$ \\
\hline South Carolina & $0.15 \%$ & $0.53 \%$ & 0.28 & 0.777 & $-0.88 \%$ & $1.18 \%$ \\
\hline South Dakota & $-0.08 \%$ & $0.29 \%$ & -0.28 & 0.777 & $-0.65 \%$ & $0.48 \%$ \\
\hline Wisconsin & $-0.09 \%$ & $0.14 \%$ & -0.61 & 0.541 & $-0.36 \%$ & $0.19 \%$ \\
\hline Michigan & $-0.12 \%$ & $0.17 \%$ & -0.69 & 0.491 & $-0.45 \%$ & $0.22 \%$ \\
\hline Nevada & $-0.20 \%$ & $0.22 \%$ & -0.9 & 0.367 & $-0.64 \%$ & $0.24 \%$ \\
\hline New Mexico & $-0.28 \%$ & $0.17 \%$ & -1.61 & 0.109 & $-0.62 \%$ & $0.06 \%$ \\
\hline Wyoming & $-0.31 \%$ & $0.34 \%$ & -0.94 & 0.349 & $-0.97 \%$ & $0.34 \%$ \\
\hline Montana & $-0.50 \%$ & $0.24 \%$ & -2.08 & 0.037 & $-0.96 \%$ & $-0.03 \%$ \\
\hline Colorado & $-0.53 \%$ & $0.23 \%$ & -2.3 & 0.022 & $-0.98 \%$ & $-0.08 \%$ \\
\hline Indiana & $-0.61 \%$ & $0.13 \%$ & -4.79 & 0 & $-0.86 \%$ & $-0.36 \%$ \\
\hline lowa & $-0.62 \%$ & $0.15 \%$ & -4.21 & 0 & $-0.91 \%$ & $-0.33 \%$ \\
\hline Illinois & $-0.63 \%$ & $0.13 \%$ & -4.78 & 0 & $-0.89 \%$ & $-0.37 \%$ \\
\hline Georgia & $-0.64 \%$ & $0.18 \%$ & -3.53 & 0 & $-0.99 \%$ & $-0.28 \%$ \\
\hline Pennsylvania & $-0.66 \%$ & $0.12 \%$ & -5.65 & 0 & $-0.89 \%$ & $-0.43 \%$ \\
\hline Maryland & $-0.72 \%$ & $0.22 \%$ & -3.24 & 0.001 & $-1.16 \%$ & $-0.28 \%$ \\
\hline Ohio & $-0.90 \%$ & $0.14 \%$ & -6.6 & 0 & $-1.17 \%$ & $-0.63 \%$ \\
\hline Mississippi & $-0.98 \%$ & $0.22 \%$ & -4.4 & 0 & $-1.41 \%$ & $-0.54 \%$ \\
\hline Nebraska & $-1.01 \%$ & $0.14 \%$ & -7.22 & 0 & $-1.29 \%$ & $-0.74 \%$ \\
\hline Alabama & $-1.11 \%$ & $0.15 \%$ & -7.6 & 0 & $-1.40 \%$ & $-0.82 \%$ \\
\hline West Virginia & $-1.46 \%$ & $0.18 \%$ & -8.05 & 0 & $-1.81 \%$ & $-1.10 \%$ \\
\hline Kentucky & $-1.52 \%$ & $0.24 \%$ & -6.32 & 0 & $-1.99 \%$ & $-1.05 \%$ \\
\hline Oklahoma & $-1.52 \%$ & $0.17 \%$ & -8.92 & 0 & $-1.85 \%$ & $-1.18 \%$ \\
\hline Utah & $-1.55 \%$ & $0.30 \%$ & -5.11 & 0 & $-2.15 \%$ & $-0.96 \%$ \\
\hline
\end{tabular}




$\begin{array}{lrrrrrr}\text { Arkansas } & -1.62 \% & 0.13 \% & -12.16 & 0 & -1.89 \% & -1.36 \% \\ \text { Kansas } & -1.64 \% & 0.19 \% & -8.61 & 0 & -2.02 \% & -1.27 \% \\ \text { Missouri } & -1.65 \% & 0.14 \% & -11.63 & 0 & -1.93 \% & -1.37 \% \\ \text { California } & -1.91 \% & 0.16 \% & -11.68 & 0 & -2.23 \% & -1.59 \% \\ \text { Maine } & -2.15 \% & 2.20 \% & -0.98 & 0.329 & -6.47 \% & 2.17 \% \\ \text { Arizona } & -2.52 \% & 0.32 \% & -7.92 & 0 & -3.15 \% & -1.90 \% \\ \text { Louisiana } & -2.59 \% & 0.23 \% & -11.37 & 0 & -3.04 \% & -2.15 \% \\ \text { Texas } & -2.72 \% & 0.31 \% & -8.76 & 0 & -3.33 \% & -2.11 \% \\ \text { Florida } & -2.90 \% & 0.37 \% & -7.9 & 0 & -3.61 \% & -2.18 \%\end{array}$

The table shows large differences in the trends. Seventeen states have positive trends with four states growing over $2 \%$ per year. Thirty-one states have declining natural gas energy intensity and five states are declining faster than $2 \%$ a year. Overall, the results show a wide range in the trends for this variable. 


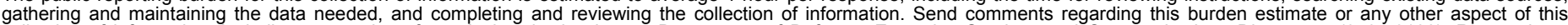

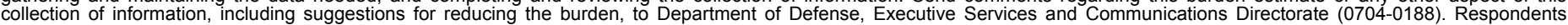

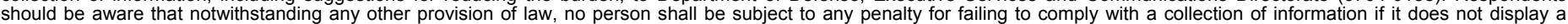

currently valid OMB control number.

PLEASE DO NOT RETURN YOUR FORM TO THE ABOVE ORGANIZATION.

\section{REPORT DATE (DD-MM-YYYY) \\ February 2006 \\ Subcontractor Report}

4. TITLE AND SUBTITLE

Regional Differences in the Price-Elasticity of Demand for Energy

3. DATES COVERED (From - To)

5a. CONTRACT NUMBER

DE-AC36-99-G010337

5b. GRANT NUMBER

5c. PROGRAM ELEMENT NUMBER

5d. PROJECT NUMBER

NREL/SR-620-39512

5e. TASK NUMBER

SA01.0100

5f. WORK UNIT NUMBER

7. PERFORMING ORGANIZATION NAME(S) AND ADDRESS(ES)

RAND Corporation.

1776 Main St., P.O. Box 2138

8. PERFORMING ORGANIZATION REPORT NUMBER

KACX-4-44454-01

Santa Monica, CA 90407

9. SPONSORING/MONITORING AGENCY NAME(S) AND ADDRESS(ES)

National Renewable Energy Laboratory

1617 Cole Blvd.

Golden, CO 80401-3393

10. SPONSOR/MONITOR'S ACRONYM(S)

NREL

11. SPONSORING/MONITORING AGENCY REPORT NUMBER NREL/SR-620-39512

12. DISTRIBUTION AVAILABILITY STATEMENT

National Technical Information Service

U.S. Department of Commerce

5285 Port Royal Road

Springfield, VA 22161

13. SUPPLEMENTARY NOTES

NREL Technical Monitor: Doug Arent

14. ABSTRACT (Maximum 200 Words)

At the request of the National Renewable Energy Laboratory (NREL), the RAND Corporation examined the relationship between energy demand and energy prices with the focus on whether the relationships between demand and price differ if these are examined at different levels of data resolution. In this case, RAND compares national, regional, state, and electric utility levels of data resolution. This study is intended as a first step in helping NREL understand the impact that spatial disaggregation of data can have on estimating the impacts of their programs. This report should be useful to analysts in NREL and other national laboratories, as well as to policy nationals at the national level. It may help them understand the complex relationships between demand and price and how these might vary across different locations in the United States.

\section{SUBJECT TERMS}

NREL; RAND Corporation; energy demand; energy prices; regions; electric utilities; spatial disaggregation; residential natural gas; commercial electricity; price elasticity; Doug Arent

16. SECURITY CLASSIFICATION OF:
\begin{tabular}{|l|l|l|}
\hline $\begin{array}{c}\text { a. REPORT } \\
\text { Unclassified }\end{array}$ & $\begin{array}{c}\text { b. ABSTRACT } \\
\text { Unclassified }\end{array}$ & $\begin{array}{l}\text { c. THIS PAGE } \\
\text { Unclassified }\end{array}$ \\
\hline
\end{tabular}

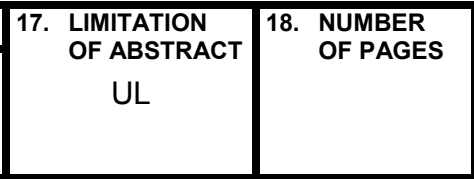

19b. TELEPHONE NUMBER (Include area code) 